\section{w. A21200-968949

NBSIR 80-2052

\title{
Energy Budget Procedures and Performance Criteria for Energy Conserving Building Illumination Systems
}
A. T. Hattenburg
J. L. Heldenbrand
D. K. Ross
R. G. Stein
W. Tao

Center for Building Technology National Engineering Laboratory National Bureau of Standards U.S. Department of Commerce Washington, D.C. 20234

April 1980

Issued May 1980

nared for:

$\begin{array}{ll}\text { QC } & \text { hnology and Consumer Products Branch } \\ 100 & \text { ice of Buildings and Community Systems } \\ \text {. } 456 & \text { i. Department of Energy } \\ 80-2052 & \text { shington, D.C. } 20545\end{array}$





\section{ENERGY BUDGET PROCEDURES AND PERFORMANCE CRITERIA FOR ENERGY CONSERVING BUILDING ILLUMINATION SYSTEMS}
A. T. Hattenburg
J. L. Heldenbrand
D. K. Ross
R. G. Stein
W. Tao

Center for Building Technology National Engineering Laboratory National Bureau of Standards U.S. Department of Commerce Washington, D.C. 20234

April 1980

Issued May 1980

\section{Prepared for:}

Technology and Consumer Products Branch Office of Buildings and Community Systems U.S. Department of Energy Washington, D.C. 20545

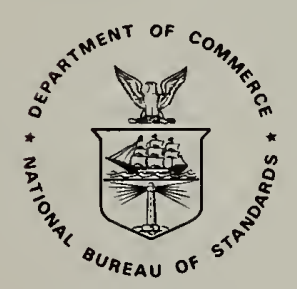

U.S. DEPARTMENT OF COMMERCE, Philip M. Klutznick, Secretary Luther H. Hodges, Jr., Deputy Secretary Jordan J. Baruch, Assistant Secretary for Productivity. Technology, and Innovation NATIONAL BUREAU OF STANDARDS, Ernest Ambler, Director 



\section{ENERGY BUDGET PROCEDURES AND PERFORMANCE CRITERIA FOR ENERGY-CONSERVING BUILDING ILLUMINATION SYSTEMS}

A. T. Hattenburg, J. L. Heldenbrand, D. K. Ross, R. G. Stein, and W. Tao

\section{ABSTRACT}

This report covers subsystem energy budget development procedures and performance criteria for building illumination which were developed by a consultant team of practitioners experienced in building illumination systems. A general procedure is described wherein the energy required for efficient illumination of a building is examined and corresponding power and annual energy budget guidelines are developed.

This methodology is applied to three classes of building - offices, schools, and residences - to illustrate the method. Representative power and energy budgets are developed.

The model performance criteria and illumination energy budget methodology are recommended as the basis for development of national consensus standards, covering the principal classes of new buildings designed primarily for human occupancy.

Key Words: Building illumination systems; energy budget; energy conservation; energy performance criteria; illumination; lighting; power budget. 
This report is one of a group documenting NBS research and analysis efforts in developing energy and cost data in support of the Department of Energy (DoE)/National Bureau of Standards (NBS) Building Energy Conservation Criteria Program. This work was supported by DoE/NBS Task order A008-BCS under Interagency Agreement No. EA 77 A 01 6010. The work was originally sponsored by DoE's Architectural and Engineering Systems Branch and is now sponsored by the Technology and Consumer Products Branch.

This document was prepared by the NBS Task Force on Illumination under the project leadership of Albert T. Hattenburg of NBS. The performance criteria and energy budget methodology described in this report were developed by Donald K. Ross, P.E., of Ross and Baruzzini, Consulting Engineers; Richard G. Stein, FAIA, of the Stein Partnership, Architects; and William Tao, P.E., of William Tao Associates, Consulting Engineers, serving under contract as consultants to NBS. Jim L. Heldenbrand and Gary T. Yonemura of NBS provided management and conceptual advice, and technical consultation, respectively.

The consultant members of the Task Force are experienced practitioners in building illumination systems design, share a common interest in energy conservation, and brought a variety of individual experiences and viewpoints to the effort. They completed their task with the limited resources provided, and without the formation and collaboration of other subsystem task forces recommended by them.

During the course of this project, the work was made available to scores of interested parties. The authors are indebted to those individuals and organizations who have contributed their time and have provided us with their valuable comments. A number of these comments have aided in the preparation of this report. The majority of the comments are more appropriate to the deliberations of the proposed ANSI committee which will receive this document, as a basis for that Committee's development of an American National Standard for use by building illumination system designers. These comments will be provided to the committee with reviewers consent.

The authors are especially indebted to Neil E. Gallagher for his major contributions to the preparation of this report. 


\section{SI CONVERSION UNITS}

In view of the present accepted practice in the U.S. building community, customary U.S. units of measurement have been used throughout this document. In recognition of the position of the United States as a signatory to the General Conference on Weights and Measures, which gave official status to the metric SI system of units in 1960, assistance is given to the reader interested in making use of the coherent system of SI units by providing conversion factors applicable to the customary U.S. units used in this document.

Length

1 inch $($ in $)=0.0254$ meter $(m)$

Area

1 square foot $\left(\mathrm{ft}^{2}\right)=0.0929$ square meter $\left(\mathrm{m}^{2}\right)$

Illuminance

1 foot candle $(\mathrm{fc})=10.76$ lux $(1 \mathrm{x})$

Luminance

1 footlambert $(\mathrm{fL})=3.426$ candela per square meter $\left(\mathrm{cd} / \mathrm{m}^{2}\right)$

Energy

1 kilowatt-hour $(\mathrm{kWh})=3.6 \times 10^{6}$ joules $(\mathrm{J})$

The conversion values for length and energy are exact; those for area, illuminance, and luminance are approximate. 


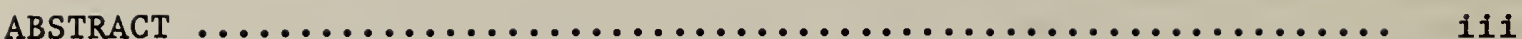

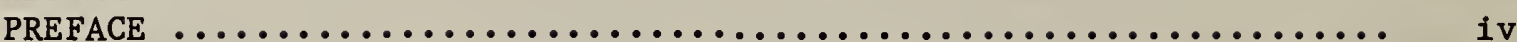

SI CONVERSIONS $\ldots \ldots \ldots \ldots \ldots \ldots \ldots \ldots \ldots \ldots \ldots \ldots \ldots \ldots \ldots \ldots \ldots \ldots \ldots$ v

1. INTRODUCTION $\ldots \ldots \ldots \ldots \ldots \ldots \ldots \ldots \ldots \ldots \ldots \ldots \ldots \ldots \ldots \ldots \ldots \ldots \ldots$

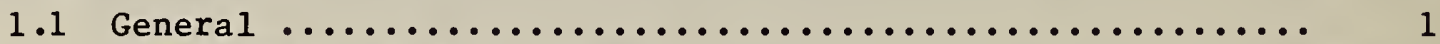

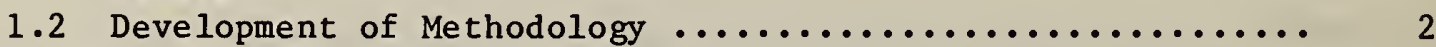

1.3 Applications of Methodology ..................... 3

2. METHODOLOGY $\ldots \ldots \ldots \ldots \ldots \ldots \ldots \ldots \ldots \ldots \ldots \ldots \ldots \ldots \ldots \ldots \ldots \ldots \ldots \ldots$

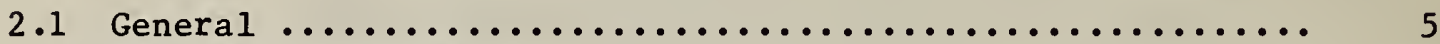

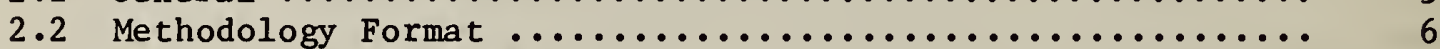

2.3 Methodology Flow Chart $\ldots \ldots \ldots \ldots \ldots \ldots \ldots \ldots \ldots \ldots \ldots \ldots \ldots \ldots$

3. BUILDING TYPE STUDY - OFFICE $\ldots \ldots \ldots \ldots \ldots \ldots \ldots \ldots \ldots \ldots \ldots \ldots \ldots \ldots$

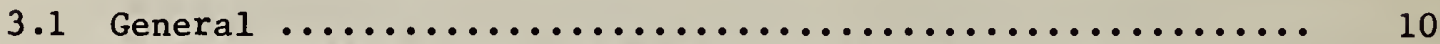

3.2 Office \& Office Building Energy Budget Metholodogy ....... 10

3.3 Methodology for office Lighting Budget ............... 24

4. BUILDING TYPE STUDY - SCHOOL $\ldots \ldots \ldots \ldots \ldots \ldots \ldots \ldots \ldots \ldots \ldots \ldots \ldots . \ldots \ldots$

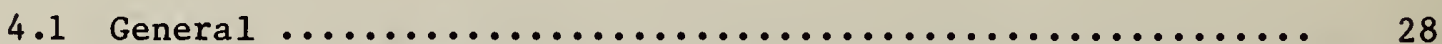

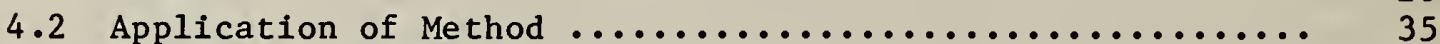

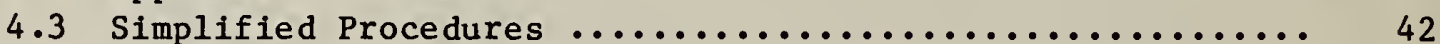

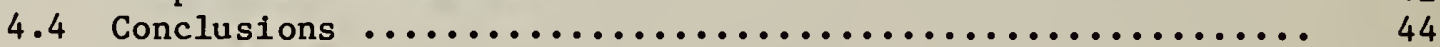

5. BUILDING TYPE STUDY - RESIDENCE $\ldots \ldots \ldots \ldots \ldots \ldots \ldots \ldots \ldots \ldots \ldots \ldots . \ldots$

5.1 General ......................................... 47

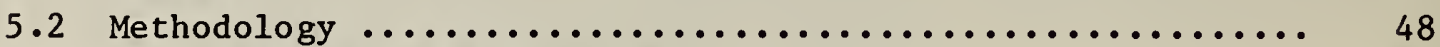

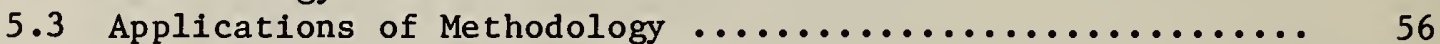

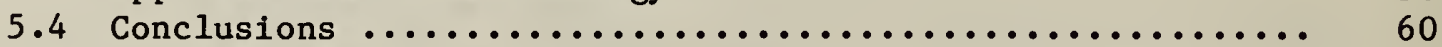

6. DISCUSSION, CONCLUSIONS AND RECOMMENDATIONS ............ 62

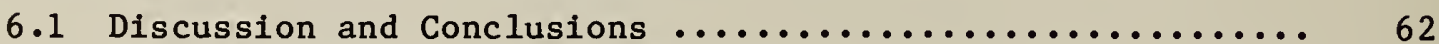

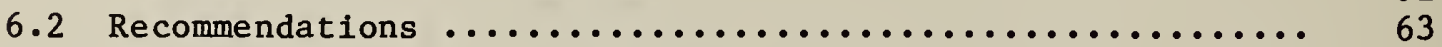

APPENDIX I Phase I Report ............................ APPENDIX II Lighting Design Factors for Energy Conservation ...... APPENDIX III Worksheets for School Analysis ................ 


\section{INTRODUCTION}

\subsection{GENERAL}

This project was originated to develop new energy-conservation guidelines for illumination in buildings. The goal was the production of a method for specifying the maximum annual energy needed to illuminate the building, 1.e., the illumination energy budget, as the next logical step beyond the existing power budget formulations (an illumination power budget is the maximum connected power allowed for illumination of the building). An innovative approach was required; human visual needs would be assessed in the context of an energy-limited society and without reliance upon recommendations and practices developed during an energy-abundant period, a period now behind us. The guidelines were intended to serve as the basis for a voluntary consensus standard, as an earlier NBS report (NBSIR 74-452) had provided the basis for ASHRAE/IES 90-75. This potential standard, along with others covering the other energy-using subsystems, could be used to demonstrate compliance with the Department of Energy's overall building design annual energy budgets ${ }^{1}$, known as BEPS.

The project was carried out by the NBS Task Force on Illumination (Albert T. Hattenburg, NBS; Donald K. Ross, Richard G. Stein, and William Tao, consultants to NBS). The Task Force consultants developed the basic methodology, tested it through detailed calculations on office, school, and residential buildings, and produced representative illumination budgets for these three building classifications. The basic methodology was outlined in the Phase I report included herein as Appendix I. The final methodology, detailed studies, and performance criteria were described in the final report of the Task Force, "Performance Criteria for Energy Conserving Building Illumination Systems," submitted to NBS in August, 1978. The present NBS report conveys the Task Force Final Report with minor changes (Chapters 2 through 5), discusses the basic principles and approaches used in its development, and in addition to the criteria presents conclusions and recommendations resulting from this work. This proposed method differs from existing standards, such as ASHRAE 90-75 (Chap. 9), principally in the specification of an energy budget in addition to a power budget. It also replaces a portion of the electrical lighting with natural lighting to reduce energy consumption, places a greater stress upon separate consideration of task lighting and general lighting, and specifies the number of controls required to manage the lighting system. In the application of the method to prototype buildings, the chosen illumination levels generally are lower than those of ASHRAE 90-75, and the budget computation forms, especially the short forms, are much less complex.

The task force chose a performance approach toward its work, following the key tenets of the performance concept without, however, utilizing the full performance statement format. Thus, the members emphasized the importance

1 Energy Performance Standards for New Buildings; Proposed Rule, Department of Energy, November 28, 1979 Federal Register, Part II. 
of the methodology for arriving at power and energy budgets rather than the values of input parameters or numerical results. Desired system attributes were stressed rather than hardware specifications.

A formal Performance Statement has four parts: the Requirement or qualitative expression of human need; the Criterion, the quantitative statement of the need and the basis for determining if it has been met; the Evaluation, the means of making the compliance determination; and the Commentary, which includes notes of rationale, uncertainty, and intent. The Task Force directed its efforts to the Criterion portion, which the existing energy concerns rendered most urgent; however, their product provides a frame of reference for the further development of Requirements, Evaluations, and Commentaries leading to formal performance statements for illumination systems.

The criteria are intended to contribute to the development of consensus standards for energy conserving illumination systems in an interim period, i.e., a period pending the development of definitive criteria resulting from ongoing vision research at the NBS, the Illuminating Engineering Research Institute, universities, and other laboratories. This document will be offered to a committee of the American National Standards Institute as a proposed basis for future American National Standards.

\subsection{DEVELOPMENT OF METHODOLOGY}

The Task Force members agreed upon certain general principles during the development of the methodology. First, the specification of a valid energy budget would require a determination of the illumination needed for the building to efficiently perform its function, and should not necessarily be based upon typical installations found in buildings designed before energy was given important consideration. Second, the required illumination should be divided into two categories for energy calculations; Task Lighting, and General Lighting (it was considered that natural lighting could be considered a third category, or included in General Lighting). Third, the lighting energy budget is only one component of the total building energy budget and is not independent of the other sub-system budgets. Finally, the criteria should include an explicit Power Budget.

The determination of the actual illumination energy needed for the various building spaces requires the selection of appropriate light levels, calculation of the power required to deliver these levels, and the usage patterns of the spaces. The levels used by each member for the calculations are derived from his knowledge, experience, and reviews of lighting practices here and abroad. Power calculations are based on available components. Usage patterns assumed are described for each example building. Both the components and usage patterns employed are used succesfully in present buildings.

The separation of task and general lighting is considered essential to an energy efficient lighting system, in order to avoid high light levels in areas where they are not needed (uniform lighting), and to provide for 
switching off of task lights during periods when they are not needed. This selective switching capability requires that sufficient controls be provided.

The lighting energy budget cannot exist as a separate entity due to the significant interactions with other buildings services (heating, cooling), and the difficulty of separately metering the lighting energy. Of ten the same convenience outlets provide power for lights and other devices (typewriters, duplicators, etc.), particularly in a system which relies heavily upon task lighting. Within the limitations of resources and schedule the Task Force has attempted to account for the interactions between illumination and other building services, and the methodology and criteria are designed to be compatible with those generated for the other sub-systems by subsequent task groups.

Although the energy budget is the final measure of the buildings energyefficient performance, the power budget forms the basis for the energy budget, and it is the power budget which determines the connected load at the time the system is designed and installed. Together with the necessary controls, the power budget allows the building to be operated within the energy budget. The explicit statement of the power budget is also needed to indicate the peak power demand of the system.

\subsection{APPLICATIONS OF THE METHODOLOGY}

The detailed methodology was applied to the three classes of building-office, school, and residence--in order to demonstrate the method, to test its validity, and to produce representative values for both energy and power budgets. In this process, the building was broken into units (spaces) according to function and duration of use; the lighting power and energy were calculated for each unit; and finally the values were summed to yield the power and energy budgets for the entire building illumination system.

The applications to the several building types were performed on an individual basis, with each Task Force consultant member concentrating on a specific type. During this process, the members discussed problems encountered, agreed upon improvements to the methodology, and provided general reviews of one another's results. Although the same basic methodology was used, the detailed approach varied in the three applications; this is reflected in the variations in emphasis and presentation which occur in chapters 3,4 , and 5 . Each of these examples provides a useful insight into particular aspects of the application process. Thus Chapter 3 (office) emphasizes task analysis and opportunities for task revision, explicit calculations of lighting power conversion factors, and daylight allowances; no specific building layout is shown, but results of the study are combined into worksheets which allow budget calculations for a specific building from a knowledge of space distribution by function. Chapter 4 (school) presents a step-by-step demonstration of the application to a specific school, with lighting layouts and detailed worksheets for each of twenty-nine spaces; daylighting allowances are implicit in the calculations, while lighting power conversion factors are listed for each lumunaire employed. After establishing power and energy densities for each space, the figures are further separated into Task and General lighting. 
Finally, spaces are grouped into six educational categories, each with a power and energy budget for both Task and General lighting. Chapter 5 (residence) stresses the dependence of required lighting energy upon occupant type, analyses five types of residence for lighting needs, and derives unit power densities and power allowances for the various functions. Daylighting contributions are accounted for in the assumed usage hours.

The detailed application of the methodology to the various building types convinced the Task Force that, although essential to demonstrate the basis for the criteria, the process was too cumbersome and time-consuming to be recommended as a compliance procedure for the practicing lighting designer. Therefore a simplified method or "short form" was developed for each building type. The short form has the advantage of simplicity and brevity. For buildings which differ significantly from the prototypes, the more detailed procedures may be required.

In view of present accepted practice in this country for building technology, common U.S. units of measurement have been used throughout this document, with SI (metric) units added parenthetically where a unit first occurs. Illumination levels (Illuminance) are stated in units of footcandles (lumens per square foot), as would be measured by a typical "footcandle meter." No specialized units such as "ESI footcandles" are used. The occasional luminance values are stated in the corresponding units of footlamberts. Power and energy are quoted in units of watts and watt-hours respectively. The use of British thermal units (Btu's) for energy values would allow a direct combination with other sub-system energies; however, other sub-system budgets are not yet available, and the use of watt-hours both simplifies calculations and postpones a decision on whether the watt-hours-to Btu's conversion factor should include the energy consumed in producing and transmitting the electricity. 


\section{METHODOLOGY}

\subsection{GENERAL}

The methodology for arriving at energy buagets for the illumination subsystem was based on determining what a reasonably designed building using adequate ambient illumination and selective task illumination would require under typical conditions. This figure, with a certain factor for the variability that occurs when different designers face the same problem, would then be incorporated in a performance energy standard after considering its interconnections with the other subsystems in the building. For example, the reduction of the performance budget for illumination would have an adverse effect on the heating budget and a favorable effect on the cooling budget. In this way values could be established that would not depend on the usual pattern of energy use through illumination that was developed in a period when there was little concern for the energy implications of illumination, but rather would start at the other end and examine what buildings need to function adequately and what technological means are available to answer these requirements.

Although the standard is primarily for establishing an energy budget for operating the illumination system, it also formulates a typical power budget that formed the basis for the energy budget calculations.

The method for determining these budgets was to examine actual situations rather than depending on past building installations and performance which would tend to continue present typical practices. A flow diagram was developed in the first phase of the project. This flow diagram took into account all of the relevant information about the building, its location, its program, and its schedule so that each would be properly considered in determining the budget. In order to be widely applicable, the information framework in the flow diagram may be more comprehensive than is necessary for certain buildings and building types.

For example, the methodology permits the recording of such information as geographic location. It is obvious that the lighting requirements in Alaska, near the North Pole in December are very different from those in Ecuador near the Equator if one is to credit the contribution of natural light. In many cases, however, this is superfluous information that would produce a degree of refinement greater than is required for both the layout and the assumed budget.

The diagram explaining the methodology is included in this report with minor modifications (Fig. 2.1). This diagram has been the basis for a data matrix which can be filled in for any building type in any location. The matrix follows (2.2). In order to test the validity of the method, it was applied to three different building types; office, school and residential buildings. Each is explained in a separate section of this report.

Based on the information examined and developed for each of these, a generalized set of recommended values has been proposed. In order to make these figures more sensitive to the particular requirements of a specific building, 
the overall figures for the entire building have been broken down into significant sub-uses that are characteristic of the particular building type. Since these reference figures are on a square foot basis, a new overall figure can be developed that will reflect more accurately the uses within the building being examined.

If either the kinds of services supplied within the building or the use schedule varies significantly from the assumptions used in developing the standards, the figures in the standards can be modified either by a factor reflecting the non-typical usage of the particular building under investigation or the entire analytical process can be undertaken to lead to a new and more specifically relevant power and energy budget figure for the nontypical building.

As is shown in the methodological diagram (Fig. 2.1), the values developed for the illumination subsystems would be incorporated with the values for the other subsystems. This would in turn result in the overall energy budget and performance standard based on subsystem performance standards.

\subsection{METHODOLOGY FORMAT}

\subsubsection{General Methodology Information}

\subsubsection{Building Type}

2.2.1.1.1 Subcategories

$2.2 \cdot 1.1 .2$

\subsubsection{Location (geographic)}

2.2.1.2.1 Position in time zone

2.2.1.2.2 Daylight hours

$2.2 \cdot 1.2 .3$

\subsubsection{Occupancy Schedule}

2.2.1.3.1 Annual operation

$2 \cdot 2 \cdot 1 \cdot 3 \cdot 2$

2.2.1.4 Time of Use

2.2.1.4.1 Daily operating schedule

$2 \cdot 2 \cdot 1 \cdot 4 \cdot 2$

2.2 .1 .5 Orientation

2.2.1.5.1 Major exposures of building

$2 \cdot 2 \cdot 1 \cdot 5 \cdot 2$ 
2.2.2 List of Spaces by Type

2.2.2.1 Type 1 space (by name)

2.2.2.1.1 Area of unit

2.2 .2 .1 .2 Number of units

2.2 .2 .1 .3 Orientation

2.2.2.1.4 Fenestration

2.2 .2 .1 .5 Special requirements

$2 \cdot 2 \cdot 2 \cdot 1 \cdot 6$

\subsubsection{Type 2 Space (by name)}

2.2.3 Spaces by Type - Illumination Requirements

\subsubsection{Type 1 space (by name)}

2.2.3.1.1 General illumination

2.2.3.1.2 Task illumination

2.2.3.1.3 Security illumination

2.2 .3 .1 .4 Special requirements

$2 \cdot 2 \cdot 3 \cdot 1 \cdot 5$

\subsubsection{Type 2 space (by name)}

2.2.4 Duration of Use

2.2.4.1 Type 1 space (by name)

2.2.4.1.1 Hours for general lighting

2.2.4.1.2 Hours for task lighting

2.2.4.1.3 Hours for security lighting

2.2.4.1.4 Hours for special requirements

\subsubsection{Type 2 space (by name)}

\subsubsection{Light Delivery Components}

2.2.5.1 Unit power for augmented illumination, $\mathrm{W} / \mathrm{fc} / \mathrm{sf}$.

2.2.5.2 Unit power for general illumination, $\mathrm{W} / \mathrm{sf}$.

2.2.5.3 Unit power for security lighting, W/sf.

2.2.5.4 Unit power for special lighting, watts

$2 \cdot 2 \cdot 5 \cdot 5$

2.2.6 Light Delivery Components - Utilizacion Patterns

2.2.6.1 Annual general building operating hours (AGH)

2.2.6.2 General diversity factor (GDF)

2.2.6.3 Net general operating hours (NGH) $=$ AGH $x$ GDF

2.2.6.4 Annual task lighting operating hours (ATH)

2.2.6.5 Task diversity factor (TDF) 
2.2.6.6 Net task operating hours $(\mathrm{NTH})=\mathrm{ATH} \times \mathrm{TDF}$

$2 \cdot 2 \cdot 6 \cdot 7$

2.2.7 Lighting Energy for Each Space (Wh/yr)

$2 \cdot 2.7 .1$ Type 1 space

2.2.7.1.1 Lighting energy for tasks

$=$ Unit Power $(2.2 .5) \times$ Area of Tasks $\times$ Utilization Pattern $(2.2 .6)$

2.2.7.1.2 Lighting energy for general

= Unit Power $(2.2 .5)$ x General Area $x$ Utilization Pattern (2.2.6)

2.2.7.1.3 Lighting energy for space

$=((2 \cdot 2 \cdot 7 \cdot 1.1)+(2 \cdot 2 \cdot 7 \cdot 1 \cdot 2))$

\section{2 .7 .2 Type 2 space}

2.2.8 Lighting Energy Budget (kWh/yr)

2.2.8.1 Summation of Total Space Lighting from 2.2.7.1, 2.2.7.2, etc.

2.2.8.2 Lighting energy for special lighting

2.2.8.3 Credit for natural lighting (Alternate Approach)

2.2.8.4 Contingency factor $=$ allowance for special conditions and

2.2.8.5 Lighting energy budget: contingencies $=1.0$ to 1.1 as evaluated

$$
\frac{((2.2 .8 .1)+(2.2 .8 .2)-(2.2 .8 .3)) \times(2.2 .8 .4)}{1000}
$$

\subsubsection{Unit Energy Budget/Lighting (kWh/sf/yr)}

2.2.9.1 Lighting energy budget (kWh/yr), from (2.2.8.5)

2.2 .9 .2 Building gross area, $\mathrm{sf}$

2.2.9.3 Unit energy budget/1ighting (UEB-L), $\mathrm{kWh} / \mathrm{sf} / \mathrm{yr}$.

$$
\text { UEB-L }=\frac{(2 \cdot 2 \cdot 9 \cdot 1)}{(2 \cdot 2 \cdot 9 \cdot 2)}
$$

\subsection{METHODOLOGY FLOW CHART}

See Fig. 2.1 


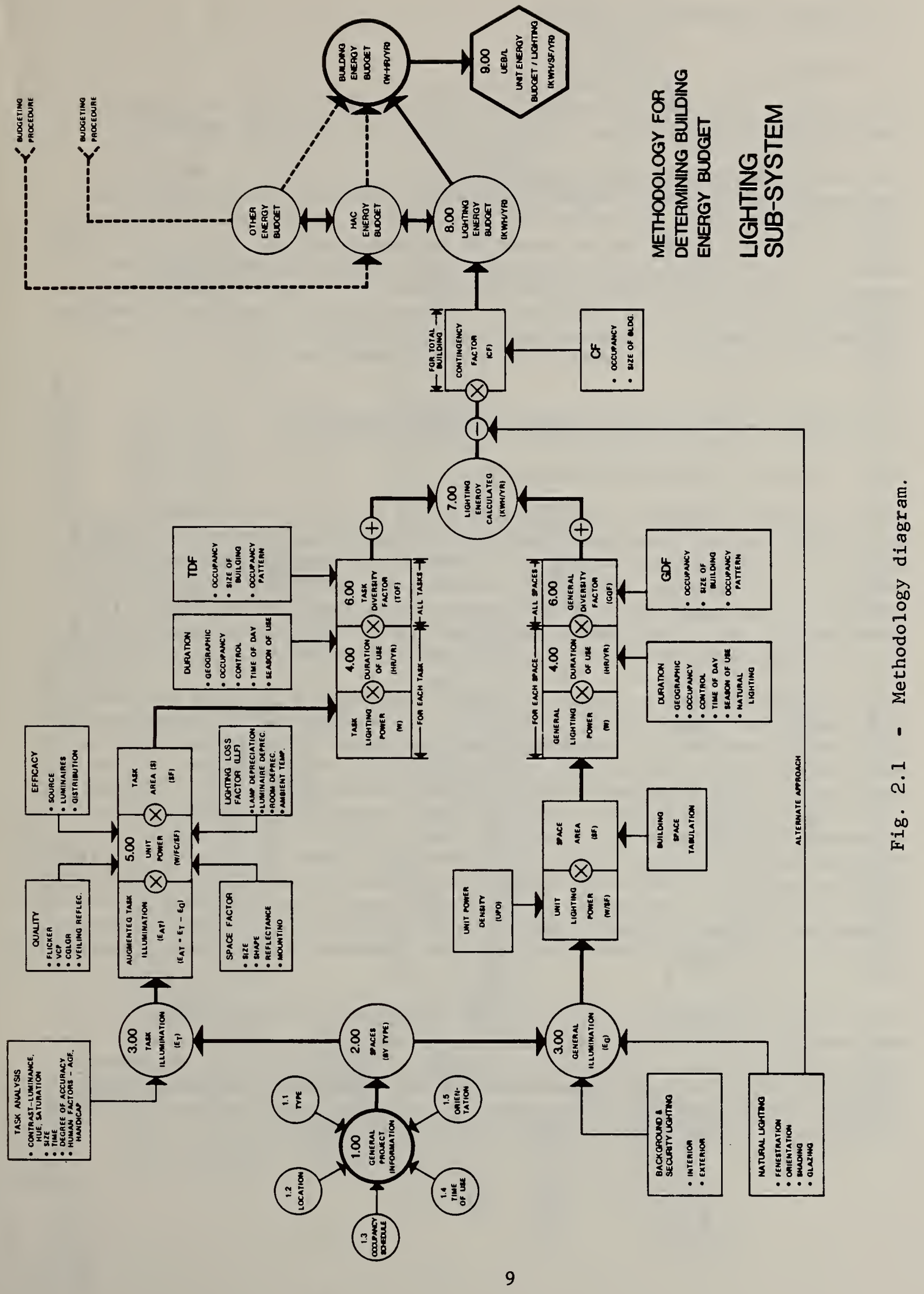




\section{BUILDING TYPE STUDY - OFFICE}

\subsection{GENERAL}

This chapter describes how the methodology of Chapter 2 has been applied for determining the energy budget for office space or an office building.

A discussion of energy conserving office lighting practice on which the development of the energy budget is based is presented in Section 3.2 of this chapter. These principles have been applied to calculations of energy budgets for typical office buildings of various sizes, as a test of the concepts. In Section 3.3, both a detailed and a simplified methodology are presented, with a discussion of their components and applications. The simplified procedure will be applicable, in most cases, to determine a realistic energy budget for a proposed office building; where a more detailed analysis is required, the detailed procedure should be used.

\subsection{OFFICE \& OFFICE BUILDING ENERGY BUDGET METHODOLOGY}

\subsubsection{Lighting Sub-System Flow Chart}

The Flow Chart of Chapter 2 has been modified to more clearly describe the methodology applied to office lighting. This modified version, shown in Figure 3.1, separates the energy calculations for offices into three categories: Task Lighting, Building Lighting, and Natural Lighting (Daylighting). The basis for lighting levels in footcandles (lux) for office tasks is developed. Additional values are given for lighting for building functions and areas not directly connected with performance of office tasks.

These lighting levels are converted into power density in watts per square foot (watts per square meter) by means of recommended conversion factors in watts/footcandles/sq. ft. (watts/lux/square meter). Multiplication of each power density by its respective area provides the power required for the building for each function. The total power for each function is multiplied by the appropriate duration of use to obtain energy. The energy for each component is multiplied by a diversity factor and totaled to obtain the building lighting energy. Next, a calculation is made of the energy that the building could have saved had it used an appropriate amount of the available natural lighting. This energy is subtracted from the total energy previously calculated. Finally, these components are totaled and this total is multiplied by a contingency factor to permit an allowance for unforseen requirements.

The detailed methodology presented here is complex and time-consuming, and the simplified procedure in Section 3.3 will be more generally useful. However, a description of the detailed method is required both to demonstrate the basis for this energy budget approach and resulting recommended energy budgets, and to show how the multitude of lighting design factors (described in Appendix II) contribute to the energy-conserving budget. 


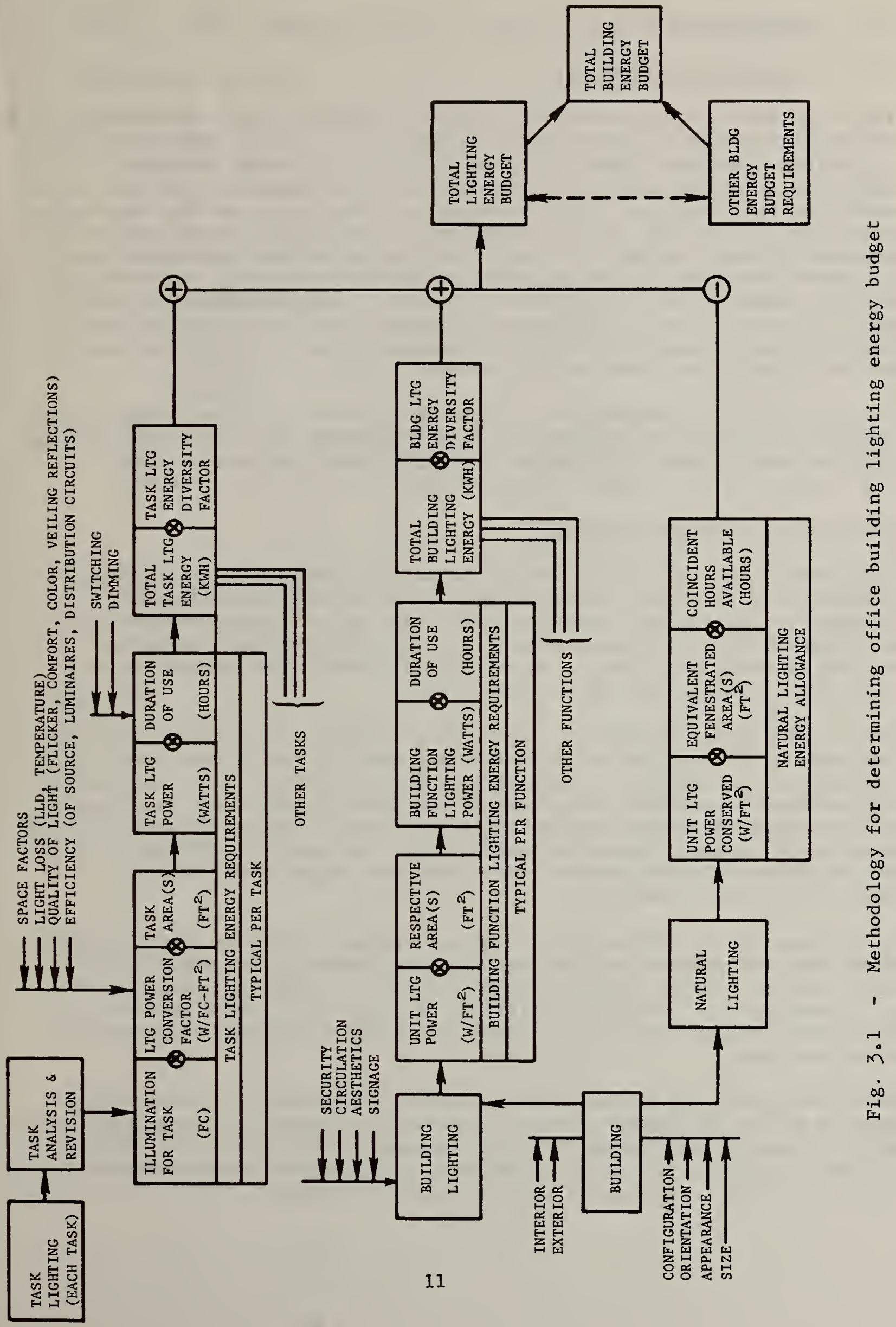




\subsubsection{Task Lighting}

\subsubsection{Task visual difficulty}

Presently, there is no generalized measure of task visibility demonstrated to predict performance as a function of illumination. The Illuminating Engineering Society developed a model using an "Equivalent Contrast" criteria: a recommended visibility level of thirteen times the threshold level was recommended for task lighting. (The threshold was later redefined to a new value approximately 1.6 times the former definition and called VLl. VLl was then increased 8 times, to VL8. VL8, which relates equivalent contrast to task background luminance, became the task performance criteria.) This concept has been demonstrated to be applicable only for very specialized non-typical tasks, if at a11. Its justification at present is that a task will never require greater illumination than the level predicts. The IES is presently considering major revision to this concept.

For the time being, performance criteria as a function of illumination can be obtained only by direct comparison with similar tasks performed under varying lighting levels. See, for example, "Task Lighting - Yet Another View," D. K. Ross, L. D. \& A., May 1978, pp. 37-43.

\subsubsection{Overall task evaluation}

The elements shown in Table 1 comprise most of the ones of importance in performing office tasks. Tasks can be categorized for these elements (formally or informally), noting any which are believed to be substantially more visually difficult than normally-occuring office tasks. Where one (or two) elements are noted to be visually difficult, they may often be offset by another factor, easier than normal.

Visual performance is much less sensitive to changes in brightness above 10 footlamberts (35 candelas per square meter) than to most of the other factors of Table 1. An analysis of these factors for the various tasks occuring in office spaces is needed to determine the required illumination, and in addition indicates where cost and energy effective task modifications may be made. Appendix II presents a detailed description of the analysis of several of the more important of these factors, and offers some suggestions for costeffective task modifications.

The performance of individuals with normal eyesight and up to about 40 years of age does not improve, or improves only very little, for normal office tasks when the average task background luminance exceeds approximately 10 to 15 footlamberts. For individuals over the age of 50 , there appears to be improvement in performance up to approximately 20 footlamberts ( 70 Candelas per square meter).

Many experiments have demonstrated that older persons do not perform visual tasks as well as do younger persons; however, for normal older eyes, increasing the illumination level above 20 to 30 footcandles ( 215 to 325 lux) improves performance only very slightly, if at all, and no amount of extra illumination can cause the older persons to perform as well as younger ones. 
TABLE 1. TASK LIGHTING ANALYSIS - FACTORS REQUIRING CONSIDERATION*

\section{Task Considerations}

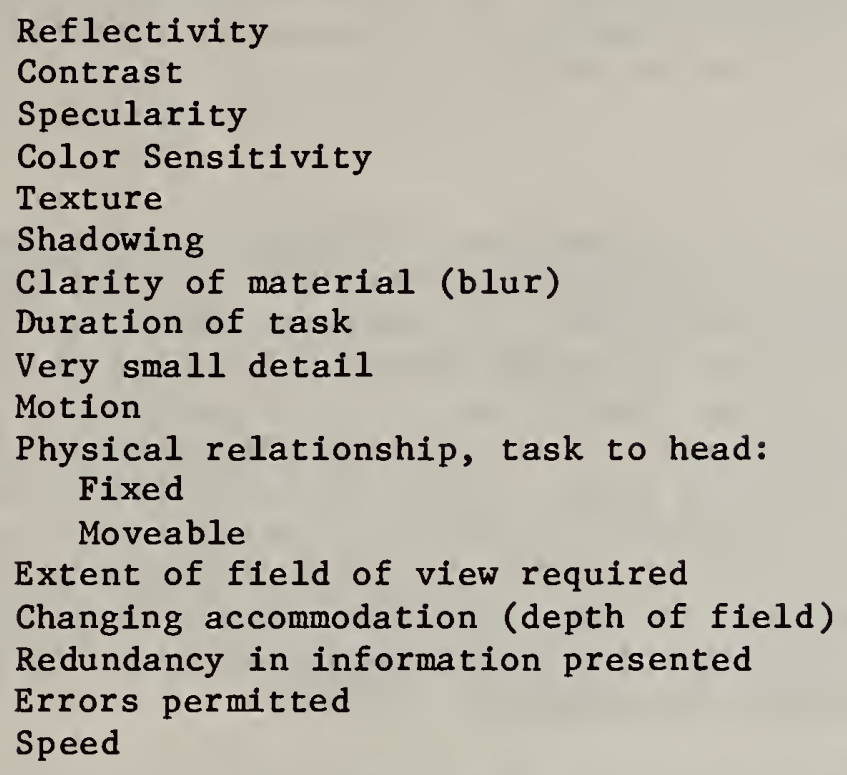

\section{Operator Considerations}

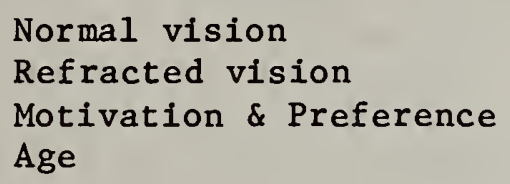

* See Appendix II for analysis description 


\subsubsection{Determination of Appropriate Task Lighting Requirements}

Tasks can be differentiated into two types: those requiring reading from paper or similar material (two dimensions), and those requiring observation of three dimensional objects such as equipment, warehousing, and requirements for personnel recognition and security.

\subsubsection{Two Dimensional Tasks}

Normal office tasks are visually satisfied above a background luminance of 20 footlamberts, provided that the illumination from the surround does not create excessive direct or reflected glare, or cause the more specular tasks to be unduly reduced in contrast by reflected glare. To the extent that glare causes problems and cannot be eliminated, the task background luminance should be increased to permit the eye to see the task with at least approximately $1 / 5$ the same intensity as the glare source. Normally the effects of glare, where troublesome, are eliminated or at least greatly offset by simply changing the relative geometric relationship between the observer, the task, and the source, and not increasing the task luminance level. This is usually done almost unconsciously by the observer moving position, since in most cases only very slight adjustment is required.

Many, if not most, office tasks involve reading from paper. An appropriate reflectivity for the background of these tasks can be considered to be no less than $75 \%$. Hence, an illumination level of 27 footcandles (20 footlamberts/.75) should be quite adequate for seeing. However, to allow for less than optimum lighting, and to adjust brightness for levels "remembered" from outdoor daylighting or when exposed to fenestration, we recommend that office task lighting be designed to provide approximately $50(+10)$ footcandles at the workplace (desk or table). This approximate doubling of illuminance should be more than enough to allow for the average run of even the more difficult types of tasks.

Guidance that may be beneficial for justification of increasing levels above 50 footcandles is given in Table 2. This information was developed by a careful review of the literature relative to good lighting practice in many countries throughout the world. More recent experiments relating actual task performance to illumination are consistent with this review. ${ }^{1}$

The total illumination furnished for the task includes the sum of the general illumination provided for the space, plus additional or augmented task lighting as may be required. This task lighting should be separately controlled and switched off when not required.

1 D. K. Ross - Task Lighting - Yet Another View, L. D. \& A., May 1978, pp. 37-43. 
TABLE 2. SUGGESTED GUIDE FOR ILLUMINATION LEVEL BASED ON TASK ANALYSIS

TASK OR AREA

Service or Public Areas, Hallway, or Corridors

Circulation Areas within Office Space, but not at Work Stations

Normal office Work, Reading, Writing, etc.

Prolonged office Work visually

difficult or critical in nature

Prolonged Office Work, both visually

difficult and critical in nature

\section{VISUAL \\ DIFFICULTY}

(VDF)

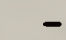

$\begin{array}{ccc}- & 30 \pm 6 & 30 \pm 5 \\ 1-40 & 50 \pm 10 & 50 \pm 10 \\ 41-60 & 75 \pm 15 & 75 \pm 15 \\ 61 \& \text { up } & 100 \pm 20 & 100 \pm 20\end{array}$

DESIGN LEVEL (FC)

$\underline{\text { GSA }^{1}} \quad \underline{\mathrm{FEA}^{2}}$

$15+3$

$10+5$
VISUAL DIFFICULTY FOR OFFICE TASKS

VISUAL

DIFFI CULTY

RATING (R)

1

2

2

3

4

4

5

6

7

8

8

12

15

\section{VISUAL DIFFICULTY FACTOR}

$\mathrm{VDF}=\mathrm{R} \times \mathrm{T}$

$\mathrm{R}$ = Visual Difficulty Rating of Tasks (from table)

$\mathrm{T}$ = Duration of the particular visual task, in hours

EXAMPLE FOR DETERMINING ILLUMINATION LEVEL

Work station used 2 hours for bookkeeping and 3 hours for shorthand work (ink), 2-1/2 hours typing from typed draft, $1 / 2$ hour telephone. $\mathrm{VDF}=(8 \times 2 \mathrm{hrs.})+(4 \times 3 \mathrm{hrs.})+(2 \times 2-1 / 2 \mathrm{hrs.})+0=33$

From Illumination Table, use 50 FC ( 540 LUX).

1 Lighting Systems Study, General Services Administration, March 1974

2 Lighting and Thermal Operations, Energy Management Action Program for Commercial, Public, Industrial Buildings, Guidelines, Federal Energy Administration, 1974 . 


\subsubsection{Three Dimensional Tasks}

Three dimensional tasks, such as operation of equipment, recognition, various types of social and business intercourse, etc., require illumination with different consideration than for two-dimensional task performance. Shadowing is important to bring out texture and features. Since there is normally a certain amount of motion permitted between the viewer and the object being viewed, the source of illumination for three dimensional objects can have a certain element of glare that would not otherwise be desirable since positions can be changed to minimize its effect. It is also important to have a lighting source that can be directed into recesses of the task for maintenance, or for viewing of interiors if this is required. Modeling is optimized by directional lighting.

Identification of human facial expression in satisfactory detail is considered to begin at about 5 footcandles.

Various safety codes promulgate levels of from 1 to 5 footcandles for illumination of areas with movement and moving machinery, although values much lower are actually quite satisfactory for many applications. For example, most people can easily read a newspaper at arm's length with an intensity of only $1 / 2$ footcandle.

The conversion from scotopic (rod vision) to photopic vision (cone vision), which includes the ability to distinguish colors, is completed at approximately 1 footlambert, while the eye can readily detect objects in bright moonlight at .01 footlamberts.

These levels describe the lower end of recommended lighting levels for three-dimensional tasks.

\subsubsection{Building Lighting Illumination or Brightness Levels *}

\subsubsection{Circulation Areas-Around and Near Desk Tasks}

20 to 30 footcandles generally on areas surrounding tasks, and on task if practical, to supplement task lighting.

\subsubsection{Exitway and Stairway Lighting}

Approximately 3 footlamberts of lighting on important safety features, steps, etc. Minimum of 1 footlambert, or code requirements, whichever greater.

\subsubsection{Outdoor Security Lighting}

Lighting at doorways, stairs, and walkways, use 1 footlambert on important safety factors.

* Note the change in units for alternate recommendations. This is deliberate and is belleved to be appropriate for each instance. 


\subsubsection{Corridor Lighting}

5 to 10 footcandles at face level, 3 to 5 footcandles at floor level

\subsubsection{Maintenance Areas, Storerooms, closets}

15 to 20 footcandles, higher if needed for machinery, etc.

\subsubsection{Indoor Parking}

An average of about 5 footcandles, 4 feet above the floor, with higher intensity provided in the aisles, dropping off to lower levels in the parking stalls.

\subsubsection{Outdoor Parking}

No more than .05 watt per square foot, power density.

\subsubsection{Lighting Power Conversion Factors}

The factor that relates lumens to watts is termed "efficacy". Efficacy is given in terms of lumens/watt, usually for the lamp alone, and does not include ballast losses, fixture light losses, circuit losses, room losses, or light depreciation factors.

The methodology used here requires a factor in terms of watts/sq. ft. per footcandle (on the task). This factor should be based on average maintained lumens over the life of the lamps used, and will vary for room size, finish, the type of luminaire, and the lamp type. These same considerations will affect task lighting differently than general lighting, but suitable conversion factors can be developed for each case as appropriate, preferably using point-by-point calculations. (The lumen method may be adequate for general lighting, but certainly not for task lighting.)

The development of the lighting power conversion factors is based upon the use of efficient sources, such as metal halide and fluorescent lamps; fixtures with a high efficiency in distributing the lamp lumens to the tasks without visual discomfort, including ceiling troffers, pod-mounted moveable units, and furniture-integrated lighting; and careful consideration of the design factors discussed in Appendix II.

A series of computations, on a point-by-point basis, were performed to determine the footcandle level on a desk for several different arrangements of ceiling-mounted troffers. The troffers are assumed to be conventional type and to have reasonably-good-quality prismatic lenses, mounted approximately 6 feet above the desk. Each luminaire has two lamps, using energy-conserving lamps and ballasts with a maintained output of 2,500 lumens per lamp. For each two-lamp ballast, the input wattage is 72 watts per 5,000 lumens for the energy-conserving equipment. The several arrangements (using two luminaries per task area) furnish a lighting level averaging 50 footcandles, over areas of approximately $75 \mathrm{sq}$. ft. to include the desk, a side table or typewriter, and a back table. 
Since we have not assumed any general lighting in this example, the task lighting furnishes all of the lighting, and the required power for two luminaires is calculated at: $2 \times 72$ watts/75 sq. ft. $\simeq 1.92$ watts/sq. ft./50FC $\simeq .038$ watts per sq. ft. per task footcandle. A corresponding conversion factor can be developed for general lighting. The general lighting factor will be more efficient because the supplementary effects of other nearby luminaires can be included. This permits the factor to be reduced to .03 watts/sq. ft. per footcandle, at a plane three foot above the floor.

Thus, for example, if general lighting is to be provided, and is to be 20 footcandles, then the budget for general lighting should be $20 \times .03=.6$ watts/sq. ft. If part of the general lighting is provided in a task area also, it is only necessary to supplement the task area with a single twolamp luminaire ( 30 additional footcandles on the task) requiring an additional 1.2 watts per square foot* to meet the total 50 footcandle task lighting requirements, or a total of 1.8 watts/sq. ft.

As an example of how these factors compare to state-of-the-art (1977): With advanced luminaire design, open-plan office space, lighted with good quality lighting, providing $50 \mathrm{FC}$ throughout, can be achieved with .9 watts/sq. ft., or about $1 / 2$ of the power required by the criteria above.

Table 3 lists the unit lighting power for general areas, derived from the recommended illumination levels and the conversion factor for general lighting.

\subsubsection{Duration (Hours of Use) for Office Lighting}

\section{$3.2 \cdot 5.1$}

Annual-hours-use-of-demand [1] for lighting in office buildings has been estimated to be 2,500 hours for the average of all office space [2]. This value increases to approximately 3,450 hours for the more active multi-tenant office buildings. (These values, incidentally, compare with 3,750 hours and 4,000 hours-use-of-demand, respectively, for the total electrical use in the buildings.) If there is available an average value in watts/sq. ft. for lighting for the entire building, it can be multiplied by the hours-use-ofdemand to determine an annual lighting energy budget.

*30 FC $\times .038$ watts/sq. ft./FC $\simeq 1.2$ watts/sq. ft.

[1] Annual hours-use-of-demand is a number derived by dividing the total kilowatt-hours used for lighting per year by the average peak billing demand for lighting (in $\mathrm{KW}$ ) that occurs during the year.

[2] Ross \& Baruzzini, Inc., Energy Conservation Principles Applied to Office Lighting, Lighting and Thermal Operations, Conservation Paper Number 18, Federal Energy Administration, April, 1975. 
TABLE 3. LIGHTING POWER BUDGETS FOR GENERAL OFFICE BUILDING AREAS

FUNCTION OR TYPE OF AREA

\begin{tabular}{l} 
ALLOWANCE \\
WATTS PER \\
SQ. FT. \\
\hline
\end{tabular}

AREA*

Emergency System

Exitways

Stairways

.1

**

Exit Signs

General Lighting for

Lobbies, Corridors, Stairs,

and Landings

.6

$16 \%$ of building area***

Janitor, Storage, and

Maintenance Space

1.0

$4 \%$ of building area

Outside

7.5 watt per

linear foot

not less

than $1.0 \mathrm{~kW}$

Task Circulation Areas

.9

Daylighting Contribution

(deduct)

$(0.6)$

use $20 \%$ of building floor

area, min.

Parking - indoor

0.3

- outdoor

0.05

* Based on typical buildings

** Use same area as for building general lighting - do not add area into total area.

*** Includes elevator shafts and utility risers. 
If component power budgets are developed; i.e., for task areas, general areas, equipment rooms, etc., then each component power unit in watts/sq. $\mathrm{ft}$. should be multiplied by the respective hours of use of that area to determine the annual energy budget. Some examples are given below. However, when specific operating data are available, they should be used in each case.

\subsubsection{Task lighting example}

Assume that the task lighting will supplement the general lighting and can be switched off when the worker is not present for at least a portion of the time. Then for one-shift operation, typical of most office space:

8 hours/day $\times 5$ days/week $\times 50$ weeks/yr. = 2,000 hours/year duration of task lighting.

The task duration suggested in Part 3.3.2 (Simplified Procedure) is more liberal and assumes that the lights will not be switched off, except when the worker is not present at all during the day. Hence,

9 hours/day $\times 52$ weeks/yr. $\times 5-1 / 2$ days/week = $2,574 \mathrm{hrs} . / \mathrm{yr}$.

which is then rounded off to 2,600 hours/year. However, it is assumed that a diversity factor of .9 occurs to account for absences from the work location for a portion of the people.

\subsubsection{General lighting example}

14 hours/day $\times 51 / 2$ days/week $\times 52$ weeks/yr. = 4,000 hrs./yr.

\subsubsection{Natural Lighting}

\subsubsection{Natural Lighting and HVAC}

The use of natural light is recommended whenever energy can be conserved. It should be noted that in terms of lumens per watt, natural light, even including a direct beam of sunlight entering through a glass window, is more efficient than flourescent lighting (but not quite so efficient as high pressure sodium). This means that if the brightness and intensity can be controlled, daylighting has less effect on an HVAC system than does the usual artificial lighting system. The problem is one of control, so that only as much light as may be required is introduced during the cooling season. During the heating season, the additional heat associated with excess light may be welcome. 


\subsubsection{Natural lighting - energy allowance}

\subsubsection{General}

The following paragraphs provide an approach for determining the lighting energy to be conserved by substituting daylight for artificial light for an office building. It is assumed for budget purposes that this daylighting will be suitable for general lighting only and cannot be relied upon for task lighting. The energy thus calculated is used to offset the general light energy budget requirements (subtracted from the energy calculated to provide the artificial lighting).

The energy saved by daylighting should be reviewed for interaction with the HVAC system to determine annual net building energy gain or loss.

\subsubsection{Floor areas exposed to fenestration}

Determine the area exposed to normal fenestration for general lighting purposes by calculating the area within a depth of 12 feet from the outside fenestrated wall (if not blocked) and 10 feet on each side of the source along the wall, (i.e., $240 \mathrm{sq}$. ft. per window opening, but such areas are not additive if fenestration occurs more frequently than at $20^{\prime}$ intervals along the wall).

For overhead skylights, etc., use the area illuminated by the light, encompassed within a contour approximately $1 / 10$ the maximum level.

Consider only fenestration that is not effectively shaded by uncontrolled outside obstructions.

Total the above areas for "fenestrated areas." If the total is less than that in 3.2 .8 .3 , use the value obtained from 3.2 .8 .3 .

\subsubsection{Minimum fenestrated floor area for budget purposes}

In the event that no fenestration is included in the building (without justification), it may be desirable to impute a certain percentage of the total wall area and roof area as a fenestrated minimum floor area and base the daylight energy conservation on this minimum floor area; for example, the following assignment seems appropriate:

$$
\begin{array}{lll}
\text { Area of walls } \times 18 \% & = & \mathrm{sq} \cdot \mathrm{ft} . \\
\text { Area of roof } \mathrm{x} \% & \mathrm{sq} \cdot \mathrm{ft} . \\
\text { Minimum fenestrated floor } & & \\
\text { area for budget purposes: } & & \mathrm{sq} \cdot \mathrm{ft} .
\end{array}
$$

\subsubsection{Duration of daylighting}

Use average annual hours from $1 / 2$ hour after sunrise to $1 / 2$ hour before sundown, at building location (precise portion of time zone). 
Subtract from this value the average annual daylight hours that the outdoor horizontal illumination is less than 300 footcandles because of cloud cover.

\section{2 .8 .5 Duration of occupancy}

Compute the hours building is occupied.

Determine the coincidence of hours occupied and the daylight hours from above.

\subsubsection{Calculation of daylighting energy allowance}

Assume daylighting will replace general lighting (20 fc) in fenestrated area. $20 \mathrm{fc} \times .03$ watts $/ \mathrm{fc} / \mathrm{sq}$. ft. $=.6$ watts $/ \mathrm{sq}$. ft. for general

lighting, replaced by daylighting.

Then, .6 watts/sq. ft. $\mathrm{x}$ fenestrated area $\mathrm{x}$ coincident daylight hours $=$ annual daylighting energy credit. This energy is used to offset general

lighting budget. The daylight power is NOT used to offset the power budget. 


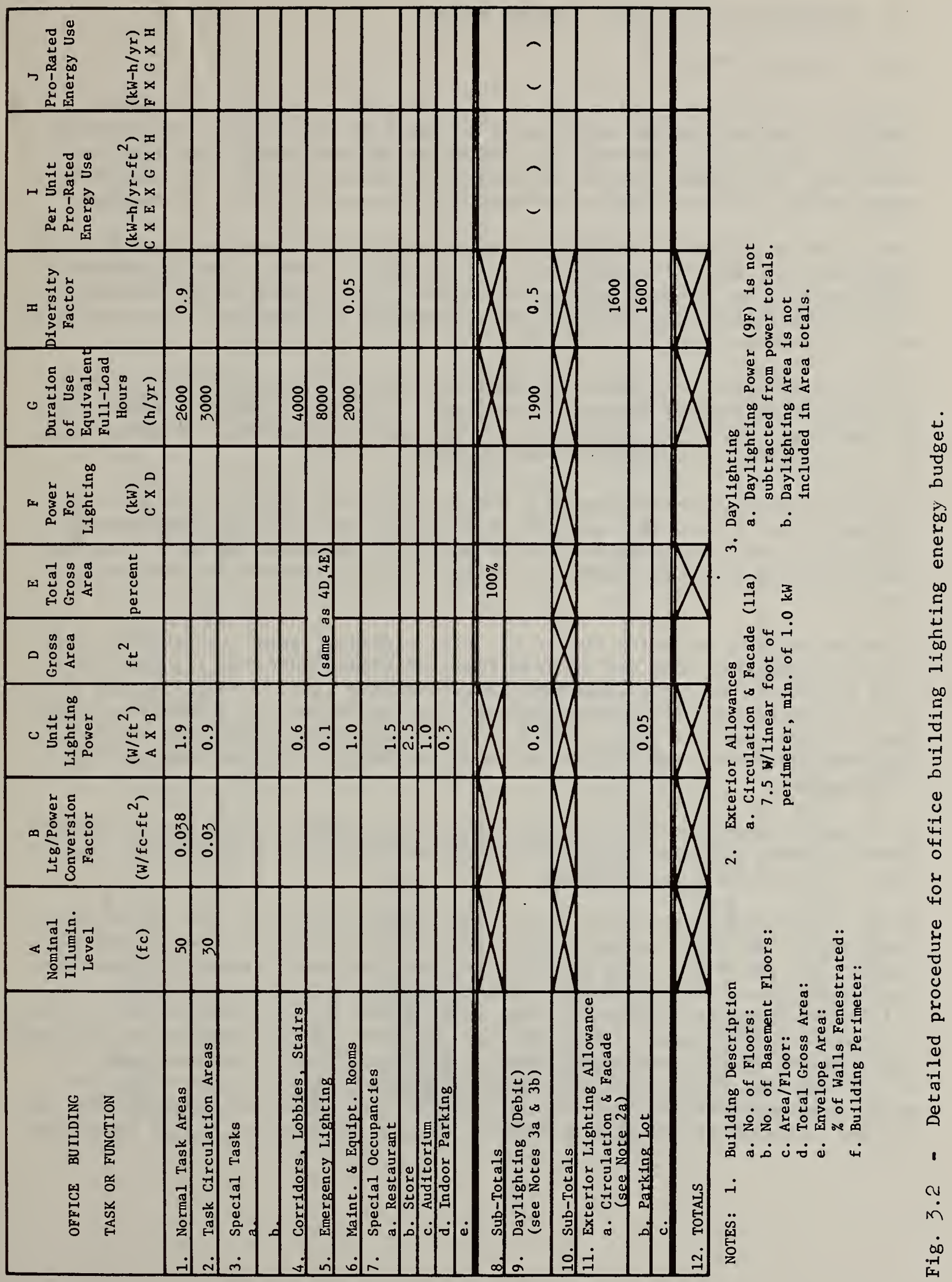




\subsection{METHODOLOGY FOR OFFICE LIGHTING BUDGET}

\subsubsection{Detailed Procedure}

A worksheet for the detailed procedure to be used to calculate an office building lighting energy budget is illustrated in Figure 3.2. The detailed procedure permits introduction of quantities for each factor required in developing the budget. Suggested values are already entered for appropriate items where these have been determined for prototypical office buildings.

Quantities are based on buildings used primarily 5 1/2 days per week, for 40 plus hours per week of normal work, per occupant. Where these recommended values are to be changed, a calculation shall be included on the worksheet (with identification of the block being changed) to demonstrate the rationale used for the change.

Allowance is made for outdoor lighting for building facade and circulation, in addition to outdoor parking if required. An energy credit is taken for daylighting. The daylighting power is not deducted from the connected load, but is only used to compute the energy credit.

The factor listed under Column H, "Diversity Factor" corrects for the decreased load caused by a portion of all loads not being on simultaneously. This factor could be accounted for in Column G, "Duration of Use" in equivalent full-load hours per year, but it is believed that the distinction is useful.

In selecting the value for Column $C$, "Unit Lighting Power", it should be borne in mind that this may be less than the total connected lighting load. This is particularly the case where supplementary task or mood lighting of one type is turned off whenever another type is turned on, when excess lighting is connected, but not switched on for future task relocation, or for emergency lighting that may not be energized until the normal source fails, for example.

It is not required to complete Columns $E$ and $I$; these columns mainly serve to identify areas of tasks using disproportionate amounts of energy per square foot, if adjustment is necessary.

Block $12 \mathrm{~J}$ indicates the total annual lighting energy budget for the building. Dividing by the gross building area (Block $8 \mathrm{D}$ ) provides the energy used per square foot per year, while dividing by the total power (Block 12F) provides the annual hours use of demand. As noted earlier, for the prototypical office building, this should be near 2,500 hours, with a range of from 2,000 minimum to 3,000 maximum. The expected value for annual prototypical building lighting energy use, excluding exterior lighting, when using the guidelines, is $3.8 \mathrm{kWhr} / \mathrm{sq}$. $\mathrm{ft} . / \mathrm{yr}$. When including exterior lighting, this value can range from approximately $3.9 \mathrm{kWhr} / \mathrm{sq}$. ft./yr. for large buildings without any special occupancies, up to $4.8 \mathrm{kWhr} / \mathrm{sq}$. $\mathrm{ft.} / \mathrm{yr}$. for smaller office buildings. 


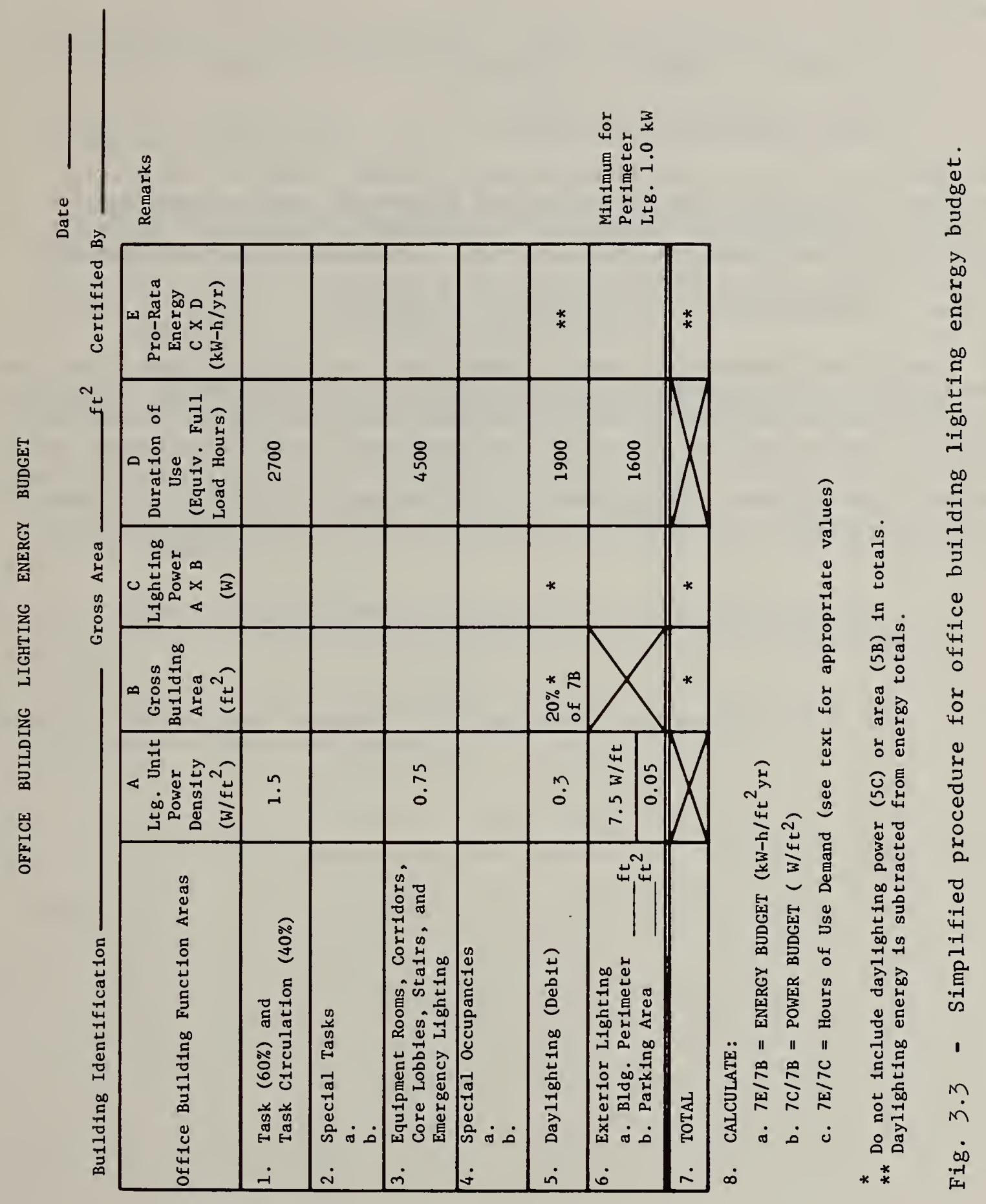


No contingency factor has been included to adjust these results. In the abstract, an increase of perhaps $10 \%$ should be considered. It is believed, however, that this factor should be applied to the entire building energy budget, rather than just to the lighting portion, so that it has been excluded here.

\subsubsection{Simplified Procedure for Calculating}

\subsubsection{Annual Lighting Energy Budget}

The worksheet for the simplified lighting energy budget is illustrated in Figure 3.3. The values tabulated on this sheet are pro-rata combinations of the values in Figure 3.2. This formulation permits entires to be made where blanks are shown. It is recommended that no alteration to the values on this form be permitted, except for Column D, "Duration of Use", and these should be justified if changed.

The simplified procedure is based closely upon the detailed procedure, and should yield similar budgets in most cases. Calculation effort is reduced by consolidation of building functions into fewer categories, basing the daylight energy debit on floor area instead of wall/roof dimensions, and absorbing the lighting power conversion factors and diversity factors into the pro-rata figures. Allowances for special tasks and occupancies are still available. 


\section{REFERENCES}

1. IES Handbook, 5th Edition, Illuminating Engineering Society of North America.

2. IES Code for Interior Lighting, Illuminating Engineering Society (British) January 1973.

3. Lighting Systems Study, General Services Administration, Public Buildings Service, March 1974.

4. Energy Conservation Principles Applied to Office Lighting, Conservation Paper No. 18, Federal Energy Administration Lighting \& Thermal Operations, April 15, 1975, NTIS No. PB 244154/AS.

5. NAVSHIPS, Display Illumination Design Guide, February 1973, U. S. Superintendent of Documents, p II-7.

6. Human Engineering Guide to Equipment Design, Revised Edition 1972, Chapter 3, American Institute for Research, Washington, DC, Library of Congress Card No. 72-600054.

7. Proceedings of The Basis for Effective Management of Lighting Energy Symposium, D. K. Ross, editor, October 29-30, 1976, NTIS No. PB-256 070 .

8. D. K. Ross, Energy Conservation Applied to Task Lighting, IEEE Transactions on Industry Applications, Vol. IA-13, January/February 1977.

9. D. K. Ross, Task Lighting - Yet Another View, Lighting Design \& Application, May 1978, p 37. 


\subsection{GENERAL}

In determining the approach for illumination performance standards for schools, it is necessary from the beginning to recognize the great diversity in school buildings, school programs, school teaching methods and objectives. Therefore, the methodology employed in developing the standards must always be apparent and accessible for modifications to suit specific requirements. While this approach avoids oversimplification, the danger at the other end of the spectrum is that in attempting to respond to this diversity no standards that have any broad meaning or applicability will evolve.

According to the classification system developed for the HUD baseline study by the AIA Research Corporation (ref. 5.), the school category is divided into three major classifications and each of these is further subdivided. The lower grade schools are combined under elementary schools with subcategories: day care, nursery school, elementary school. The next category is secondary schools with sub-categories: junior high school, high school, vocational school. The next category is college with two subcategories: junior college and college/university. It is obvious that even within this detailed breakdown, there are further sub-categories that could very well be introduced. For example, all of college/university is grouped as a single classification. In actuality this includes classroom buildings, laboratory buildings, gymnasiums, dormitories, administration buildings and research centers. It includes colleges with highly individualized methods of teaching, and those with primarily lecture-type of presentation. In other words, merely listing the classification for a building cannot be the basis for determining what a reasonable illumination budget would be for that particular building.

An alternative approach is to rely entirely on rule of thumb, power budget figures and reported energy usage from various schools and consider these to represent the state of the art in school illumination. Either by computation or by assumption of a certain built-in extravagance, a percentage reduction can be applied to these figures, and the new figure can be considered as a starting energy budget. This approach, which has strong champions, still gives no information as to whether the original assumptions in any way reflect an efficient use of ilumination, an essential idea if energy budgets are to be effective in reducing energy use in buildings to those levels that are necessary for the satisfactory performance of the activities that take place within those buildings. In order to determine these levels, there must be an actual computation using a lighting approach which is in fact energy efficient, reasonable, and within the working knowledge of the profession and the technical capacity of the industry that provides the components. It is this latter approach that was taken in the sample energy budget analysis for illumination in schools.

A typical elementary school building was selected as a vehicle for establishing a target budget. This school had a variety of different kinds of teach- 
ing spaces and administrative and service spaces. The assumed schedule for the school was a typical elementary school schedule that probably characterizes the vast majority of elementary schools throughout the country.

The size of the school and the variety of spaces make the recommendations applicable for most elementary schools. Smaller schools would have fewer spaces and might not have some of the spaces provided in the program. Larger schools would have more spaces but probably not more types of spaces. Open classroom schools in general would have larger area spaces, but these would have illumination requirements substantially similar to the more typical classrooms.

The illumination was laid out based on the performance characteristics of reasonably well-designed, commercially available luminaires. The computations are not that marginal that there is no leeway either in fixture type or in lighting arrangement. It is assumed that as fixture design improves throughout the industry, and as the light quality and output of the lamps themselves improve, the illumination called for can be provided with a lower power budget and energy budget.

The sample computations that were made for an elementary school situation would have to be tested and amplified for secondary schools, and for colleges and universities. These buildings, which are inherently more complex, also tend to be less typical and more specialized. Nevertheless, both the approach and the analysis of many of the components would be applicable to these buildings.

Central to the determination of any budget is the determination of appropriate light levels to be provided. The performance criteria are related to the Federal office Building criteria accepted by FEA and GSA for those buildings. They are above the IES recommendations that pertained prior to 1958 and are above the recommendations of the British Government in their Bulletin No. 33 on "Lighting in Schools" (ref. 6).

There has been a three-level approach to the lighting standards in the present study. For the greatest number of spaces--the classrooms--a background level of 30 footcandles (325 lux) is provided. A task lighting level would increase this to approximately 60 footcandles (650 lux) at critical areas such as chalkboards and bulletin boards which are provided with higher light levels. Circulation areas are designed for not over 10 (110 lux) footcandles, average. While specific room configurations provided the basis for the computation and detailed layouts, none of these were so unusual or uncharacteristic as to prevent the transfer of the conclusions to rooms of other dimensions and other configurations. The tasks assumed were typical but were not so special to the layouts that other requirements could not have been met within the connected allowances provided. A minimal credit was taken for the contribution of outside light, and only in those kinds of rooms where its provision could reasonaly be expected. 


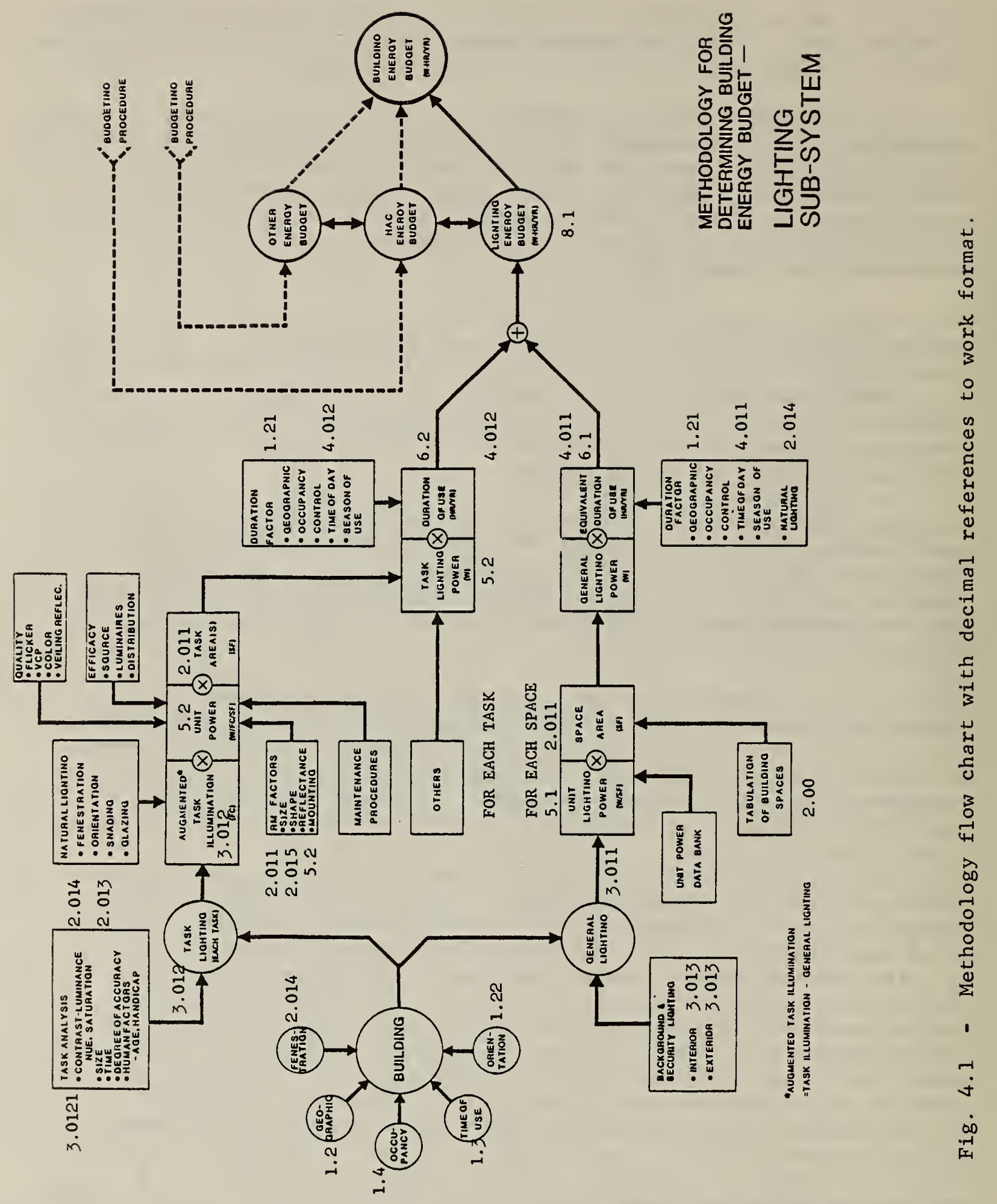


It is important to realize that with an energy budget based on task lighting, the opportunity for selected use of the task lighting when the task is being performed is fundamental to the design approach and the computations. If the task lighting were considered to be on at all times, the power load and the energy budget could well be greater than a system with only minimally satisfactory area lighting. The layouts must therefore provide for extensive individual switching, and we must assume that the user will be sufficiently in sympathy with the intent of the installation to use the system as intended. It is therefore important in accepting the connected loads that were developed in the study to keep them coupled to the provision of the related control switching in order to keep the annual use within the energy budget. In the specifications for illumination design, it is necessary to maintain the distinction between the connected power load for area lighting and the connected power load for task lighting. In other words, the application of these standards will not be a single power load per square foot as carte blanche for the designer, but rather a power load for area lighting, a power load for task lighting, and a requirement for adequate switching.

The methodology is based on the graphic flow diagram developed by the Task Force with decimal references that tie into the step-by-step work format described below (See figure 4.1). The format includes information that that may be pertinent for some locations but not all. (For example, a school designed for primarily winter use in Nome Alaska would have less access to natural light as a replacement for artifical light, particularly during the November, December, January months. The hours for utilizing certain lights would be modified in relation to this information). Where the information is unessential, it has been considered not applicable but has not been deleted from the methodological sequence.

The information that follows describes limitations on the use of the methodology.

1. Further investigation and verification of the various assumed levels and quality of delivered illumination for the tasks to be performed.

2. Modifications of requirements to satisfy the actual building under study versus the model building.

3. Addition of site illumination (site considerations vary widely for actual buildings).

4. Modification of schedule to satisfy the intended use of the actual building versus the model building.

5. Determination of the latitude of the building and its location (East or West) in its time zone, for inclusion in program.

6. Special spaces not covered in the model building would have to be added. 
7. The master program applicable as a base for all buildings of its type would be in catalog form with all assumptions and limitations described for each generic space.

\section{Outline of the Methodology}

1. General project information

1.1 Building type e.g. school

1.11 sub categories e.g. elementary, k-6

1.2 Location (geographic)

1.21 position in time zone $-E$ or $W$ (re daylight hours) and latitude

1.22 building orientation

1.3 Schedule - hours of operation - extent of operation

1.4 Population served

1.41 special characteristics

2. List of spaces by type - general description

2.01 Type 01 space

2.011 area of unit

2.012 number of units

2.013 orientation

2.014 fenestration

2.015 special requirements

2.016 space utilization patterns (see 6.1)

2.02 Type 02 space

2.03 Etc.

3. List of spaces by type - illumination requirements

3.01 Type 01 space

3.011 basic illumination (general lighting)

3.0111 Purpose A (Amount and quality of light required)

(Illumination Utilization factor)

3.0112 Purpose B (Amount and quality of light required)

(Illumination utilization factor)

3.012 supplemental illumination (task lighting)

3.0121 Purpose A (same as above)

3.0122 Purpose B (same as above)

3.0123 Etc.

3.013 security illumination

3.014 no illumination

3.02 Type 02 spaces

3.03 Etc. 
4. Hours of use for required illumination described in 3.00 per KEY to ANNUAL HOURS DESIGNATION*

4.01 Type 01 space - Annual hours of use for various illuminations

4.011 Hours for general lighting

4.0111 Hours for Purpose A

4.0112 Hours for Purpose B

4.012 Task lighting

4.0121 Hours for Purpose A

4.0122 Hours for Purpose B

4.0123 Etc.

4.013 Hours for security lighting

4.02 Type 02 space - (See type 01 space)

4.03 Etc.

5. Light delivery components - power and performance characteristics

5.11 Component A (power and performance characteristics)

5.12 Component B

5.13 Component $C$

5.14 Etc.

6. Light delivery components - utilization hours

hours of use $=$ (Annual hours of space use) $\mathrm{x}$ (illumination utilization factor, 3.00).

Annual hours of space use $=$ sum of hours for listed Space Utilization Patterns, 2.006

6.1 Space Utilization Patterns

6.11 Pattern A (in hours/yr)

6.12 Pattern B (in hours/yr)

6.13 Etc.

* Month Week Day Hours

Normal School

1

$1 \quad 1 \quad 1-24$

1 a.m. - Midnight

Illumination Hours

$2 \quad 25-48$

$8 \quad 16$

$3 \quad 49-72$

$32 \quad 40$

$56 \quad 64$

$4 \quad 73-96$

$80 \quad 88$

$\begin{array}{rr}4 & 97-120\end{array}$

$104 \quad 112$

$\begin{array}{lll}6 & 121 & -144 \\ 7 & 145 & -168\end{array}$

$128 \quad 132$

2

$169-192$

176

184

9

$193-216$

200

208

KEY to ANNUAL HOURS DESIGNATION 
6.2 Utilization hours - calculation

6.201 Space type 01

6.202 Space type 02

6.203 Etc.

7. Lighting design for each space - in terms of illumination requirements (3.00) given as component type (5.00) and number of components.

7.01 Space type 01

7.011 Basic illumination

7.0111 Purpose A (component type \& No.)

7.0112 Purpose B (component type \& No.)

7.012 Supplemental illumination

7.0121 Purpose A (same as above)

7.0122 Etc.

7.02 Space type 02

7.03 Etc.

8. Energy Consumption Calculation (kWh/hr)

Space Energy Consumption = sum for all illumination purposes of (Lighting Design, 7.00) x (Utilization hours)

8.01 Space type 01

8.011 Basic illumination

8.0111 Purpose A

(component power char.)x(No. of components) = load (load)x(utilization hours) = energy consumption

8.0112 Purpose B (same as above)

8.012 Supplemental illumination

8.0121 Purpose A

8.0122 Purpose B

8.0123 Etc.

9. Establishment of Annual Lighting Energy Budget

$\Sigma$ of all spaces Energy Consumption = Annual Lighting Energy Per total SF of bldg area $=$ Unit Area, $\mathrm{kWh} / \mathrm{ft}^{2} \cdot \mathrm{yr}\left(\mathrm{J} / \mathrm{m}^{2} \cdot \mathrm{yr}\right)$ 
NBS School Worksheet Description

A worksheet for each space has been made (see Figure 4.2) that:

1. restates the space type, size, and number (f rom 2.00)

2. gives the space use patterns and total space use hours (this could be added to information given in the example outline).

3. lists illumination requirements for each lighting use (this could be included in the example outline).

4. establishes lighting design for each use with a diagram (this also could be included in the example outline).

5. calculates the load for each lighting use.

6. totals the above to give the connected load for the space.

7. calculates actual illuminatior hours for each lighting use from information given in 2 and 3 above: (annual space use) $x$ (illumination utilization factor).

8. calculates energy consumption for each lighting use from information established in items 5 and 7 above: (load) x (actual illumination hours).

9. totals energy consumption for each lighting use to give the energy consumption for each space.

\subsection{APPLICATION OF METHOD}

Since the methodology is based on determining the energy budget required for performance of teaching and learning tasks in a school under redefined criteria for providing this illuminated environment, it is not possible merely to extrapolate from previous installations in a so-called state-of-the-art exercise. Rather, it is necessary to understand the complete set of educational requirements in a school and understand how each of these makes its own unique demands for lighting. This was the approach and the test both for the methodology and for the resulting recommended figures.

Using the methodology described under IV-A, the typical school was analyzed. The worksheets developed for space-by-space analysis are included in Appendix III. 


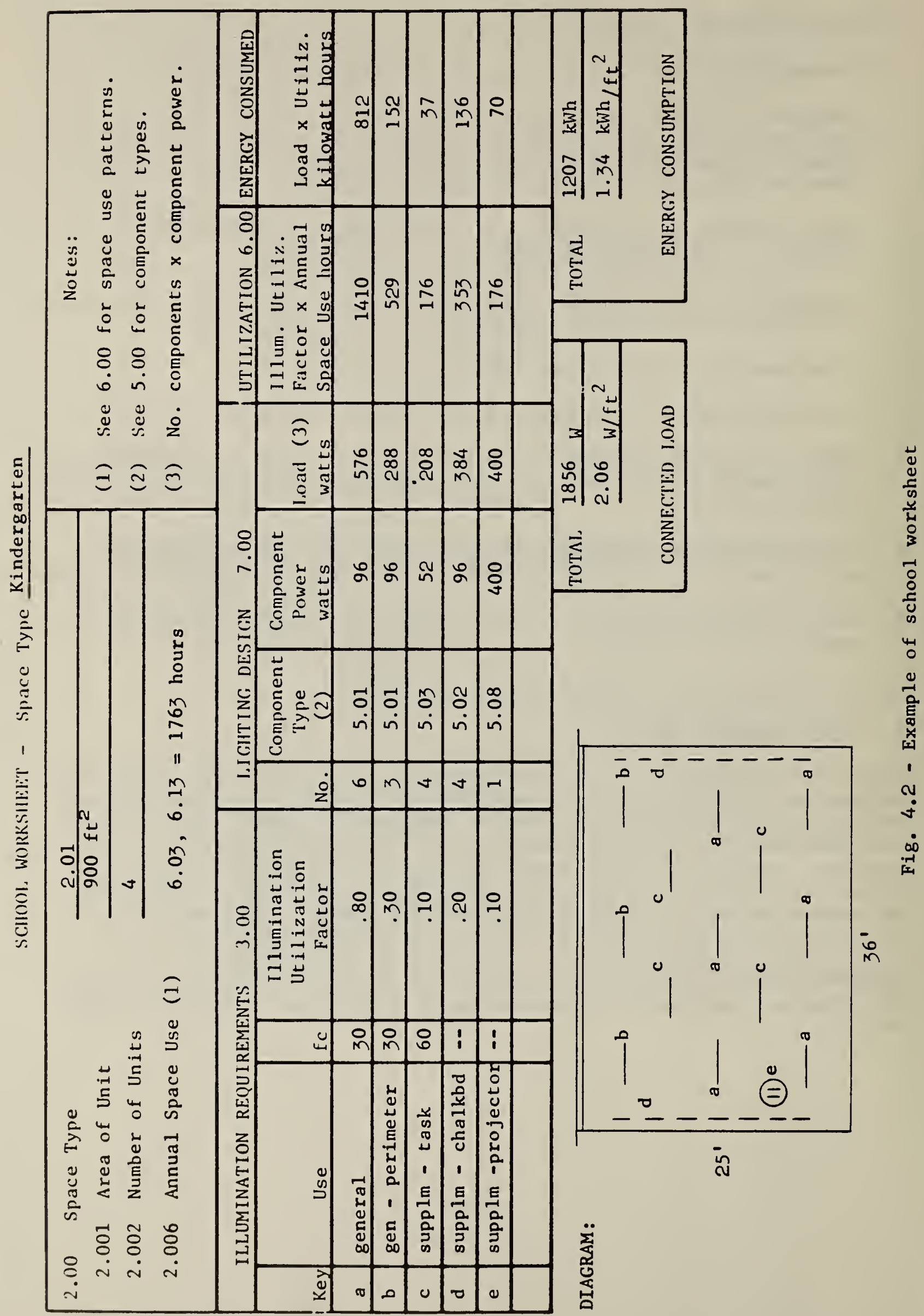


Example

1. General Project Information

1.1 School

1.11 elementary - kindergarten through sixth grade

2. List of Spaces by type, number, and area

2.01 Kindergarten Classroom

2.02 Classroom $1-3$ grade

2.03 Classrooms, 4-6 grade

2.04 Special tutorial rooms

2.05 Music Room

2.06 Instrument Storage

2.07 Cafeteria

2.08 Food prep \& Service

2.09 Gymnasium

2.10 Gymnasium Office

2.11 Gymnasium Lockers

2.12 Gymnasium Toilet Rooms

2.13 Gymnasium Showers

2.14 Auditorium Seating

2.15 Auditorium Stage

2.16 Auditorium Dressing Room

2.17 Auditorium Toilets

2.18 School offices

2.19 Principal's Office

2.20 Teachers' Room

2.21 Library

2.22 Librarian's Office

2.23 Entrance - Lobby

2.24 All Corridors

2.25 All Stairs

2.26 Boiler Room

2.27 Fan Rooms

2.28 Storage

2.29 Toilet Rooms

2.30 Janitor's Closets

TOTAL

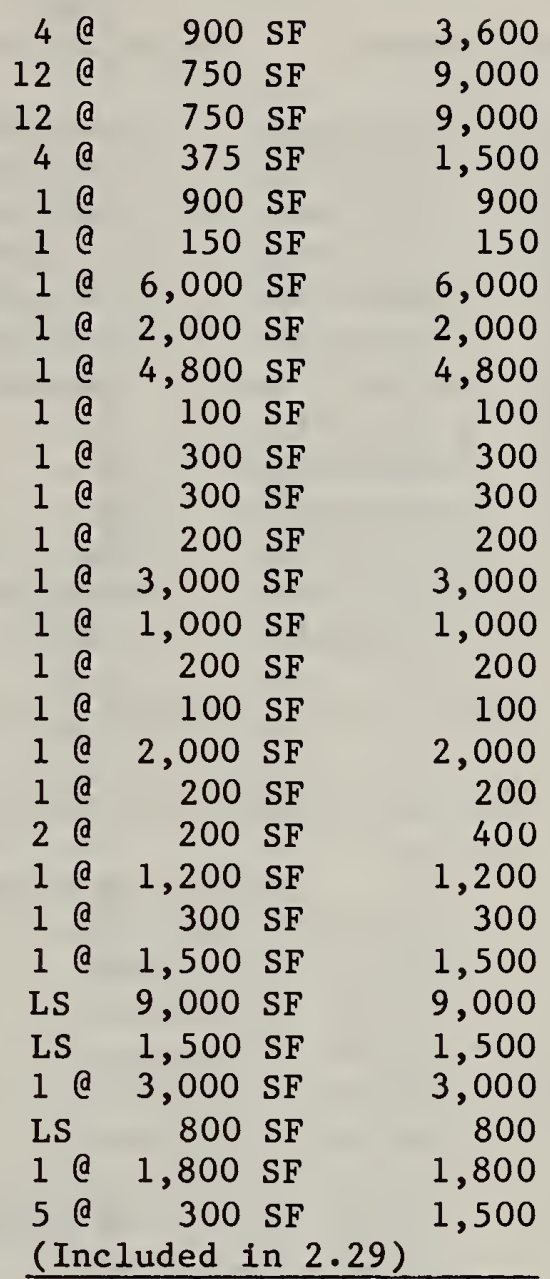

$65,350 \mathrm{SF}$ 
3. List of spaces by type - Illumination Requirements

(see worksheets in Appendix III)

4. Not applicable

5. Light Delivery Components

W/SF to Obtain

$\begin{array}{llllrrrr}\text { Type } & \text { Source } & \text { Reflector } & \text { Diffuser } & \text { W } & \text { 10 FC } & 30 \text { FC } & 60 \text { FC } \\ 5.01 & \text { 2-4' fluor } & \text { aluminum } & \text { none } & 96 & 0.3 & 1.0 & 1.6 \\ 5.02 & 1^{\prime} 8^{\prime} \text { fluor } & \text { a luminum } & \text { none } & 96 & 0.3 & 1.0 & 1.6 \\ 5.03 & 1^{\prime} 4^{\prime} \text { fluor } & \text { aluminum } & \text { none } & 52 & 0.3 & 1.0 & 1.6 \\ 5.04 & 1-4^{\prime} \text { fluor } & \text { aluminum } & \text { acrylic } & 52 & 0.6 & 1.6 & 3.3 \\ 5.05 & \text { incandescent } & \text { desk lamp } & \text { none } & 60 & - & - & - \\ 5.06 & \text { incandescent } & \text { downlite } & \text { none } & 150 & 1.9 & 5.7 & 11.4 \\ 5.07 & \text { mercury vapor } & \text { aluminum } & \text { none } & 700 & 0.4 & 1.1 & 2.2 \\ 5.08 & \text { projector } & - & - & 400 & - & - & - \\ 5.09 & \text { incandescent } & \text { RLM } & \text { none } & 150 & 1.6 & 4.8 & 9.6 \\ 5.10 & \text { incandescent } & \text { RLM } & \text { none } & 200 & 1.1 & 3.2 & 5.6 \\ 5.11 & \text { incandescent } & \text { RLM } & \text { none } & 300 & 0.9 & 2.8 & 5.2 \\ 5.12 & \text { 2-4' fluor } & \text { aluminum } & \text { acrylic } & 96 & 0.6 & 1.6 & 3.3 \\ 5.13 & \text { spotlights } & \text { metal } & - & 200 & - & - & -\end{array}$

6. Light Delivery Components - Utilization Hours

6.1 Space Utilization Patterns

$\begin{array}{llllr} & \text { Season (see note) } & \text { days/wk } & \text { hrs/day } & \text { hrs/yr } \\ 6.01 & \text { winter } & 6 & 7 & 1,819 \\ 6.02 & \text { winter } & 51 / 2 & 9 & 2,145 \\ 6.03 & \text { winter } & 51 / 2 & 7 & 1,667 \\ 6.04 & \text { winter } & 51 / 2 & 5 & 1,191 \\ 6.05 & \text { winter } & 51 / 2 & 3 & 714 \\ 6.06 & \text { winter } & 51 / 2 & 2 & 476 \\ 6.07 & \text { winter } & 5 & 8 & 1,732 \\ 6.08 & \text { winter (night) } & 2 & 3 & 260 \\ 6.09 & \text { winter (night) } & 1 & 5 & 216 \\ 6.10 & \text { winter (n } & 3 & 130 \\ 6.11 & \text { summer } & 51 / 2 & 4 & 191 \\ 6.12 & \text { summer } & 51 / 2 & 3 & 96 \\ 6.13 & \text { summer } & 51 / 2 & 2 & 78 \\ 6.14 & \text { summer } & 3 & 3 & \\ & & & \end{array}$

\subsection{Utilization Hours - Calculation \\ (see worksheets in Appendix III)}


7. Lighting Design for Each Space

(see worksheets in Appendix III)

8. Energy Consumption Calculation

(see worksheets in Appendix III)

9. Establishment of Lighting Requirements

\begin{tabular}{|c|c|c|c|c|c|c|}
\hline & & SF & $\begin{array}{l}\mathrm{kWh} / \\
\mathrm{SF}\end{array}$ & kWh & $\mathrm{W} / \mathrm{SF}$ & W \\
\hline 2.01 & Kindergarten classrooms & 3,600 & 1.34 & 4,828 & 2.06 & 7,424 \\
\hline 2.02 & Classrooms, $1-3$ grades & 9,000 & 1.68 & 15,132 & 2.35 & 21,120 \\
\hline 2.03 & Classrooms, 4-6 grades & 9,000 & 1.38 & 12,432 & 2.35 & 21,120 \\
\hline 2.04 & Special tutorial rooms & 1,500 & 0.55 & 824 & 2.60 & 3,904 \\
\hline 2.05 & Music room & 900 & 1.19 & 1,068 & 1.62 & 1,456 \\
\hline 2.06 & Instrument storage & 150 & 0.12 & 18 & 0.35 & 52 \\
\hline 2.07 & Cafeteria & 6,000 & 0.51 & 3,078 & 0.99 & 5,952 \\
\hline 2.08 & Food prep \& serving & 2,000 & 1.16 & 2,328 & 1.15 & 2,304 \\
\hline 2.09 & Gymnasium & 4,800 & 1.79 & 8,615 & 1.23 & 5,900 \\
\hline 2.10 & Gymnasium office & 100 & 1.43 & 143 & 1.56 & 156 \\
\hline 2.11 & Gymnasium lockers & 300 & 0.66 & 197 & 0.35 & 104 \\
\hline 2.12 & Gymnasium toilets & 300 & 1.87 & 561 & 0.99 & 296 \\
\hline 2.13 & Gymnasium showers & 200 & 1.82 & 364 & 0.96 & 192 \\
\hline 2.14 & Auditorium seating & 3,000 & 0.15 & 457 & 0.29 & 864 \\
\hline 2.15 & Auditorium stage & 1,000 & 1.55 & 1,551 & 3.88 & 3,876 \\
\hline 2.16 & Auditorium dressing room & 200 & 0.27 & 54 & 1.44 & 288 \\
\hline 2.17 & Auditorium tollets & 100 & 0.65 & 65 & 3.00 & 300 \\
\hline 2.18 & School offices & 2,000 & 1.74 & 3,474 & 1.64 & 3,288 \\
\hline 2.19 & Principal's office & 200 & 1.28 & 256 & 1.26 & 252 \\
\hline 2.20 & Teachers' rooms & 400 & 1.60 & 638 & 1.52 & 608 \\
\hline 2.21 & Library & 1,200 & 1.67 & 2,009 & 1.71 & 2,056 \\
\hline 2.22 & Librarian's office & 300 & 1.27 & 382 & 1.16 & 348 \\
\hline 2.23 & Entrance - Lobby & 1,500 & 3.16 & 4,735 & 2.18 & 3,276 \\
\hline $\begin{array}{l}2.24 \\
2.25\end{array}$ & $\begin{array}{l}\text { All corridors } \\
\text { All stalrs }\end{array}$ & $\begin{array}{l}9,000 \\
1,500\end{array}$ & $\begin{array}{l}0.84 \\
1.08\end{array}$ & $\begin{array}{l}7,560 \\
1,620\end{array}$ & $\begin{array}{l}0.32 \\
0.42\end{array}$ & $\begin{array}{r}2,912 \\
624\end{array}$ \\
\hline 2.26 & Boiler room & 3,000 & 0.22 & 672 & 0.40 & 1,212 \\
\hline 2.27 & Fan rooms & 800 & 0.25 & 203 & 0.44 & 348 \\
\hline 2.28 & Storage & 1,800 & 0.06 & 113 & 0.32 & 576 \\
\hline \multirow[t]{2}{*}{2.29} & Tollets & 1,500 & 1.93 & 2,890 & 1.19 & \\
\hline & & 65,350 & 1.17 & 76,267 & 1.42 & 92,598 \\
\hline
\end{tabular}

Lighting Energy Budget

$=\frac{76,267 \mathrm{kWh}}{65,350 \mathrm{SF}}=1.17 \frac{\mathrm{kWh}}{\mathrm{SF}}$ 
This resulted in an overall Power Budget of 1.42 watts per square foot and an overall Energy Budget of 1.17 kilowatt hours per square foot. By going back to the worksheets, a further breakdown by space type or unit permits the separation into General lighting and Task lighting, with W and $\mathrm{kWh}$ for each unit. Using these watts and kilowatt hours per square foot and multiplying by the number of square feet of each unit in the school, new totals were computed, which showed watts and kilowatt hours per square foot for the entire school divided between General lighting $(0.81 \mathrm{~W} / \mathrm{SF}$ and $0.91 \mathrm{kWh} / \mathrm{SF})$ and Task lighting $(0.60 \mathrm{~W} / \mathrm{SF}$ and $0.26 \mathrm{kWh} / \mathrm{SF})$. It can be seen that the connected load for General lighting is used about 1,120 hours a year, but the load for Task lighting is used only for about 420 hours on the average. (See Figure 4.3)

For wider applicability, all spaces have been grouped in more generic categories (see figure 4.3 for category assignments):

Teaching spaces

Administrative and office spaces

Auditorium

Gymnasium

Cafeteria

Service, Circulation and Mechanical Spaces

These in turn have been examined to determine watts per square foot connected load for Power Budgets, and kilowatt-hours per square foot for Energy Budgets in both General and Task Lighting Categories (see Table 1 below). The resulting Power and Energy Budgets for these categories form the basis for a simplified procedure to determine Annual Lighting Budgets.

TABLE 1. SUMMARY OF ILLUMINATION REQUIREMENTS BY MAJOR EDUCATIONAL CATEGORIES

\begin{tabular}{|c|c|c|c|c|c|c|c|c|c|}
\hline \multirow[t]{2}{*}{ CATEGORY } & \multirow[t]{2}{*}{ AREA } & \multicolumn{2}{|c|}{$\begin{array}{l}\text { CONNECTED } \\
\text { LIGHT ING } \\
\text { LOAD (W) }\end{array}$} & \multicolumn{2}{|c|}{$\begin{array}{l}\text { ANNUAL } \\
\text { ELECTRIC } \\
\text { USE (kWh) }\end{array}$} & \multicolumn{2}{|c|}{$\begin{array}{l}\text { POWER } \\
\text { BUDGET } \\
(W / S F)\end{array}$} & \multicolumn{2}{|c|}{$\begin{array}{l}\text { ENERGY } \\
\text { BUDGET } \\
(\mathrm{kWh} / \mathrm{SF})\end{array}$} \\
\hline & & GEN & TASK & GEN & TASK & GEN & TASK & GEN & TASK \\
\hline TEACHING & 25,350 & 25,492 & 31,640 & 26,710 & 9,601 & 1.01 & 1.25 & 1.05 & 0.38 \\
\hline OFFICE, ADMIN & 3,000 & 2,976 & 1,676 & 3,216 & 1,677 & 0.99 & 0.56 & 1.07 & 0.56 \\
\hline $\begin{array}{l}\text { AUDITORIUM } \\
\text { GYMNASIUM }\end{array}$ & $\begin{array}{l}4,300 \\
5,600\end{array}$ & $\begin{array}{l}2,160 \\
6,388\end{array}$ & $\begin{array}{r}3,168 \\
104\end{array}$ & $\begin{array}{r}860 \\
9,540\end{array}$ & $\begin{array}{r}1,267 \\
197\end{array}$ & $\begin{array}{l}0.50 \\
1.14\end{array}$ & $\begin{array}{l}0.74 \\
0.02\end{array}$ & $\begin{array}{l}0.20 \\
1.70\end{array}$ & $\begin{array}{l}0.29 \\
0.04\end{array}$ \\
\hline CAFETERIA & 8,000 & 6,720 & 1,536 & 4,014 & 1,392 & 0.84 & 0.19 & 0.50 & 0.17 \\
\hline SERV, CIRC, MECH & 19,100 & 9,330 & 1,408 & 15,170 & 2,623 & 0.49 & 0.07 & 0.79 & 0.14 \\
\hline
\end{tabular}




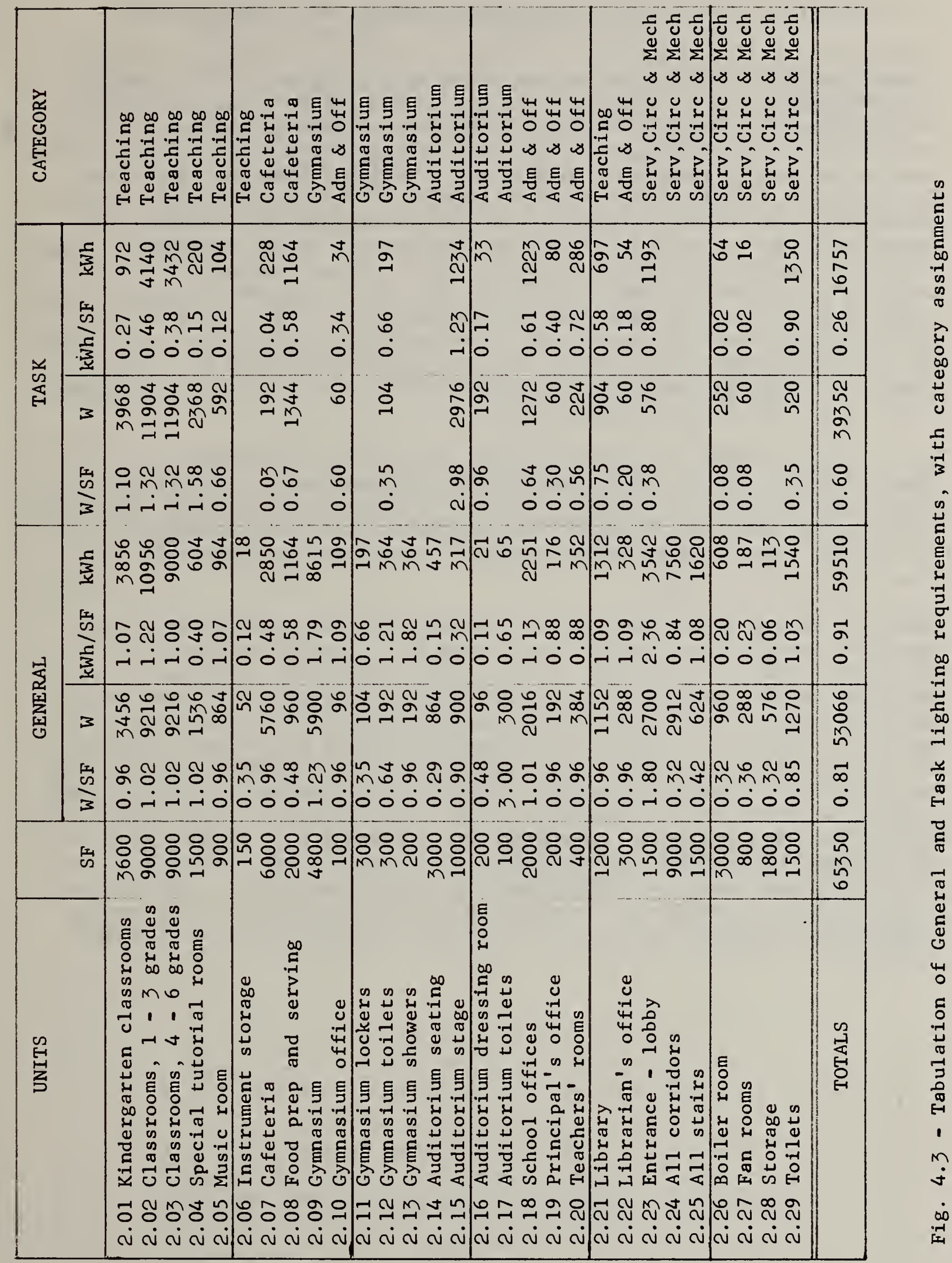




\subsection{SIMPLIFIED PROCEDURES FOR DETERMINING SCHOOL ILLUMINATION BUDGET}

A simplified procedure has been developed to permit the design of lighting layouts which conform to the criteria established in the previous section, without duplicating the analytical process. The procedure is based on a description of building conditions and square foot energy budgets that can be used either on an overall or a department-by-department basis. For a specific school, the energy budget can be directly determined from the information developed for the prototype or can be modified if the school varies significantly from the prototype either in facilties, program, or schedule. If schedule is the one difference between the specific school and the prototype, the power budget would remain the same, but the annual energy budget would be modified to accommodate this variation. The prototype school is based on a programmed use of 1,667 hours per year (or 43 weeks at $381 / 2$ hours). The lighting layout must provide at least one switch for the general illumination for each 300 square foot of floor area and a separate switch for each task light. For initial budget puposes, this can be considered one control per 50 watts of task lighting power budget.

The prototype school is a K-6 school for 700 pupils at approximately 100 square feet per pupil. The following chart (Figure 4.4), "A Short Method for Determining Illumination Budgets (Power and Energy) for Elementary Schools," gives values in watts per square foot for general and task budgets according to teaching spaces and kilowatt hour per square foot for general and task uses for an energy budget.

The short method can be used in its simplest form by applying the overall power and energy densities for general and task lighting to the gross area of the school. This would result in total power and energy densities of 1.6 watts per square foot and 1.3 kilowatt-hours per square foot respectively, somewhat higher than the detailed analysis yielded for the prototype ( 1.41 and 1.17). Should the schools distribution of space by category vary significantly from the prototype, new figures can be developed by applying the new "percent of space per category" figures to the tabulated densities, and summing to obtain the four density values. For example, a space distribution of $60 \%$ Teaching, 5\% Office, no Auditorium, 10\% Gymnasium, 5\% Cafeteria, and $20 \%$ Service, Circulation and Mechanical would yield total densities of 1.77 watts per square foot and 1.40 kilowatt-hours per square foot. Should the schedule for the school vary significantly from the prototype, the energy budget can be modified by the ratio of annual operating hours of the two schools. 
A SHORT METHOD FOR DETERMINING ILLUMINATION BUDGETS (POWER AND ENERGY) FOR ELEMENTARY SCHOOLS

\begin{tabular}{lccccc}
\hline \multicolumn{1}{c}{$\begin{array}{c}\text { SPACE } \\
\text { CATEGORY }\end{array}$} & POWER BUDGET & ENERGY BUDGET & $\begin{array}{c}\text { \% OF SPACE } \\
\text { PER CATEGORY } \\
\text { IN PROTOTYPE }\end{array}$ \\
\cline { 2 - 6 } & $\begin{array}{c}\text { Gen } \\
\text { W/SF }\end{array}$ & $\begin{array}{c}\text { Task } \\
\text { W/SF }\end{array}$ & $\begin{array}{c}\text { Gen } \\
\text { kWh/SF }\end{array}$ & $\begin{array}{c}\text { Task } \\
\mathrm{kWh} / \mathrm{SF}\end{array}$ & $39 \%$ \\
\hline Teaching Spaces & 1.0 & 1.3 & 1.1 & 0.4 & 5 \\
Office \& Admin & 1.0 & 0.6 & 1.1 & 0.6 & 7 \\
Auditorium & 0.5 & 0.8 & 0.2 & 0.3 & 8 \\
Gymnasium & 1.2 & 0.1 & 1.7 & 0.1 & 12 \\
Cafeteria & 0.9 & 0.2 & 0.5 & 0.2 & 29 \\
Serv, Circ, Mech & 0.5 & 0.1 & 0.8 & 0.2 & $100 \%$ \\
\hline
\end{tabular}

Fig. 4.4 Short method for school illumination budgets. 


\subsection{CONCLUSIONS}

In order to set up energy budgets, three steps were undertaken. First was the determination of an acceptable difinition of the energy budget; second, the development of a methodology that could be applied for all conditions, and third, a detailed utilization of that methodology to test its applicability to several different building types. Based on the detailed study for schools, a simplified procedure was developed and conclusions were drawn in regard to the widest possible use of the resulting recommended standards.

The Energy Budget is the amount of energy permitted annually for the operation of the systems within buildings. Since artificial illumination represents a part of the building's electrical use, and both modifies and is modified by other systems, its budget can be looked at only as a component in an overall budget.

From the designers' point of view, while the budget describes the annual functioning of the installed system, it is the installed system which is actually detailed and specified on the architectural and engineering documents. The installed system has a connected load that represents the Power Budget, but until a time of use factor is added, the Energy Budget is purely theoretical. Users' housekeeping patterns, schedule of usage, and maintenance procedures can produce large variations in energy usage without changing power load. Moreover, verification is difficult, and in most cases, impossible. The source for verification of a lighting budget would be the monthly electric utility bills. The problems in policing these and comparing the results against projected energy budgets are immense--technically, politically, and constitutionally. There is also the problem of identifying which part of the electric bill is related to lighting. Even if the lights were metered separately, task lighting, a major component in an energy-efficient lighting scheme, is often provided through the convenience outlet circuits, along with electricity for office machines, water coolers, vacuum cleaners and television sets. Where the various energy budgets for different systems are combined into a single annual electrical energy budget, there is the assumption that the building user can determine trade-offs-more illumination can be provided if there is less ventilating fan usage, for example.

Since the initial control, and probably the most effective one, takes place when the school building is designed and filed for government approvals, the buildings filed will have to be assumed to be capable of being operated at the energy budget assigned. Since this is dependent on a low level of general light plus extensive dependence on task illumination, the filing must differentiate between the connected loads in the power budget in each category and must also have a demonstrated capability of allowing the selective operation on which the energy budget depends. This means that control mechanisms, switches, must be installed or provided for generally in the amount noted under IV-C above, Simplified Procedure. 
Ultimately, after schools have been designed and built to these criteria, the situation will have been established where performance can be measured. As has been mentioned frequently, the illumination use of electricity cannot be separated from all the other electrical usages even with separate metering because of the use of the convenience outlet circuits for task lighting. It is therefore obvious that the budget can be verified only as part of the total electrical use budget which includes the electrical use for mechanical equipment, connected equipment and the discretionary electrical uses that must be provided for all times.

Based on these projections, the school would use about 1.17 kilowatt hours per square feet per year. By way of comparison, a detailed examination of New York City public schools, conducted in 1974 and using the recorded experience of $1,000 \mathrm{schools}$ in the systems, indicated an electric use that averaged 3.86 kilowatt hours per square foot for oil-heated schools and 3.11 kllowatt hours per square foot for the older, coal-heated schools; an NBS analysis of these figures indicated that 61 percent of the electrical use was for lighting. This would be 2.35 kilowat hours for lighting in the oilheated schools and $1.90 \mathrm{kilowatt}$ hours per square foot in the coal-heated schools. A study made at that time of an efficient lighting scheme indicated a 60 percent savings in the oil-heated category or an energy use of $1.41 \mathrm{kilo-}$ watt hours per square foot per square foot per year. The hours of usage were somewhat greater than those in a prototypical case which suggests that the 1.17 kilowatt hours is, in fact, a realistic and achievable annual energy use per square foot for schools. 
1. Low Energy Utilization School Research, Phase I: Interim Report, Richard Stein and Carl Stein, U.S. Government Printing Office, Washington DC 20402, Stock No. 3800-00194, August 1974. Research for the New York City Board of Education.

2. Low Energy Utilization School Phase 2 Report, Richard G. Stein, Carl Stein, Paul F. Deibert, U.S. Department of Commerce, National Technical Information Service, Springfield, Virginia 22161, PB-269 407/3WE. NSF/RA-77/0032, March 31, 1977. For the New York City Board of Education.

3. IES Lighting Handbook, Illuminating Engineering Society, Fifth Edition, 1972.

4. Architecture and Energy, Richard G. Stein, FAIA. Anchor Books, Anchor Press/Doubleday, Garden City, New York 1978.

5. Building Classification System Phase One - Base Data for the Development of Energy Performance Standards for New Buildings, U.S - Department of Housing and Urban Development, Office of Policy Development and Research, November 10, 1977.

6. Lighting in Schools, Department of Education and Science Building Bulletin 33. London: Her Majesty's Stationery Office, 1967 Tillotson (Bolton) Ltd. S. 0. Code No. 27-373-33. 


\section{BUILDING TYPE STUDY - RESIDENCE}

\subsection{GENERAL}

This section describes how the methodology of Chapter 2 can be used to determine the annual lighting energy budget for residences on unit building area basis, so that the lighting energy budget can be combined with the energy budget of other building subsystems to constitute a single building energy budget.

\subsubsection{Residential Building Classifications}

Residential buildings can be divided into the following classifications. For purpose of this study, hotels and dormitories are excluded.

1.1 Single family detached

1.2 Single family attached (flats, duplex, townhouses, etc.)

1.3 Multi-family, low-rise (condominiums, apartments, etc.)

1.4 Multi-family, high-rise (condominiums, apartments, etc.)

\subsubsection{Characteristics of Lighting Energy Consumption in Residential Buildings}

Insofar as lighting energy consumption is concerned, there should be no difference between the living spaces, such as bedrooms, living rooms, kitchen, dining areas, bathrooms, etc., for all classes of residential buildings. However, the lighting usage in residences is more "people" oriented than "area" related. It can be readily identified that a large residence will normally require more energy for heating and/or air conditioning, but a larger residence with few people may consume less lighting energy than a smaller residence having more people. The difference could be further amplified by a number of people-oriented factors, such as:

2.1 No. of occupants in residence

2.2 Mix of occupants--adults vs. children

2.3 Age of adult occupants--retired, working age, etc.

2.4 Age of children--pre-school, elementary school, high school and college age groups

2.5 Working habit of adults--husband or wife work only, both work or not working

2.6 Social habit of occupants--stay more at home, have frequent visitors or guests, seldom stay at home, etc.

2.7 Use of residence--permanent home, summer or winter home, etc.

2.8 Economic background of occupants

2.9 Educational background of occupants

When all factors identified above are taken into consideration, it is not difficult to conclude that the annual lighting energy consumption of two identical residences could have extreme differences even if both families are energy conscious. 
Attempts have been made to study the behavior of a "typical" American family, but who is a typical American family? There is so much individuality among people that neither a so-called "typical" or "average" family, based on national census data, can be used to establish a realistic lighting budget for all families. It would appear that the energy budget for residential buildings should be based on a combination criteria of building size and character of occupants. Since the character of occupants may change from year to year, the budget for residences would have to be modified annually, if necessary.

Fortunately, lighting energy consumption is normally small when compared to other uses. For example, take a $1000 \mathrm{sq}$. ft. single family residence of a middle income family, total lighting installed would probably be between 2,000 to 3,000 watts operating not more than 2 hours per day on the overall basis. In the meantime, the total amount of electrical appliances could exceed 20,000 watts for televisions, range, oven, toaster, refrigerator, washer and dryer, not counting electrical power for heating, air conditioning, or hot water.

The energy per square foot basis is the simplest workable solution for nonresidential buildings. For the sake of a unified approach to determine annual energy consumption of all building types, this same methodology to determine lighting energy consumption on a square foot basis will also be tested on residential buildings.

\subsection{METHODOLOGY}

\subsubsection{General Project Information}

\subsubsection{Building Type - Residential}

5.2.1.1.1 Single Family - Detached and Attached

5.2.1.1.2 Multi-family - Low-rise and High-rise

5.2.1.2 Geographic location - Minimum impact

5.2 .1 .3 Occupancy - Varies

5.2 .1 .4 Time of Use - Varies

5.2.1.5 Orientation - Minimum impact

\subsubsection{Spaces by Type - General Description}

\subsubsection{Living Spaces}

$\begin{array}{ll}5 \cdot 2 \cdot 2 \cdot 1 \cdot 1 & \text { Living and Family Room } \\ 5 \cdot 2 \cdot 2 \cdot 1 \cdot 2 & \text { Dining Room } \\ 5 \cdot 2 \cdot 2 \cdot 1 \cdot 3 & \text { Kitchen } \\ 5 \cdot 2 \cdot 2 \cdot 1.4 & \text { Bedrooms } \\ 5 \cdot 2 \cdot 2 \cdot 1 \cdot 5 & \text { Bath Rooms } \\ 5 \cdot 2 \cdot 2 \cdot 1 \cdot 6 & \text { Hallways } \\ 5 \cdot 2 \cdot 2 \cdot 1.7 & \text { Laundry }\end{array}$




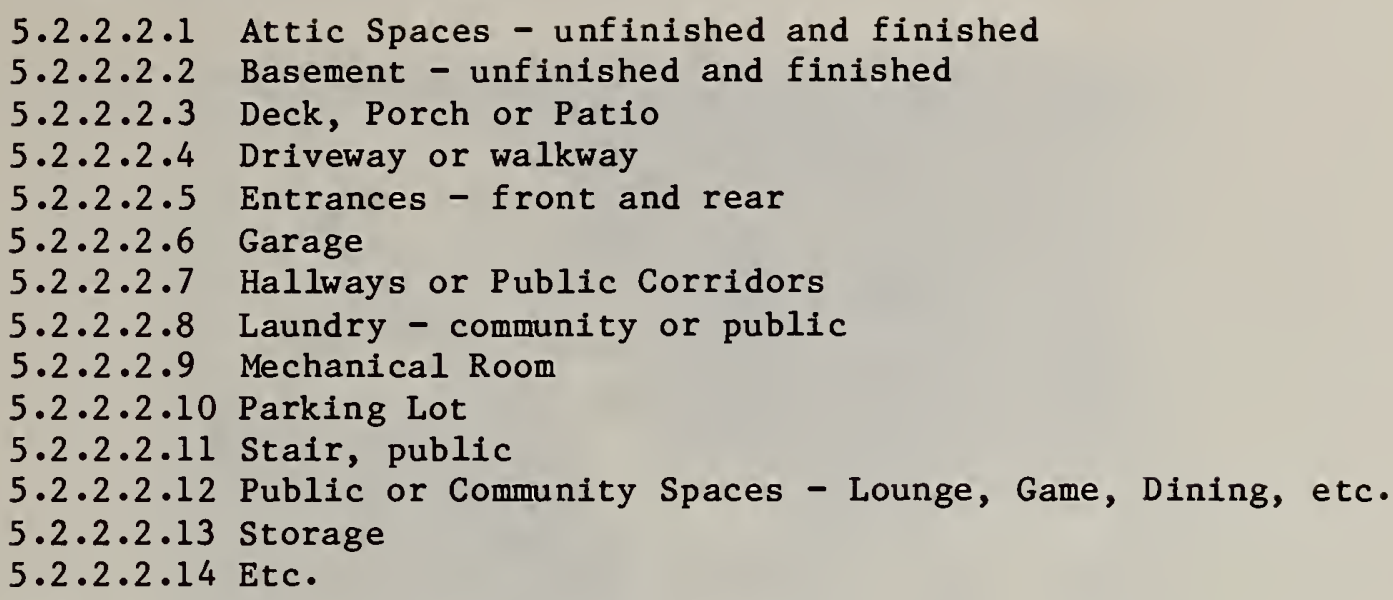

\subsubsection{Spaces by Type - Illumination Requirements}

5.2.3.1 Living Spaces - Lighting installation of most living spaces in residences are generally on task lighting basis employing a variety of lighting equipment and concepts. Thus, lighting power required can be best evaluated on an overall layout basis. For this purpose, five residential plans ranging from a $580 \mathrm{sq}$. ft. efficiency apartment to a 2,000 sq. ft. 2-story house have been selected as illustrated in Figures 5.1 through 5.5 (Reference 4). The unit power density (UPD) of all these plans fall consistently btween 2.2 and 2.5 watts/sq. ft. It can be concluded that 2.3 watts/sq. ft. should be a reasonable UPD for living spaces for all residential sizes and classes.

5.2.3.2 0ther Spaces - Lighting requirements for other spaces identified in 5.2.2.2 varies widely in size and use. These could be determined individually as follows:

\section{TASKS/AREAS}

1. Attic, unfinished

2. Basement, unfinished

3. Basement, finished

4. Deck, Porch or Patio

5. Driveway or Walkway

6. Garage

7. Hallways/Public Corridors

8. Laundry, Public

9. Mechanical Room

10. Parking Lot

11. Stair, Public

12. Public (community)

13. Storage

14. Etc.

\begin{tabular}{ccc}
$\begin{array}{cc}\text { UPD } \\
\text { (W/SF) }\end{array}$ & POWER \\
\cline { 1 - 1 } 0.1 & & - \\
ALLOWANCE (W) & \\
0.25 & & - \\
0.5 & - \\
- & 200 \\
- & 100 \\
0.25 & - \\
0.25 & - \\
0.25 & - \\
0.25 & - \\
0.05 & - \\
- & 100 \\
2.0 & - \\
0.25 & - \\
- & -
\end{tabular}

\section{REMARKS}

Average 2 fc Average $5 \mathrm{fc}$ Average $10 \mathrm{fc}$ (2) 100-watt per 50 linear feet ASHRAE 90-75 (R) ASHRAE 90-75 (R) ASHRAE 90-75 (R) ASHRAE 90-75 (R) Minimum $1 \mathrm{fc}$ 200 SF per floor Lounge, Lobby, Cafeteria, etc. ASHRAE 90-75 (R) as required 


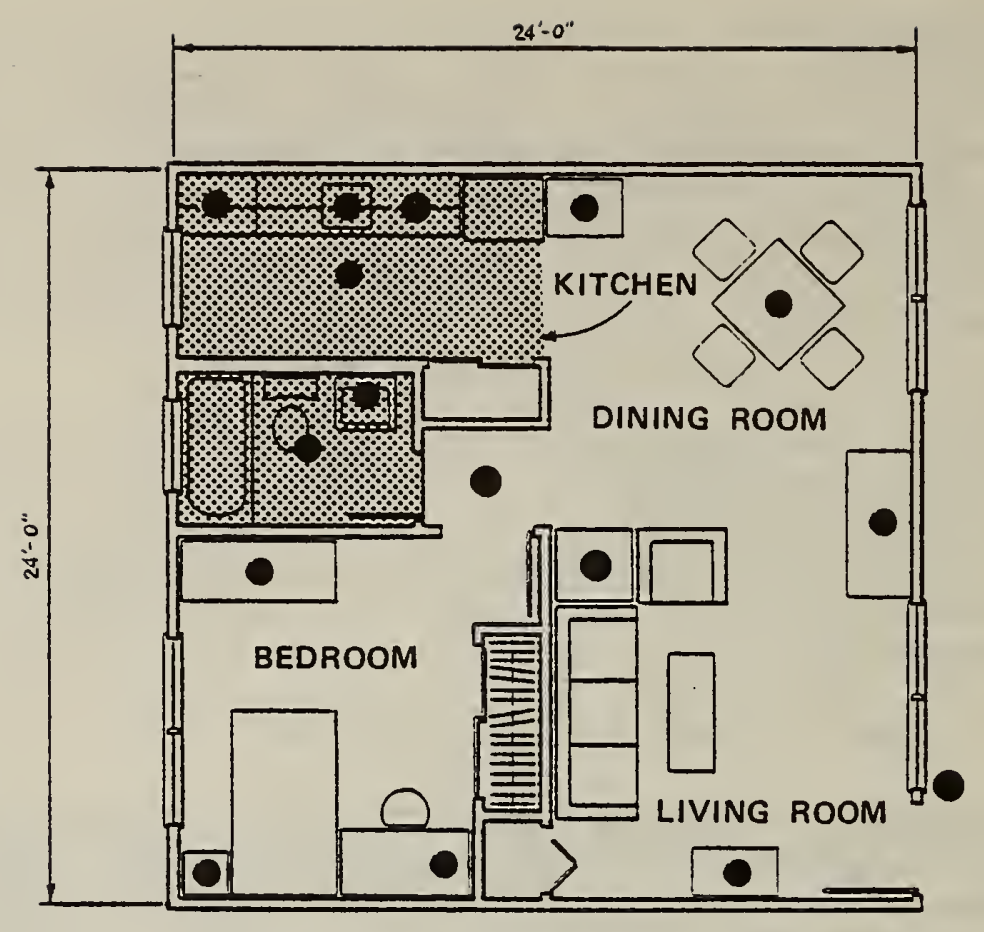

TOTAL FLOOR AREA $=580$ S.F.

FLOOR PLAN OF A TYPICAL EFFICIENCY APARTMENT

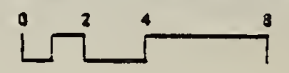

\begin{tabular}{|l|c|c|c|}
\hline \multicolumn{4}{|c|}{ NOMINAL LIGHTING POWER LOADS } \\
\hline ROOM & AREA (S) & LOAD (W) & REMARKS \\
\hline LIVING ROOM & 144 & 350 & (3) TABLE \\
\hline OINING ROOM & 108 & 175 & (1) TABLE, (1) CE)LING \\
\hline KITCHEN & 72 & 320 & ASHRAE 90-75R \\
\hline BEDROOM & 120 & 325 & (3) TABLE \\
\hline BATHROOM & 40 & 160 & ASHRAE 90-75R \\
\hline & & & \\
\hline MISCELLANEOUS & 96 & & \\
\hline HALLWAY & & 60 & (1) CEILING \\
\hline ENTRANCE LIGHT & & 60 & (1) WALL \\
\hline & & & \\
\hline TOTAL & 580 st & $1450 \mathrm{w}$ & \\
\hline UPD & \multicolumn{2}{|c|}{2.5 w/St } & \\
\hline & & & \\
\hline
\end{tabular}

Fig. 5.1 - Efficiency apartment. 


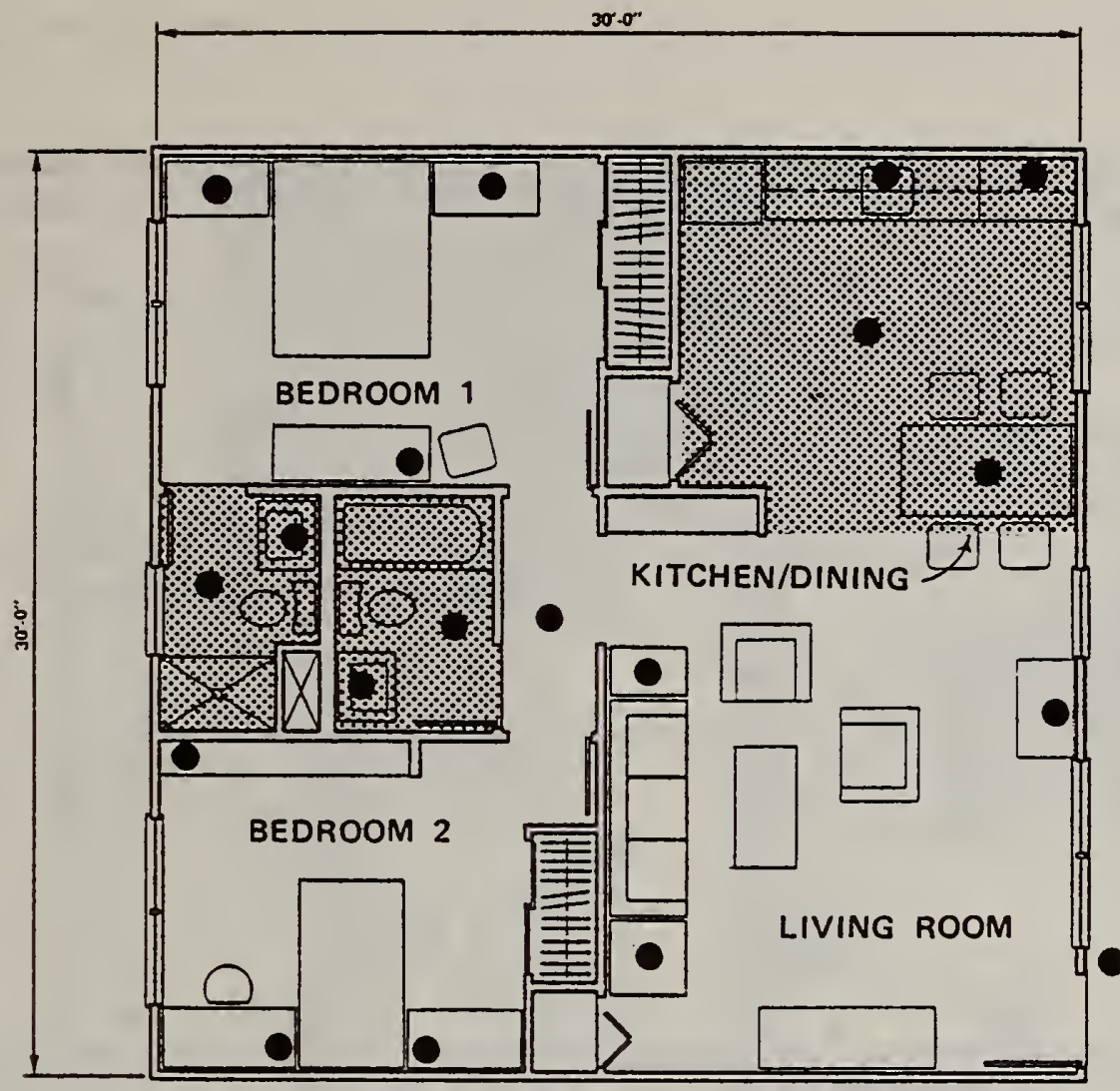

TOTAL FLOOR AREA $=900$ S.F.

FLOOR PLAN OF A TYPICAL 2-BED ROOM APARTMENT OR HOUSE

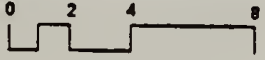

\begin{tabular}{|c|c|c|c|}
\hline \multicolumn{4}{|c|}{ NOMINAL LIGHTING POWER LOADS } \\
\hline ROOM & AREA (sf) & LOAD $(w)$ & REMARKS \\
\hline LIVING ROOM & 210 & 425 & (4) TABLE \\
\hline KITCHEN/OINING & 156 & 400 & ASHRAE $90-75 \mathrm{R}$ \\
\hline 8EDROOM 1 & 154 & 350 & (3) TABLE \\
\hline 8EDROOM 2 & 132 & 325 & (3) TABLE \\
\hline BATHROOM & 40 & 160 & ASHRAE $90-75 R$ \\
\hline BATHROOM & 40 & 160 & ASHRAE $90-75 R$ \\
\hline MISCELLANEOUS & 168 & 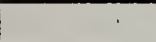 & \\
\hline HALLLWAY & & 60 & (1) CEILING \\
\hline ENTRANCE LIGHT & & 60 & (1) WALL \\
\hline TOTAL & 900 sf & $1940 \mathrm{w}$ & \\
\hline UPO & & w/st & \\
\hline
\end{tabular}

Fig. 5.2 - Two-bedroom dwelling. 


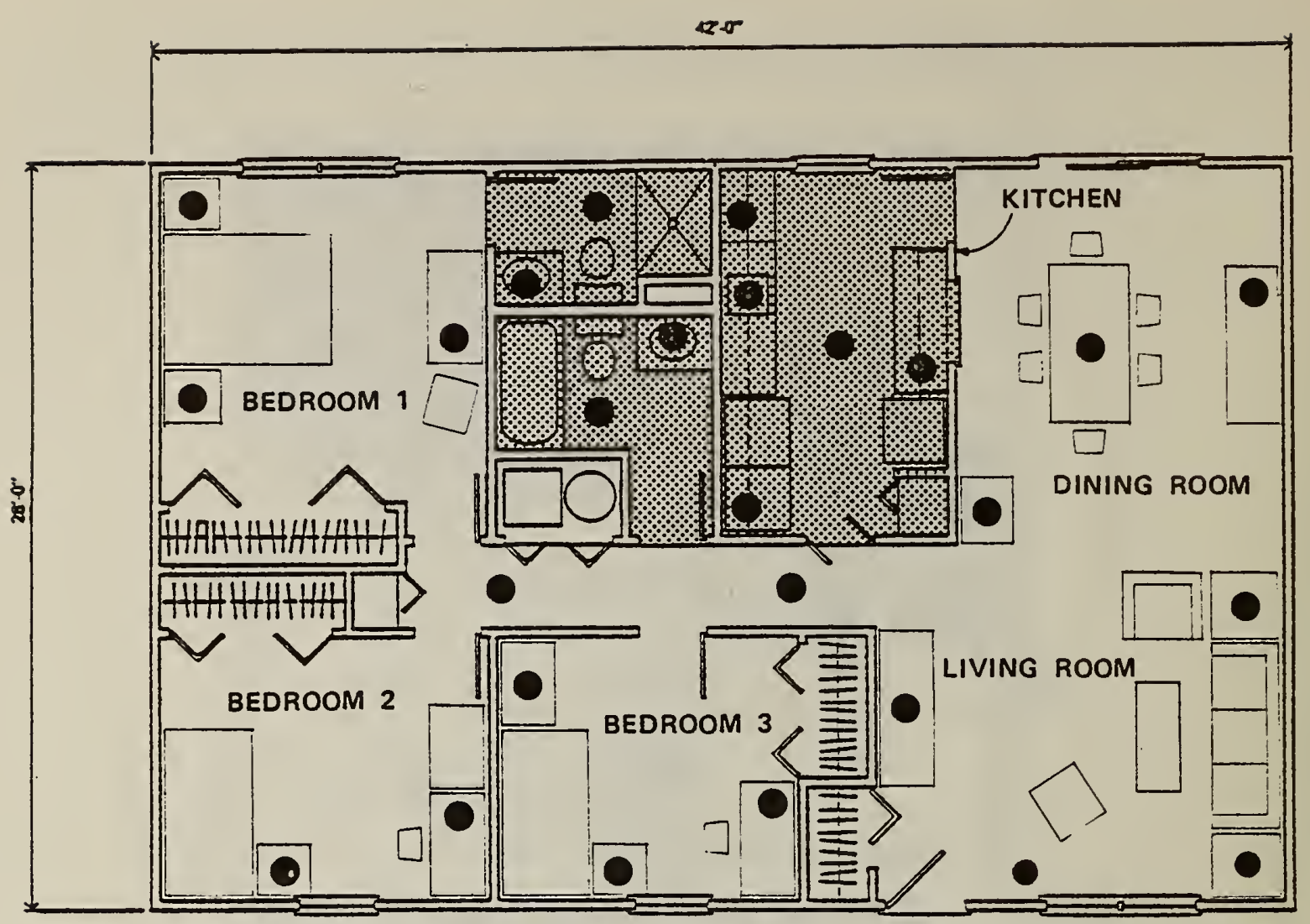

TOTAL FLOOR AREA $=1,180$ S.F.

RLOR PLAN OF A TYPICAL RANCH HOUSE

$L^{2} L^{8}$

\begin{tabular}{|c|c|c|c|}
\hline \multicolumn{4}{|c|}{ NOMINAL LIGHTING POWER LOADS } \\
\hline ROOMS & AREA (sf) & LOAD $(w)$ & REMARKS \\
\hline LIVING ROOM & 190 & 475 & (3) TABLE, (1) FLOOR \\
\hline DINING ROOM & 168 & 325 & (2) TABLE, (1) CEILING \\
\hline KITCHEN & 126 & 400 & ASHRAE $90-75 R$ \\
\hline BEDROOM 1 & 156 & 350 & (3) TABLE \\
\hline BEDROOM 2 & 120 & 250 & (2) TABLE \\
\hline BEDROOM 3 & 120 & 325 & (3) TABLE \\
\hline BATHROOM & 40 & 160 & ASHRAE $90-75 R$ \\
\hline BATHROOM & 50 & 160 & ASHRAE 90-75R \\
\hline MISCELLLANEOUS & 210 & & \\
\hline HALLWAY & & 120 & (2) CEILING \\
\hline ENTRANCE LIGHT & & 60 & (1) WALL \\
\hline TOTAL & $1180 \mathrm{st}$ & $2625 w$ & \\
\hline UPD & & w/sf & \\
\hline
\end{tabular}




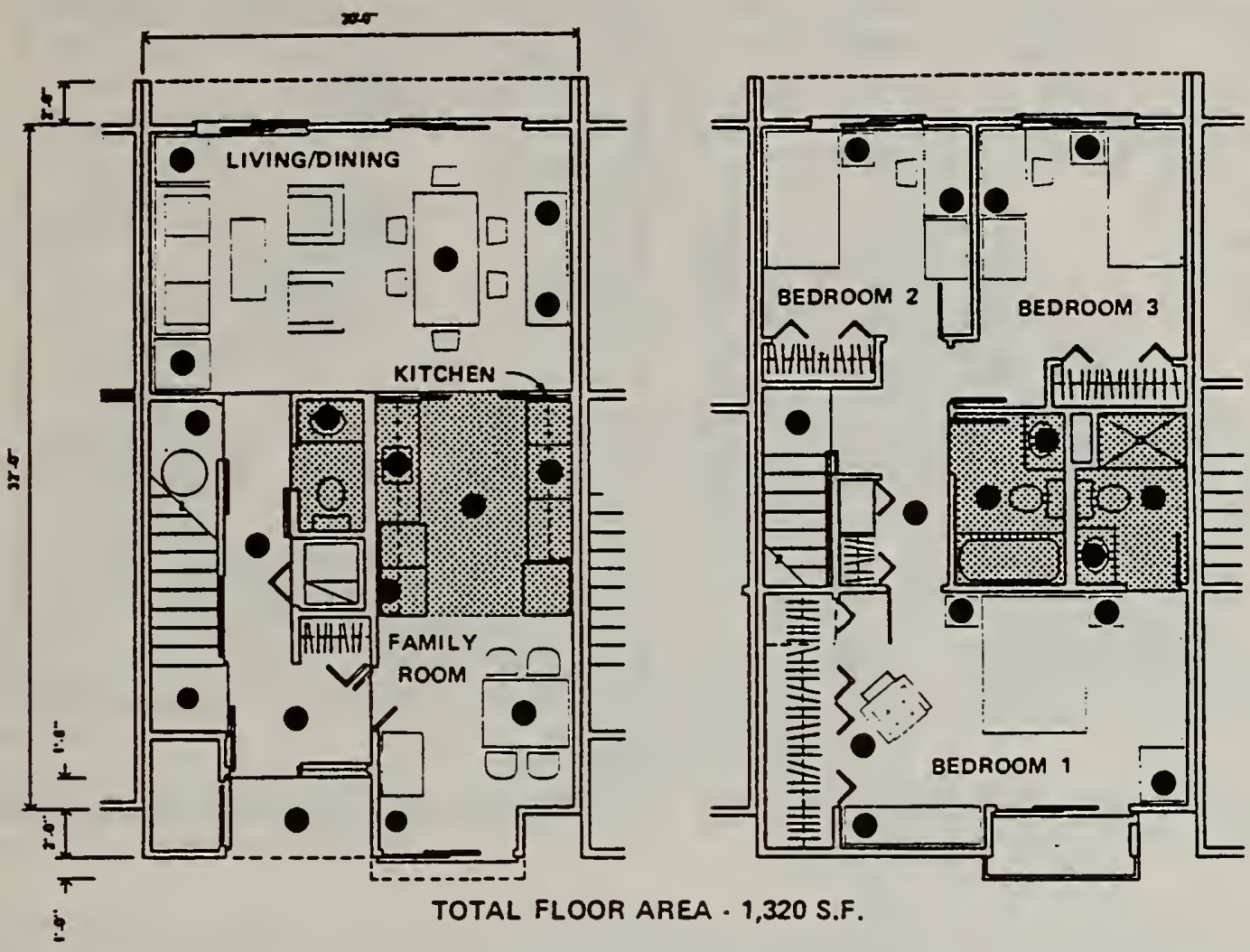

UPPER FIOOR PLAN OF A TYPICAL TOWNHOUSE LOWER FLOOR PLAN OF A TYPICAL TOWNHOUSE ín'i

\begin{tabular}{|c|c|c|c|}
\hline \multicolumn{4}{|c|}{ NORMAL LIGMTING POWER LOADS } \\
\hline ROOM & AREA $(x)$ & LOAD (w) & REMARKS \\
\hline LIVING/DINING ROOM & 240 & 580 & (4) TABLE. III CEILING \\
\hline KITOMEN & $\infty 0$ & 400 & ASHAAE SO-TJA \\
\hline FAMILY AOOM & $\infty 0$ & 200 & (1) CEILUNG. (1) FLDOR \\
\hline SEOROOM I & 170 & 450 & (4) TABLE, (I) FLOOA \\
\hline BEDROOM 2 & $\infty$ & 200 & (2) TABLE \\
\hline BEDROOM 3 & 8 & 250 & (2) TABLE \\
\hline CATMROOM & 40 & 100 & ASHAAE 9O-7SA \\
\hline LATMADOM & 40 & 100 & ASHAAE SO-75A \\
\hline 1/2 \&ATH & 18 & 100 & ASHRAE SO-75R \\
\hline MSCELLANEOUS & 48 & & \\
\hline MALLWAY & & 100 & I3) CEILING \\
\hline CLOSET & & $\infty$ & (1) CEILING \\
\hline STAIAS & & 200 & (2) CEILING \\
\hline ENTAANCE LIGNT & & $\infty$ & (I) CEILING \\
\hline TOTAL & $1320 \mathrm{H}$ & $3000 \%$ & \\
\hline UPO & 23. & & \\
\hline
\end{tabular}

Fig. 5.4 - Townhouse. 


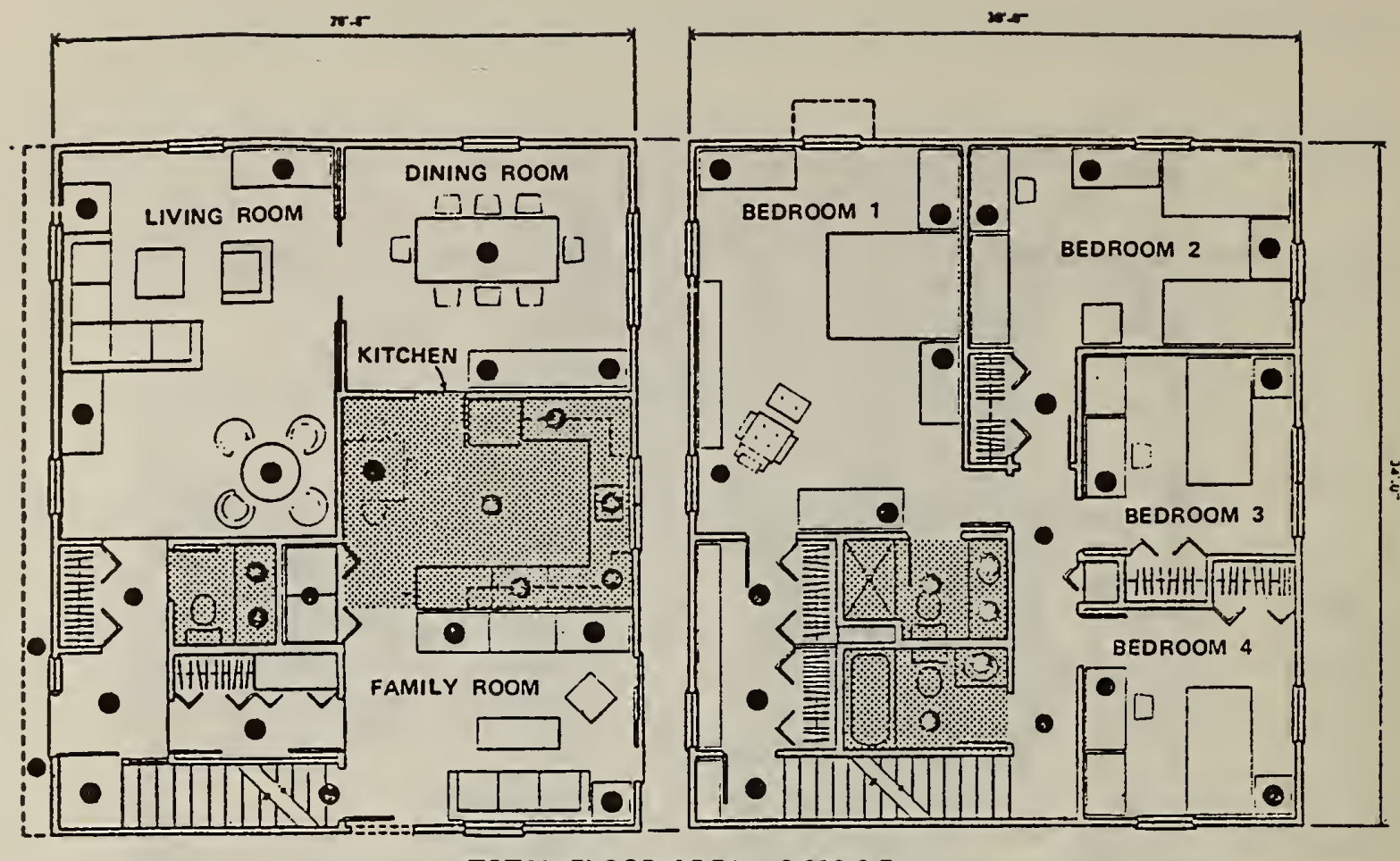

TOTAL FLOOR AREA $=2,000$ S.F.

IOWER FLOOR PLAN OF A TYPICAL 2-STORY HOUSE UPPER FLOOR PLAN OF. A TYPICAL 2.STORY HOUSE irí:

irí-i

\begin{tabular}{|c|c|c|c|}
\hline \multicolumn{4}{|c|}{ NOMINAL LIGHTING POWER LOADS } \\
\hline ROOM & AREA (sf) & LOAD Iwi & RENIARKS \\
\hline LVING ROOM & 280 & 450 & (3) TABLE, (11) CEILING \\
\hline OINING ROOM & 168 & 350 & (2) TABLE. I1) CEILING \\
\hline KITCHEN & 154 & 400 & ASHRAE 90-75R \\
\hline FAMILY ROOM & 154 & 325 & (3) TAQLE \\
\hline BEDROOM 1 & 250 & 500 & (4) TABLE. (1) FLOOR \\
\hline BEDROOM 2 & 160 & 435 & (3) TABLE \\
\hline BEDROOM 3 & 100 & 250 & 12) TABLE \\
\hline BEDROOM 4 & 100 & 250 & 12) TABLE \\
\hline BATHROOM (2-GROOMING SPACES) & \pm 0 & 225 & ASHRAE $30-759$ \\
\hline BATHROOM & $\$$ & 160 & ASHAAE $30.75 R$ \\
\hline \% BATH & 24 & 900 & ASHRAE $30-75 \mathrm{~A}$ \\
\hline 1 & 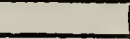 & 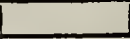 & 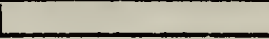 \\
\hline MISCELLANEOUS & 520 & 1 & 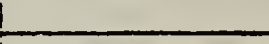 \\
\hline HALLWAYS & & 240 & (4) SEILING \\
\hline CLOSETS & & 240 & (4) CEIL:NG \\
\hline STAIRS & & $300 \quad 1$ & (3) $=$ SILING \\
\hline ENTRANCE LIGHT & & $120 \quad 1$ & 1 (2) WALL \\
\hline & & 1 & $I$ \\
\hline TOTAL & 2000 at & $5345 \mathrm{w}$ & 1 \\
\hline UPD & & $-1 / 14$ & \\
\hline & 7 & 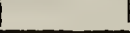 & \\
\hline
\end{tabular}

Fig. 5.5 - Two-story house. 


\section{2 .4 Duration of Use}

5.2.4.1 Living Spaces - The use of living spaces by occupants of a residence is expected to vary widely. Furthermore, occupants move about the different living spaces depending on time of day and the many occupancy factors identified in paragraph 5.1.2. Evaluating the living habits of a number of families with diversified background indicates that a 2-hour average, based on all living spaces, is a reasonable assumption for a median use pattern.

5.2.4.2 Other Spaces - The use of other spaces is quite different, thus must be assumed individually. The following assumptions are patterns of median usage.

\section{TASKS/AREAS}

1. Attic, unfinished

2. Basement, finished

3. Basement, unfinished

4. Deck, Porch or Patio

5. Driveway/Walkway

6. Garage, private Garage, Underground

7. Hallways/Corridors

8. Laundry, public

9. Mechanical Room

10. Parking Lot

11. Stair, private Stair, public

12. Public (community) spaces

13. Storage
ASSUMED USAGE (Hrs/Day)

\section{REMARKS}

$\mathrm{Nil}$

2

1

1

10

NiI

12

$12 *$

8

1

6

1

$12 *$

6

1
Based on 720 hours per year Based on 360 hours per year Based on 360 hours per year Average from dusk to dawn

24 hours at $50 \%$ demand

For public security

For standby use by tenants at $50 \%$ demand

Based on 360 hours per year Average from dusk to mid-night Based on 360 hours per year For public safety From 10 AM to $10 \mathrm{PM}$ average at $50 \%$ demand Average 360 hours per year

* Assuming daylighting available

5.2.5 Light Delivery Components - Power and Performance Characteristics

Consolidated with Paragraph 5.2.3

5.2.6 Light Delivery Components - Utilization Hours

Consolidated with Paragraph 5.2.4

5.2.7 Lighting Design for Each Space

Consolidated with Paragraph 5.2 .3 
5.2.8 Energy Consumption Calculations

5.2.8.1 Living Spaces - shall be equal to the gross area of living spaces times UPD ( 2.3 watts/sq. ft.), times average hours of operation per day, times 365 days/year.

5.2.8.2 Other Spaces - shall be the power required (watts) of each task or area, times the hours of usage per year.

5.2.9 Establishment of Unit Energy Budget for Lighting (UEB-L) - kWh/SF/YR

The Unit Energy Budget for lighting (UEB-L) can be calculated by using the UEB/L table shown in Figure-5.6. The procedure is as follows:

5.2.9.1 Annual Energy of Space - Wh/YR

Multiply size of space, number of units, UPD or Power allowance, and annual duration of use.

5.2.9.2 Gross Annual Energy of Spaces - Wh/YR

Summation of annual energy of all spaces including a ( 1.1$)$ contingency factor.

$5 \cdot 2 \cdot 9 \cdot 3$ Building Areas - SF

The total of all spaces for living and basement, but excluding garage and other not normally integral with the building.

5.2.9.4 Unit Energy Budget for Lighting (UEB-L) $-\mathrm{kWh} / \mathrm{SF} / \mathrm{YR}$

The quotient of Gross Energy divided by the Building Area.

\subsection{APPLICATIONS OF METHODOLOGY}

Two residential buildings were selected to illustrate the method for determining the Unit Energy Budget for Lighting (UEB-L). The procedures of 5.2.9 were followed, using the unit power densities of 5.2 .3 and the duration values of 5.2.4. The calculations for a single-family residence and a 200-unit apartment building are shown on the following pages. 


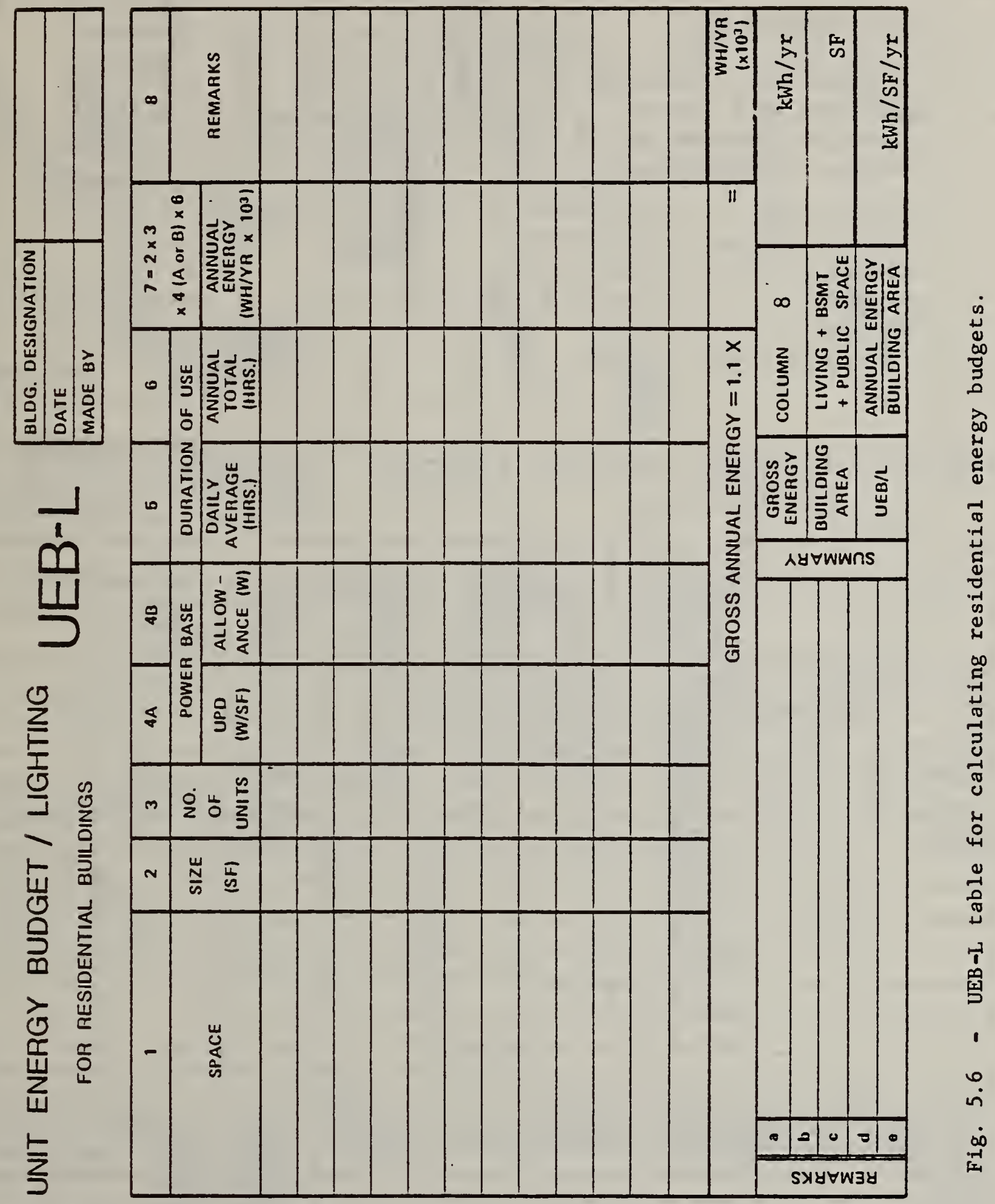


C. WORK PROBLEMS

Two residential buildings were selected to illustrate the method for determining Unit Energy Budget for Lighting. (UEB/L).

1.00 Work Problem No. 1

A single family residence consisting of a 2-story house with attached garage has the following spaces: Living Space --- 2,400 SF Basement, unfin.- 1,200 SF Carage ------- $600 \mathrm{SF}$ Driveway ------- 1 unit Walkway--------- 1 unit Patio ----------- 1 unit
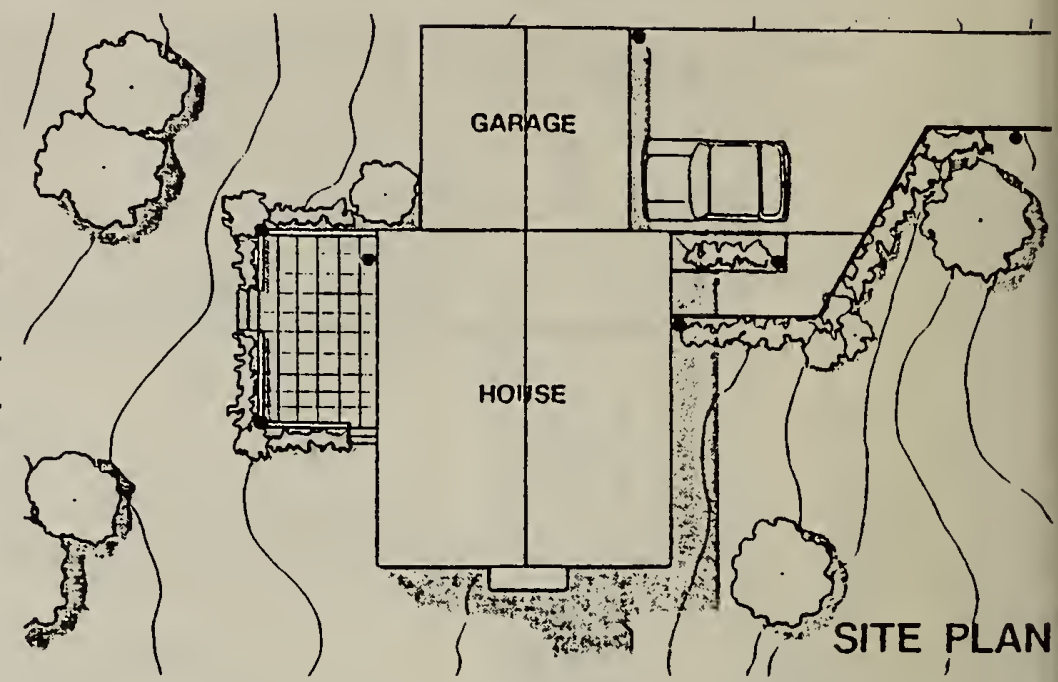

UNIT ENERGY BUDGET / LIGHTING FOR RESIDENTIAL BUILDINGS

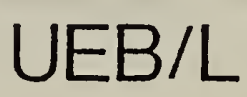

\begin{tabular}{|l|c|}
\hline BLDG. DESIGNATION & WORK PROB. NO. \\
\hline DATE & $6 / 12 / 78$ \\
\hline MADE BY & WILLIAM TAD \\
\hline
\end{tabular}

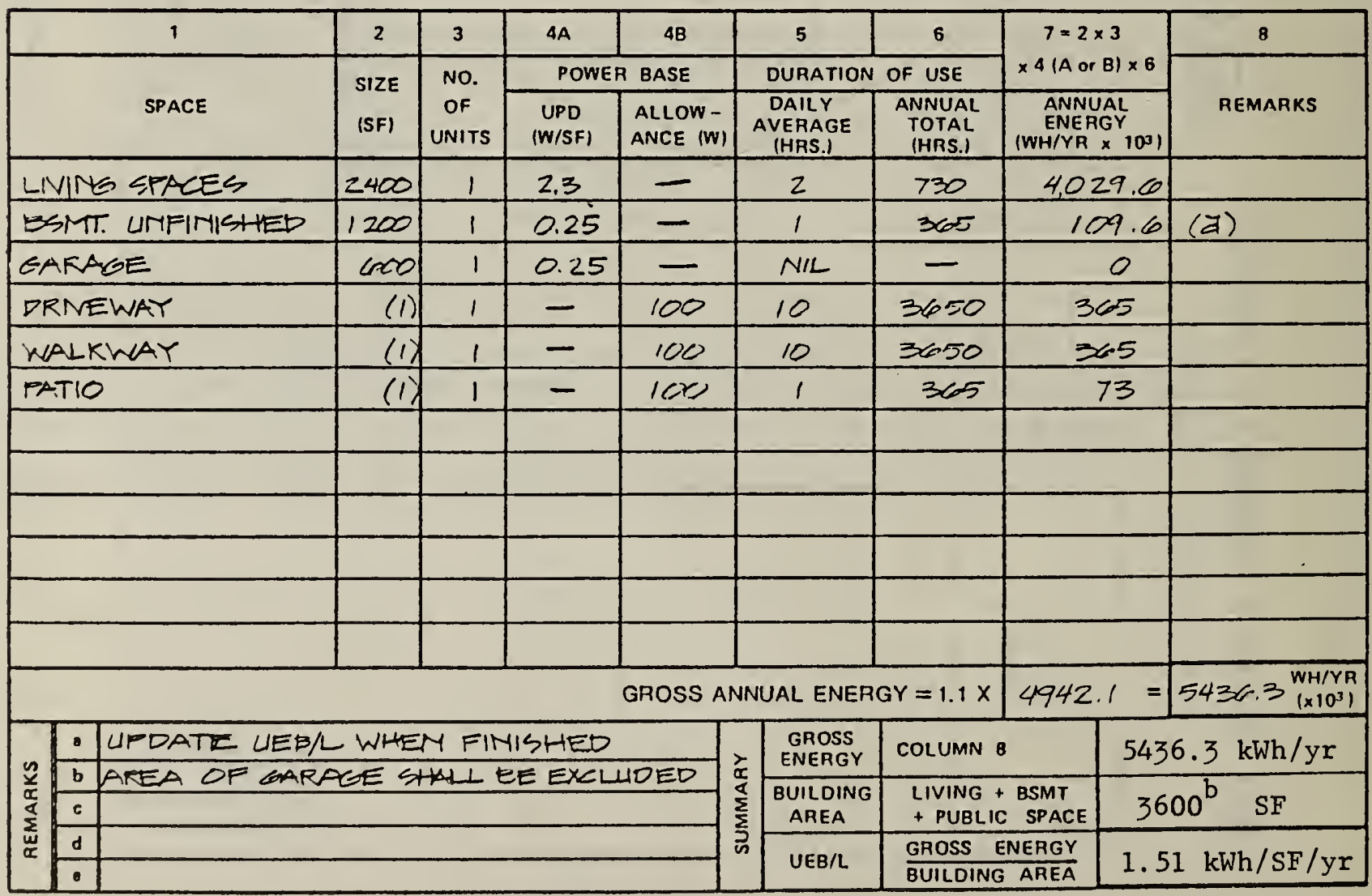


2.00 Work Problem No. 2 - Apartment Building

An apartment building consisting of 20 floors with 10 apartments per floor has the following spaces:

Apartments (living spaces) $-(200) @ 900$ SF Hallways - 22,000 SF Stairs -- (3) @ 200 SF per Floor Mechanical \& Storage (20) @ 200 SF Public Spaces (first floor) --- 20,000 SF Basement and Storage --.--- 10,000 SF Garage (underground) -..-- 30,000 SF Parking Surface - 60,000 SF
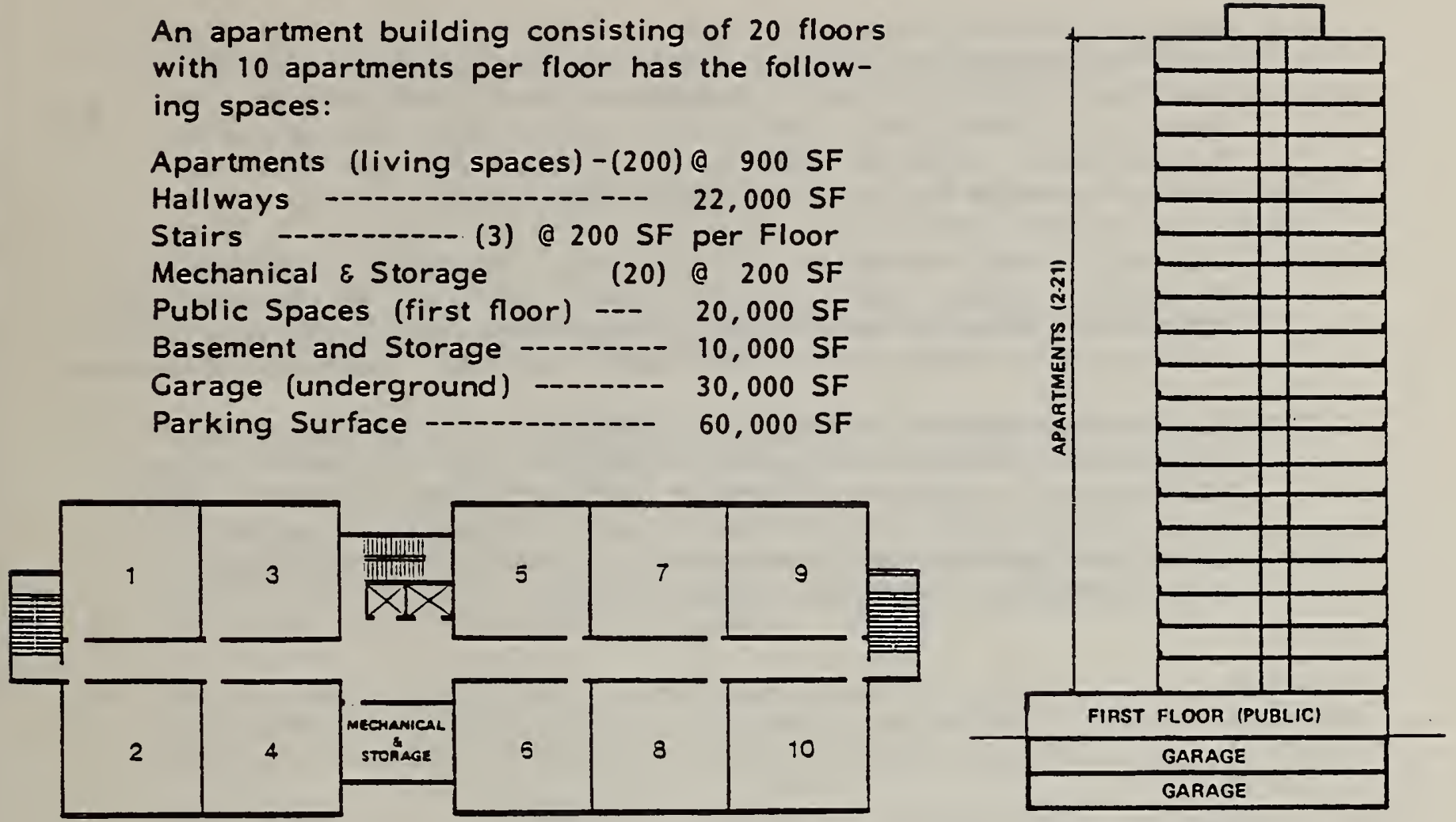

UNIT ENERGY BUDGET / LIGHTING FOR RESIDENTIAL BUILDINGS

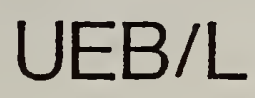

\begin{tabular}{|l|c|}
\hline BLDG. DESIGNATION & WORK FPOD NO. 2 \\
\hline DATE & G/12/78 \\
\hline MADE BY & WILLIAM TAO \\
\hline
\end{tabular}

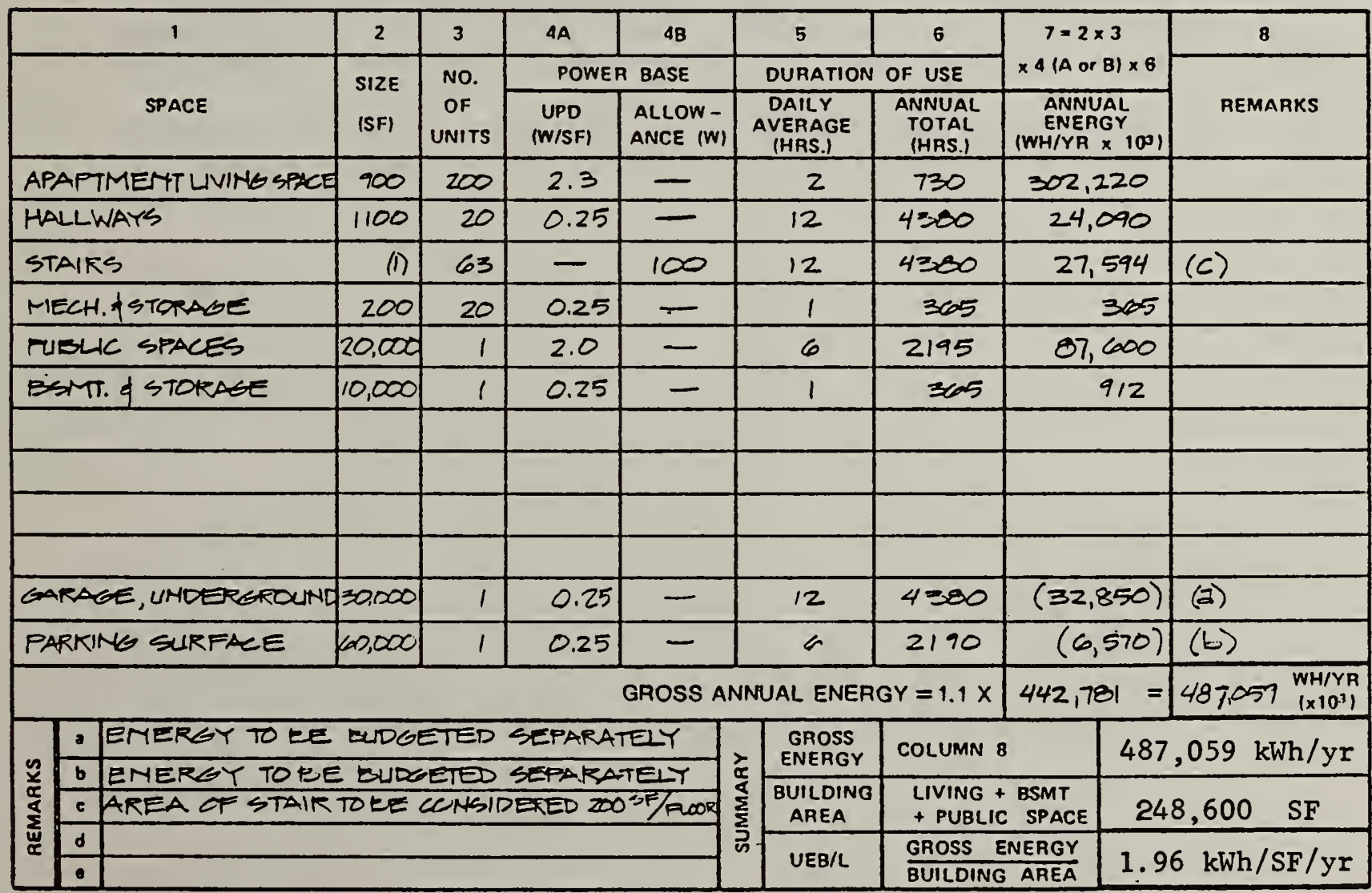




\subsection{CONCLUSIONS}

5.4.1 There are little or no data available regarding the connected power load for residential lighting. Starting from energy conserving lighting layouts of typical residences, it was concluded that the connected lighting power for various spaces falls between 2.2 to 2.5 watts/SF. A median value of 2.3 watts/SF was considered as a reasonable basis for lighting power budget.

5.4.2 Lighting energy consumption in residential buildings is related more to "people" rather than to "square foot." When all of these peopleoriented factors are taken into consideration,' annual lighting energy consumption of two identical residences could have extreme differences.

5.4.3 Based on a number of assumptions, UEB/L for a random residence and a high-rise apartment were calculated to be $1.51 \mathrm{kWh} / \mathrm{SF} / \mathrm{Yr}$ for the residence with unfinished basement and $1.96 \mathrm{kWh} / \mathrm{SF} / \mathrm{Yr}$ for the apartment. If one representative value must be selected to express the impact of lighting energy consumption in residential buildings, $1.75 \mathrm{kWh} / \mathrm{SF} / \mathrm{Yr}$ would be the logical choice. 


\section{REFERENCES}

1. ASHRAE Standard 90-75 (R): "Energy Conservation in New Building Design," American Society of Heating, Refrigerating and Air Conditioning Engineers, Inc.

2. IES Lighting Handbook, 5th Edition: Section 9-"Lighting Calculations," and Section 15-"Residential Lighting," Illuminating Engineering Society of North America.

3. Tao, William, "Systems Approach for Energy-Conserving Power Budget," Lighting Design \& Applications (LD\&A), March 1978.

4. Hastings, S. Robert, "Three Proposed Typical House Designs for Energy Conservation Research," NBSIR-77-1309, National Bureau of Standards, U.S. Department of Commerce, October 1977 .

5. Task Force on Illumination: "Performance Criteria for Energy Conserving Building Illuminations Systems - Phase I Report," National Bureau of Standards, U.S. Department of Commerce.

6. Gajjar, Jagdish: "Automated Individual Area Energy Control in Commercial and Residential Building," ERDA Conference on Technical Opportunities for Energy Conservation in Buildings Through Improved Controls, May 10, 1976.

7. Lewis, Stephen A., and Degelman, Larry 0., "Single Family Dwelling Natural Resource Consumption Effects and Energy Budget, " presented at ASHRAE Annual meeting in Boston, Masachusetts on June 25, 1975.

8. Energy Resources Center, Honeywell, Inc., "Mixed Strategies for Energy Conservation and Alternative Energy Utilization (Solar) in Buildings, Final Report, Volume III - Appendix," U.S. Department of Energy, Nov 1977.

9. Department of Housing and Urban Development: "Residential Energy Consumption, Phase I report "Report No. HUD-HAl-1, March 1972. 


\subsection{DISCUSSION AND CONCLUSIONS}

The performance criteria developed by the NBS Task Force on Illumination includes ( 1 ) the methodology for analyzing the illumination requirements of the building, (2) the illumination parameters inserted into this analysis, and (3) the energy and power budgets of typical buildings which result from the analysis.

The essence of the criteria is the Methodology of Chapter 2. The illumination requirements of a specific building (actual or prototype) are examined in detail, without reliance upon past practice. Task and General lighting are treated separately in terms of power requirements and hours of use. Both power and energy budgets are determined. The methodology is an innovative approach to a realistic determination of the energy and power required for a building to perform its function with efficient energy consumption.

The application of the methodology requires the selection of appropiate illumination parameters, including light levels and lighting power conversion factors (these may be combined into unit power densities), daylight contributions, and usage hours. No complete scientific basis for the specification of illumination levels exists at the present time; the levels used in these applications were chosen to provide a balance between visual performance requirements and the need for energy conservation. Power conversion factors are based on the use of efficient luminaires. Daylight contributions and usage hours are in line with accepted practice.

The energy and power budgets for office, school, and residential buildings were derived by application of the same methodology, although the approach and choice of parameters varied in the three cases. The specific budget values result from the choice of parameters and, to some extent, the specific building used as a prototype; however, the format of the criteria readily allows adjustment for a building with space distributions or operating hours which differ from the prototypes. Thus, the simplified procedures developed for each building class allow the calculation of power and energy budgets for actual buildings, while the budgets derived for the prototypes provide criterion values for comparison.

In the application of the methodology to residential buildings, described in Chapter 5, it became evident that lighting energy consumption in residences is more dependent upon the type of occupacy than upon the size of the unit, and that there is a wide range in occupancy type (e.g., working couple, "stayat-home" retired couple, family with many students, etc.). This suggests that the lighting energy budget for a residence should be based on a combination of occupancy and size parameters. The power budget is more size-related, but the large use of various electrical applicances and portable lights, all connected to the same convenience outlets, seriously dilutes the significance of the lighting power budget. The problem is compounded by the scarcity of data on residential energy usage. These factors dictate the need for further research on residential energy patterns and the development of a modified methodology for residential performance criteria. 
The application of the methodology to the office (Chapter 3) and the elementary school (Chapter 4) indicate that the process is well matched to these buildings. The simplified procedures, developed to minimize the time and effort of the budget calculations, could readily serve in their present formats as the basis for interim standards for these building types. Further work is required to extend the methodology to other building types.

These performance criteria are intended to serve as the basis for voluntary consensus standards for building illumination. Although intended as interim criteria, pending the development of a widely accepted basis for illumination requirements, the format of the criteria allows for ready adaptation as advances are made in the knowledge of visual needs and the efficiency of illumination systems.

The greatest limitation on this lighting performance criteria is the lack of corresponding methodologies and criteria for the remaining building subsystems. Only when these subsystem criteria are developed, and integrated with the lighting criteria into a total building energy budget, will the energy performance of the building be measurable.

\subsection{RECOMMENDATIONS}

6.2.1 The Energy Budget Procedures and Performance Criteria for Energy Conserving Building Illumination Systems presented in this document should be used as the basis for development of a voluntary consensus standard through the processes of the American National Standards Institute.

6.2.2 The criteria for residences should be developed as a separate standard from commercial buildings, with adequate provision for occupancy-related factors.

6.2.3 The feasibility of establishing similar performance criteria for retrofit of illumination systems in existing buildings should be determined.

6.2.4 Task Forces should be formed to develop performance criteria for the remaining building sub-systems and to integrate such criteria into a Total Building Energy-conserving Performance Criteria.

6.2.5 Expanded research efforts should be undertaken in seven areas:

6.2.5.1 Development of an acceptable definition for quality of lighting, related to visual tasks.

6.2.5.2 Vision research to develop an acceptable basis for quantity of illumination.

6.2.5.3 Field studies to differentiate between needs and preferences for Task and General lighting environments.

6.2.5.4 Determination of the range of lighting requirements related to physiological differences among people. 
6.3.5.5 Development of laboratory and field methods to measure accurately the delivered quantity and quality of illumination.

6.3.5.6 Development of predictive techniques to assure the provision of the required illumination.

6.3.5.7 Illumination usage patterns in residences. 


\author{
APPENDIX I \\ Performance Criteria for \\ Energy Conserving Building Illumination Systems \\ Phase I Report
}

Prepared for

National Bureau of Standards

U.S. Department of Commerce

Prepared by

Task Force on Illumination

August 1977 



\section{INTRODUCTION}

The task force, consisting of William Tao, Chairman, Richard Stein, and Donald Ross, was invited by the National Bureau of Standards under Agreement No. 62237 to develop a model performance criteria for energy-conserving building illumination systems. The primary objective of the performance criteria is to achieve energy conservation with good visual performance. An optimized illumination system subject to an energy conservation constraint may not provide the same illumination as a system optimized for other considerations.

In addition to information exchanges among members, the task force met in St. Louis on May 9 and in Washington, D.C., May 25 and June 22, 1977.

Albert T. Hattenburg, Project Manager, (462.03) for NBS participated in all meetings and Gary Yonemura (463.03) of NBS in the second and third and Jim Heldenbrand ( 465.00$)$ of NBS in the first two meetings.

The purpose of Phase I was to recommend an approach and methodology for developing performance criteria; and the purpose of Phase II will be to prepare a draft version of the performance criteria in a format that will serve as the framework for developing a consensus standard suitable for application as a mandatory minimum requirement. The standard would cover both natural and artificial lighting for new residential and commercial buildings.

Up to the present, standards developed to meet energy conservation goals, including NBSIR-74-452 and ASHRAE 90-75 (IES/EMS-1), generally approach the issue on a "power budget" basis. While this approach provides an interim solution, it is recognized that only an "energy budget" and not a "power budget" can fulfill the final objective in conservation, since controlling the duration of use is as important as limiting the power input to a building system. In order to establish a realistic energy budget, the occupancy, size, geographic location, and time of use for each building must be taken into consideration. NBS is currently developing a building classification method, and it would be desirable to use the same classification scheme as a basis for specifying the energy budget for all buildings.

As a result of the Phase I effort, the task force was able to develop:

1. A methodology for determining lighting energy budget,

2. Detailed work statements for Phase II effort, and

3. Qualifications for a consensus-developing body to convert the performance criteria into consensus standard.

William Tao, P.E., Chairman William Tao \& Associates, Inc. Consulting Engineers

Richard G. Stein, FAIA Richard G. Stein and Partners Architects

Donald K. Ross, P.E. Ross \& Baruzzini, Inc. Consulting Engineers 
Annual energy consumed in a building depends on the varying power demand of building subsystem times the duration of use. This fundamental principle applies to the lighting subsystem as well as systems for heating, air conditioning, hot water, and processing.

Most all energy consumed by lighting systems eventually converts into heat, thus will have pronounced effect on the thermal performance of the building. Therefore, lighting energy budget must be interfaced with that for other subsystems. An isolated lighting energy budget is difficult, if not impossible, to enforce since electric circuits for lighting are commonly intermixed with other appliance and equipment circuits. Furthermore, trade-offs between building subsystems to account for specific conditions and potential reduction in overall energy consumption of the building should be encouraged. For these reasons, the taks force recommends that a coordinating committee be established to integrate the efforts of the task forces for various building subsystems in order that an annual energy budget for the building as a whole can eventually be determined.

For energy budgeting purposes, it was concluded lighting may be divided into two categories--Genera 1 Lighting and Augmented Task Illumination. General Lighting includes ambient or background lighting for areas for visual tasks and minimum security lighting for areas with no specific visual tasks. Energy budget for general lighting can be budgeted directly on electrical energy basis without the need of complex calculations. The Augmented Task Illumination is defined as additional illumination required to augment the general lighting for visual task performance. Since there are diversified visual tasks in hundreds of building classifications, the energy budget for augmented task illumination must be calculated independently.

The methodology can be illustrated by the following block diagram.

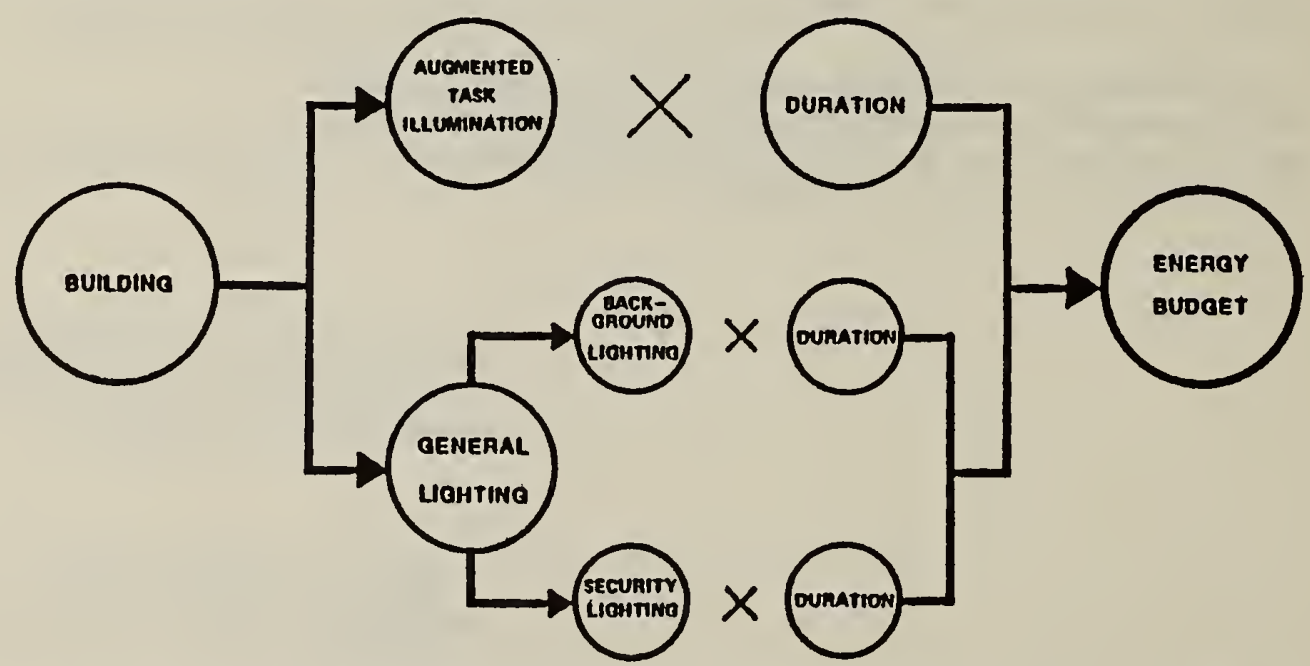

Many factors affect the requirements and values of each block. These can be elaborated as follows: 
Bullding

Task Lighting Illumination
Fenestration, geographic location, type of occupancy, time of use, orientation, and shading by trees and bulldings.

Tasks, extent of natural lighting, required quality, efficacy of light sources and luminaires, room characteristics, maintenance procedures and duration of use of individual tasks.

General

Lighting
Background and security lighting, unit power data, and duration of occupied and unoccupied hours of the building.

A detalled methodology flow diagram was developed to illustrate the energy budget determination procedures for lighting as well as the interrelationship with other bullding subsystems. The diagram consolidates background and security lighting into a general lighting energy budget using an equivalent duration factor, inasmuch as energy consumed by security lighting is usually small compared to that of background lighting. 


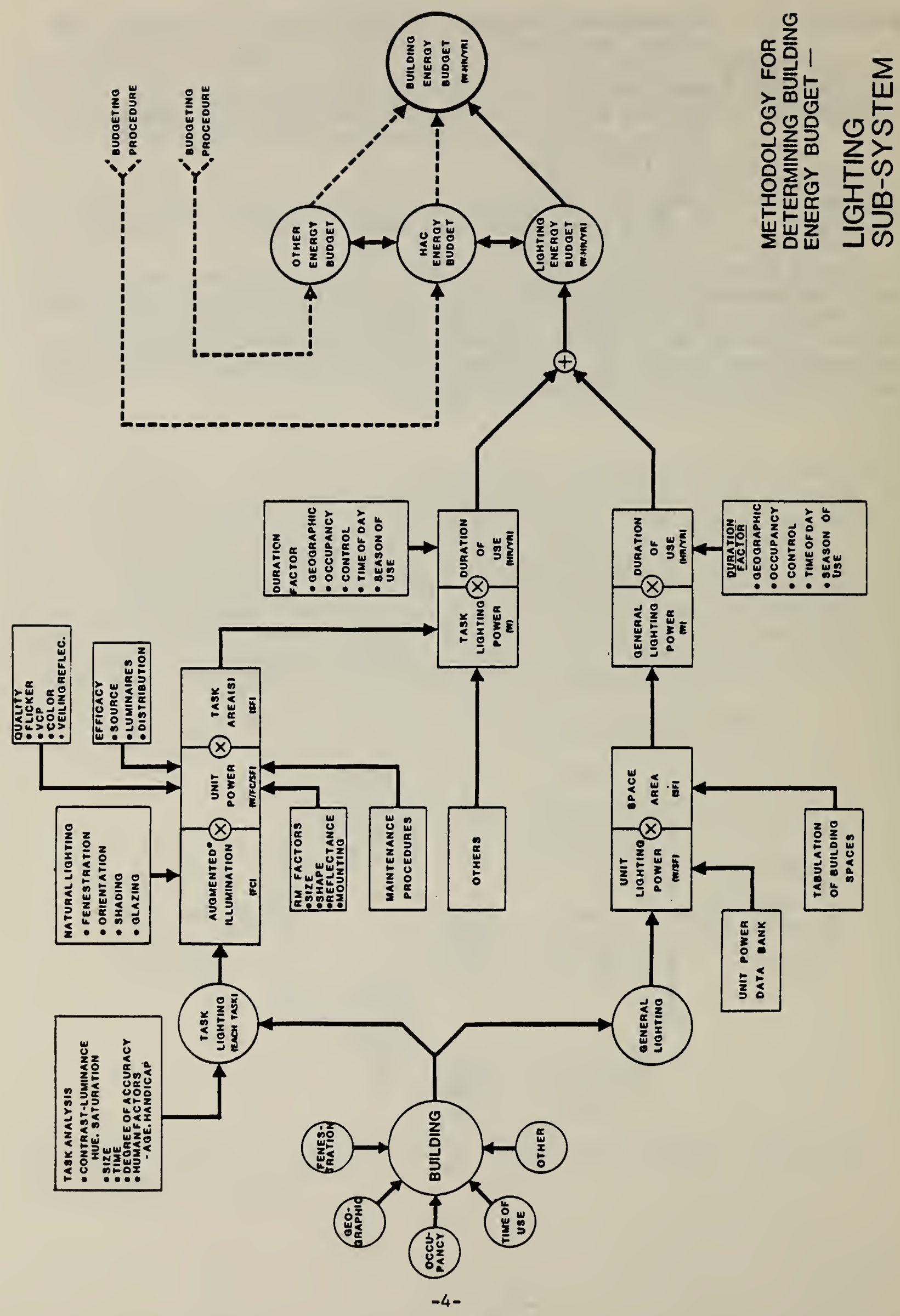




\section{CONSENSUS STANDARD DEVELOPING ORGANIZATION}

It is recognized that once the framework of performance criteria is proven by the Phase II effort on some prototype buildings, additional effort to complete the criteria should be continued by a consensus-developing organization(s) over ensuing years to convert it into a national consensus standard. It is a long-term process involving both research and consensus activity. The task force agrees the consensus developing organization(s) should posess all of the following qualifications:

1. An organization having scientific credibility.

2. Which is recognized as authority in research and development.

3. Which is broad-based with membership makeup from diversified disciplines, some related to the art and science of vision and illumination.

4. Which is permanent, having established continuity and longevity potential--not an ad hoc group.

5. With balanced objectivity--an organization which will not represent the interest of one specific segment of society but will act in the national interest.

6. Which is familiar with the procedure of generating consensus standards.

7. Willing to support and improve the proposed task force effort.

8. Capable of revising the standards in response to feedback.

9. Related to the building industry, building designers, and users in the application of illumination.

10. Responsive to improved human performance constrained by the need of energy conservation. 
Based on the experience of Phase I effort, the Task Force agrees that scope for phase II effort could be described by the following work statements:

1. To test, evaluate and modify methodology for energy conservation illumination performance criteria recommended in Phase $I$.

2. To demonstrate the feasibility of performance criteria on 2 or 3 mode 1 building classes and to determine the annual energy budget for same. One of these shall be in the residential category and the other nonresidential.

3. To review pertinent literature and research data related to lighting performance.

4. To make recommendations for futhering research efforts leading to better understanding of vision and human performance.

5. To make recommendations for selecting a consensus-developing organization(s) to fully develop the energy budget on all categories of buildings.

6. To make recommendations as to procedure for obtaining consensus by the consensus-developing organization(s).

7. To interface with task forces on other building subsystems for determining energy budgets of these model building categories.

With the present task force, it is estimated the above scope of work can be accomplished in three months. During the three month period, the task force should convene five times at preliminary, intermediate, progress, conclusion, and final presentation meetings. Occasionally special consultants may be desired to provide input during one or more of the scheduled meetings. To successfully conduct the Phase II effort, it will require participation of a project manager from NBS specifically assigned as liaison with the task force and the availability of expert support from other NBS staff members. 
APPENDIX II

LIGHTING DESIGN FACTORS FOR

ENERGY CONSERVATION 



\section{APPENDIX II. LIGHTING DESIGN FACTORS FOR ENERGY CONSERVATION}

\section{GENERAL}

This appendix discusses a number of factors which are important in the design of lighting systems to provide adequate illumination for visual performance while consuming modest amounts of energy. These factors have been utilized in the development of Chapter 3 of this report.

\section{TASK LIGHTING}

\subsection{ANALYSIS OF VISUAL TASK REQUIREMENTS}

\subsubsection{Task Visual Difficulty}

Presently, there is no generalized measure of task visibility demonstrated to predict performance as a function of illumination. A literature search relative to good lighting practice has resulted in the Visual Difficulty Factors for office tasks, which are included in Table 2 of Chapter 3 .

\subsubsection{Error Penalties}

The amount and quality of illumination has been shown to be one of many factors affecting performance errors. The cost-benefits ratio associated with an improved error rate from illumination is one of the criteria used in design. This factor is generally of importance when a worker is under considerable and continuous time pressure, and is dealing with material of poor visual quality.

\subsubsection{Time for Performance}

Within limits, there is a trade-off between time available to observe a task and the required illumination quantity and quality. If a visual task consistently requires performance that limits observation of the more difficult portions to less than $1 / 4$ second, then greater emphasis on illumination is indicated.

\subsubsection{Task Orientation}

If the task is fixed in location; i.e., the observer cannot pick it up and reorient it, as he could by picking up a piece of paper, or cannot readily shift his head to observe it from a slightly different angle, for example, then lighting quality is of greater importance.

\section{1 .5 Visual Surround}

If large differences in contrast (greater than approximately 10 to 1 ) subtend wide angles of the normal viewing direction, or if bright glare occurs directly in the line of sight necessary for task observation, changes in 
the required viewing angles are recommended. The conventional solution to this problem, increasing task illumination to within $1 / 3$ to $1 / 10$ the intensity of the glare source, could be quite wasteful of energy.

\subsubsection{Overal1 Task Evaluation}

The elements shown in Table 1 of Chapter 3 comprise most of the ones of importance in performing office tasks. Each task should be categorized for these elements (formally or informally), noting any which are believed to be substantially more visually difficult than normally occuring office tasks. If only one (or two) elements are believed to cause visual difficulty, it is quite possible it may be offset by another factor "easier" than normal that will compensate.

For example, a deficiency in elements such as contrast, acuity, required field of view, or observation time can be compensated by an increase in one of the others, within limits. It is of interest to note that performance is much less sensitive to changes in brightness above 10 footlamberts than any of the other factors.

Determine also that task performance is not limited by other features (cognition, for example) such that the visual portion is of little actual consequence. As a similar case in point, it is not always necessary to have a high fidelity stereo reproduction of sound in order to respond properly to the stimulus.

\subsubsection{Operator Analysis}

The performance of individuals with normal eyesight and up to about 40 years of age does not improve for normal office tasks when the average task background luminance exceeds approximately 10 to 15 footlamberts. For individuals over the age of 50, there appears to be improvement in performance up to approximately 20 footlamberts. Thus, for tasks with lower reflectivity, (near $40 \%$ ), an increase in illumination of up to $50 \%$ greater than recommended in Table 2 may be warranted.

Many experiments have demonstrated that older persons do not perform visual tasks as well as do younger persons; however, for normal older eyes, increasing the illumination level above 20 to 30 footcandles improves performances only very slightly, if at all, and no amount of extra illumination can cause the older persons to perform as well as younger ones.

There are many abnormalities of the eye. Some of them are such that increased illumination is of benefit (as, for example, for presbyopia with eyes not properly refracted). In other cases, increased illumination can be detrimental. For most older persons with properly refracted eyeglasses, there is a 50-50 chance as to which alternative is better. In these cases, if the visual performance requirements are continuous and time pressure is considerable, the advice of a physician is recommended. Alternatively, the individual can be given local control of task illumination. 


\subsection{SUGGESTED COST EFFECTIVE TASK MODIFICATIONS}

Once the task has been examined for potential visual difficulties, but before designing an appropriate lighting system, modification of difficult tasks should be considered. It is often possible to revise the task in a cost-effective manner so that lighting systems and associated energy costs for operation can be minimized.

\subsubsection{Paper and Printing}

If a task requires a considerable amount of reading, is it possible to change the paper from glossy to matte? (Matte finish is generally less expensive than polished paper!). Is it possible to increase the size of the printing or its legibility? Is it possible to go from hard pencil to felttip pen; or is it possible to use originals or better copies rather than poor copies for the actual working papers?

\subsubsection{Visual Surround}

The direction of view of the worker while performing his task is important. It should contain no bright sources such as very bright windows, bright lighting, or surfaces that refect bright images into the eyes of the observer. Contrasts should preferably be in the range of 3 to 1 for large areas of view; however, 10 to 1 is not unacceptable.

\subsubsection{Ability to Reorient Task}

If a task is visually difficult, it can often be made substantially easier to see if it can be reoriented, preferably by being picked up in the worker's hands. Dramatic improvements are often obtained by changing the angle of the paper with respect to the available lighting, bringing the task closer to the eyes, or holding the task normal to the viewing direction. If this flexibility is available, visual performance can often be made acceptable, even though the visual materials and the lighting systems are deficient. For some kinds of tasks, polarized lighting may improve visibility at viewing angles that would otherwise present problems.

\subsubsection{Performance Time}

When portions of the task are difficult, if the operator is given sufficient time, say perhaps one or two seconds to perform the operations or to change the location of his head with respect to a fixed task, satisfactory performance can often be obtained. If the task is uniformly visibly bad, this expedient would probably lead to unacceptable performance time. Alternate solutions are required; the most effective probably being to improve the task, since increased lighting levels could only make a bad task brighter.

\subsection{Determination of Appropriate Task Lighting Requirements}

After the task has been optimized as may be cost-effective, then an appropriate type of artificial lighting can be designed. Tasks can be differen- 
tiated into two types: Those requiring reading from paper or similar material (two dimensions), and those requiring observation of three dimensional objects such as equipment, warehousing, and requirements for personnel recognition and security.

\subsubsection{Two-dimensional Tasks}

\subsubsection{Lighting angles}

Lighting shall be so positioned related to tasks and observers that shadows are minimized on the object being observed and conditions causing glare are reduced. In particular, the type of lighting that leads to veiling reflections being reflected from the object being observed should be avoided.

\subsubsection{Illumination levels}

Normal office tasks are visually satisfied above a background luminance of 20 footlamberts, provided that the illumination from the surround does not create excessive direct or reflected glare, or cause the more specular tasks to be unduly reduced in contrast by reflected glare. As previously noted, to the extent that glare causes problems and cannot be eliminated, the task background luminance should be increased to permit the eye to see the task with at least approximately $1 / 5$ the same intensity as the glare source. Normally the effects of glare, where troublesome, are eliminated or at least greatly offset by simply changing the relative geometric relationship between the observer, the task, and the source, and not increasing the task luminance level. This is usually done almost unconsciously by the observer moving position, since in most cases only very slight adjustment is required.

Many, if not most, office tasks involve reading from paper. An appropriate reflectivity for the background of these tasks can be considered to be no less than $75 \%$. Hence, an illumination level of 27 footcandles ( 20 footlamberts/.75) should be quite adequate for seeing. However, to allow for less than optimum lighting, and to adjust brightness for levels "remembered" from outdoor daylighting or when exposed to fenestration, we recommend that office task lighting be designed to provide approximately $50( \pm 10)$ footcandles at the workplace (desk or table). This approximate doubling of intensity should be more than enough to allow for the average run of even the most difficult types of tasks.

Should a task require special consideration when reviewing the factors listed in the Task Analysis section, revise the illumination system in that task area only.

Guidance that may be beneficial for justification of increasing levels above 50 footcandles is given in Table 2 of Chapter 3. This information was developed by a careful review of the literature relative to good lighting practice in many countries throughout the world. More recent experiments relating actual task performance to illumination is given in "Task Lighting - Yet Another View," D.K. Ross, LD\&A, May 1978, pp. 37-43. 
The total illumination furnished for the task includes the sum of the general illumination provided for the space, plus additional or augmented task lighting as may be required. This task lighting should be separately controlled and switched off when not required.

\subsubsection{Three-dimensional Tasks}

Three-dimensional tasks, such as equipment operation, recognition, various types of social and business intercourse, etc., require illumination with different consideration than for two-dimensional task performance.

\subsubsection{Modeling required}

In the case of three-dimensional objects, shadowing is important to bring out texture and features. Since there is normally a certain amount of motion permitted between the viewer and the object being viewed, the source of illumination for three-dimensional objects can have a component of glare that would not otherwise be desirable, since positions can be changed to minimize its effect. It is also important to have a lighting source that can be oriented into the depth of the task for maintenance or for viewing of interiors if this is required. Modeling is optimized by directional lighting.

\section{$2 \cdot 3 \cdot 2.2$ Motion}

If motion of the object being observed is of consequence in task performance, the source must be relatively free of flicker that might synchronize with the motion or otherwise make the observation difficult.

\subsubsection{Illumination levels}

Identification of detailed human facial expression in satisfactory detail is considered to begin at about 5 footcandles.

Various safety codes promulgate levels of from 1 to 5 footcandles for illumination of areas with movement and moving machinery, although values much lower are actually quite satisfactory for many applications. For example, most people can easily read a newspaper at arm's length with an intensity of only $1 / 2$ footcandle.

Photopic vision, which includes the ability to distinguish colors, begins at approximately 1 footlambert, while the eye can readily detect objects in bright moonlight at .01 footlamberts. 
These levels describe the lower end of suggested lighting levels for threedimensional tasks.

It is suggested that building corridors be lighted to an average value of 10 footcandles, 4' above the floor; maintenance rooms, 30 footcandles, average, at $3^{\prime}$ above the floor; and other areas should be within these ranges.

For repair of machinery requiring high intensity lighting infrequently and at various locations, a portable trouble lamp is appropriate, depending on the frequency of use.

There may be an advantage in some cases to providing light sources located so that the illumination in the vertical plane exceeds that in the horizontal, which is not the case for most installations. Where this consideration is important, the illumination level specification should so indicate.

\subsection{TASK LIGHTING SYSTEMS FOR SELECTED TASKS AND AREAS}

\subsubsection{Conventional Office Space}

Consider the use of ceiling-mounted fluorescent troffers specifically located with reference to the task to minimize veiling reflections. Use special lenses, polarizing filters, or parabolic reflectors where appropriate. These might take the form of the bat-wing distribution for larger offices. Alternately, a pod-mounted metal halide lighting system, each approximately 250 to 400 watts, might be used to furnish indirect lighting. The pods should be mounted with the top surface approximately 2-1/2 feet to 3 feet (or more) below the surface of the ceiling.

Whatever lighting system is selected, the illumination should be of good quality to minimize direct glare and veiling reflections.

\subsubsection{Open-plan office space}

Flexible ceiling lighting of fluorescent troffers or pod-mounted metal halide is suggested, with luminaires again located to provide lighting at the tasks with lighting dropping off in other areas. Pod-mounted, moveable, metalhalide fixtures with up-light are particularly suitable and can be used effectively in these layouts. Task lighting located directly in furniture or on moveable partitions is also suggested as an application here, but considerable care is required to insure effective lighting from furniture-mounted sources. An important use of ceiling-mounted lighting or colored lighting in open-plan offices encompassing large areas, can be to give directions for orientation purposes for visitors or for traffic control. For example, walkways could be of a certain type of ceiling-mounted fixture or of a certain hue that can be readily identified, in what otherwise might be a maze. Similar direction can be given by the use of color, painting on ceiling or walls or on carpets, or by significant features in the landscape that can be identified. 


\subsubsection{Conference Rooms}

Again, the pod-mounted metal halide or ceiling-mounted fluorescent lights are recommended. Levels of approximately 30 footcandles are believed suitable with special lighting for blackboards, film presentation, etc. Special conference rooms may require dimming systems.

\subsubsection{Public Circulation}

Since these areas primarily require lighting for modeling of three-dimensional characteristics, some glare will be permissible. Incandescent lighting should be avoided in these areas, since the lights are on for long periods of time. The lighting should also have automatic control so that when natural light is present, the artificial light is turned off. This could be either by time clock or photocell, or both.

\subsubsection{Shipping, Receiving and Storage}

These areas require special consideration, depending upon ceiling height and function. Lighting levels from 5 footcandles to 30 footcandles are appropriate, with lights being off when not required. If frequent switching is required, fluorescent is most suitable. If lamps are only on for short periods, incandescent may be acceptable.

\subsubsection{Computer Rooms, Equipment Rooms, etc.}

These areas have primarily two functions, one involving continuing interaction of people and equipment, and the other involving relatively infrequent maintenance of equipment. In those locations where operating personnel are required to interface with machinery, task lighting is required that can be either equipment-mounted, console-mounted, desk-mounted, or ceiling-mounted. Lighting should be designed so that it does not cause excessive glare when the primary function of working with the equipment is taking place, and in particular there should be no reflections caused by the lighting system reflecting off of the equipment into the eyes of the operator in the normal operating position. It is recommended that lighting for operator consoles be dimmer-controlled with a range of from 15 footcandles to approximately 100 footcandles. For those portions of the area where there is required to be man/machine interface only for maintenance or trouble-shooting, the lighting can generally be switched off. If this is the case, it is recommended that these areas be isolated visually by means of partitions.

Lighting can be ceiling-mounted with fluorescent fixtures so located with respect to the equipment and the operating locations required for maintenance that light is allowed to impinge within the interiors of the cabinets, for example. A uniform lighting layout IS DISCOURAGED. Luminaries should be installed appropriately for the locations of equipment, aisles, etc. Provision could be made, when working on interiors of cabinets, for trouble lights to be plugged in that are brought to the location by the operator. 
General lighting levels of from 30 to 50 footcandles, depending on the application, are recommended when the lights are on. Switching should be provided to maintain some minimal level, say 5 footcandles, in the area. This could be provided as part of the emergency exit lighting system, if personnel must pass through the area to perform other functions for safety, if appropriate.

If these areas are seldom used, and only occasionally visited by personnel, incandescent lighting is recommended, as it should be switched off most of the time. If, on the other hand, equipment is regularly visited by people and lighting is on for longer periods of time, stem- or chain-suspended industrial type fluorescent fixtures are recommended with about $25 \%$ up-light. Lighting levels of 30 footcandles to 50 footcandles are appropriate, except for special tasks which may require a different kind of lighting. If incandescent lamps are used, time switches may be applicable, or indicator lamps located outside the space that glow when the lamps are on.

\section{BUILDING LIGHTING}

\subsection{CIRCULATION AREAS - AROUND AND NEAR DESK TASKS}

3.1.1 Provide 20 to 30 footcandles generally on areas surrounding task, and on task if practical, to supplement task lighting.

3.1.2 Minimize glare on task areas, and in visual field of pedestrians.

3.1.3 Minimize shadows on task.

3.1.4 Switch off when not required, or when daylight will provide lighting.

3.1.5 For open-plan office, use different color sources for area of pathway indentification, if practical.

\subsection{SECURITY LIGHTING}

\subsubsection{Exit Lighting}

Provide adequate illumination to meet code requirements.

3.2.1.1 Use internally lighted (electrically-operated) exit signs only when lighting from exitway is not adequate to illuminate sign.

3.2.1.2 Turn off exit lighting if building or major areas are unoccupied.

\subsubsection{Exitway and Stairway Lighting}

Provide circuity to keep separate from normal corridor and stairway lighting (or use separate system that switches on only when normal power fails). Leave on only when building is occupied. Turn off when daylighting is adequate. Furnish approximately 3 footlamberts of lighting on important safety features, steps, etc. Minimum of 1 footlambert, or code required, whichever is greater. 


\subsubsection{Outdoor Security Lighting}

Provide lighting at doorways, stairs, and walkways as may be required. Control on with photcell, off with time clock, if not required until daylight. Use 1 footlambert on important safety factors.

3.2.3.1 For area lighting to detect persons, moving traffic, etc., use principles of silhouette lighting to greatest extent possible, unless indentification is necessary.

\subsubsection{Corridor Lighting}

Use 5 to 10 footlamberts at face level, 3 to 5 footlamberts at floor level. Switch off when daylight is available or after building is unoccupied.

\subsubsection{Maintenance Areas, Storerooms, Closets}

Use 15 to 20 footlamberts, higher if required for machinery, etc. Switch off when unoccupied.

\section{2 .6 Parking}

\subsubsection{Indoor Parking}

Design for an average of approximately 5 footcandles, 4' above the floor. Higher intensity should be provided in the aisles, dropping off to lower footcandles in the parking stalls.

\subsubsection{Outdoor Parking}

Should be designed to use no more than .05 watt per square foot.

\section{LIGHTING COMPONENTS}

\subsection{EFFICIENT SOURCES}

For artificial lighting that is to be operating for long periods of time, the most efficient sources of light should be selected. For offices we would limit consideration to metal halide, high-pressure sodium, and fluorescent sources. The particular embodiment selected will depend upon ceiling height, type of fixture, and specific application, but in each case the lamp and ballast combination should be selected to provide maximum lumens per watt based on life-cycle cost considerations. This will include lamp life, lamp efficacy, ballast efficiency, and ballast life, together with firstcosts of each of these elements. Fluorescent lamps should be selected if important savings can be realized by switching lamps off and on during the day, keeping in mind it takes about 5 minutes for the HID lamps to come up to full intensity when switched on. Incandescent lamps can be considered for application where lights are required to be operated only for short periods of time (i.e., closets, certain equipment spaces, trouble lights, desk lamps, dimmer-controlled task lighting of high intensity), or for limited use access lighting. 


\subsection{EFFICIENT FIXTURES}

Fixtures should be selected that have a high efficiency in distributing the total number of lumens available from the lamps to the task without causing visual discomfort. For task lighting, the use of manufacturers' published coefficients of utilization are not satisfactory. Point-by-point calculation are required. In particular, it is found that task lighting is not sensitive to room size and reflectivity nearly to the extent that occurs for general lighting. This is because task lighting is much more affected by the direct component of the luminaire than by the interreflection components.

\subsection{OPEN-PLAN OFFICE FLEXIBILITY}

Open-plan fixtures may be mounted in furniture, on pods directed upward toward the ceiling, on desks or file cases, or in the ceiling. In all cases, it is essential to the concept of open-plan layout that the equipment be readily moveable, and it is suggested that it be plugged into outlets for this purpose. Ceiling-mounted fixtures should have similar flexibility and the ceiling system should permit relatively easy relocation of the fixtures to correspond to changing task locations, but again it is recommended that these fixtures be associated with an electrical distribution system that permits unplugging the fixtures from the electrical system and reconnection without requiring the services of an electrician. (Local switching is required.)

\subsection{CONTROL}

All lighting should be capable of being switched off when not required to perform a task or to provide supplementary lighting for the general area.

\section{$4.5 \quad$ RELIABILITY}

Equipment shall have the capability of performing for long periods without maintenance and shall be serviceable as to finish and ability to be relocated without damage. It is of particular importance when designing for energy conservation that an extra degree of reliability be provided because a substantial amount of redundancy previously present in lighting systems, which contributed to excess use of energy, is being eliminated and the lack of a single light source has a greater consequence than it previously would have had.

\subsection{APPEARANCE}

Fixtures should be compatible with the interior environment. The use of artificial lighting for artistic effect should be used sparingly, with greater emphasis being placed upon color, texture, and geometry so as not to consume energy for this effect.

\subsection{ACOUSTICS}

Lighting equipment should be selected so that the noise level emanating from the equipment is not objectionable in the environment in which it is located. Secondly, the exposed surface of ceiling-mounted lighting fixtures should be 
be selected, particularly in open-plan offices, so as not to compromise the acuostical treatment by reflecting sound from hard surfaces in an otherwise acoustically controlled area.

\subsection{FLICKER}

Sources such as mercury, high-pressure sodium, and fluorescent lamps require lead-lag ballasts, or the operation of adjacent fixtures from alternate electrical phases in order to minimize the effects of flicker. Metal halide lamps appear to suffer the least in this regard and can be operated from a single-phase source withought lead-lag ballasts. This is a particularly important consideration where motion is to be observed.

\section{NATURAL LIGHTING}

\subsection{NATURAL LIGHTING AND HVAC}

The use of natural light is recommended whenever energy can be conserved. It should be noted that in terms of lumens per watt, natural light, even including a direct beam of sunlight entering through a glass window, is more efficient than fluorescent lighting (but not quite so efficient as highpressure sodium). This means that if the brightness and intensity can be controlled, daylighting has less effect on an HVAC system than does the usual artificial lighting system. The problem is one of control, so that only as much light as may be required is introduced during the cooling season. During the heating season, this additional heat asociated with excess light may be welcome.

\subsection{SKYLIGHTS}

The use of skylight concepts to introduce light into the interior is encouraged. Systems should be provided to maintain the skylights clean and free of accumulation of dirt. Regular cleaning is required.

\subsection{WINDOWS}

The use of windows around the perimeter for introducing light is encouraged, provided this treatment is compatible with all other considerations.

\subsection{INTENSITY}

One of the problems with daylighting is the change in intensity, sometimes too intense, and other times not sufficient. Systems such as venetian blinds or gauze drapes are effective in controlling the intensity of lighting. Another technique is the use of reflecting glass or even reflecting shades to transmit a portion of the spectrum and reflect a substantial amount. The shades can be raised or lowered for control. The shades would be in position during the bright summer days and could be removed by being rolled up during winter months, for example. They can further be incorporated as thermal barriers during cold winter nights. 


\subsection{CONTROL}

The advisability of providing automatic control to maintain proper lighting conditions is recommended; particularly if skylights are incorporated into the design. This control might take the form of moveable shutters or shades, design of suitable overhangs to block the direct sunlight, etc. It is further recommended that the artificial lighting systems be automatically controlled by means of photoelectric control to adjust for changes in the naturally occurring light caused by cloud cover or diurnal or other changes.

\subsection{EYE ADAPTATION}

The normal eye adjusts to reductions in brightness by two principal mechanisms: More quickly by changes in the size of the iris, and then more slowly by chemcal changes in the eye itself, causing it to be less sensitive. The first reaction takes place in fractions of a second, and can accommodate brightness levels of 30 to 1 . The second requires about $1 / 2$ hour to be complete, and can accommodate changes in level of about 3,000,000 to 1 .

This latter reaction, because of its lag, tends to "remember" conditions such as the outside brightness levels when one comes indoors, or bright windows that may be in the field of view from time or time. When the eye still retains the integrated effects of this very bright scene, indoor lighting during daylight hours may appear dim; whereas, the same level of indoor lighting at night appears bright.

When lower levels indoors are to be used effectively, very bright outdoor sources must be properly controlled to minimize the integration effect. This requires some amount of skill if it is to be done properly. These design techniques are well within the capability of the knowledgeable lighting designer, but are often lacking in many of today's installations.

It is important that where daylighting is introduced over large areas, and workers are required to move from these areas to substantially less brilliant ones, that time be permitted for eye adaptation to occur. This is particularly the case when traveling from outdoors to indoors. 
APPENDIX III

WORKSHEETS FOR SCHOOL ANALYSIS 



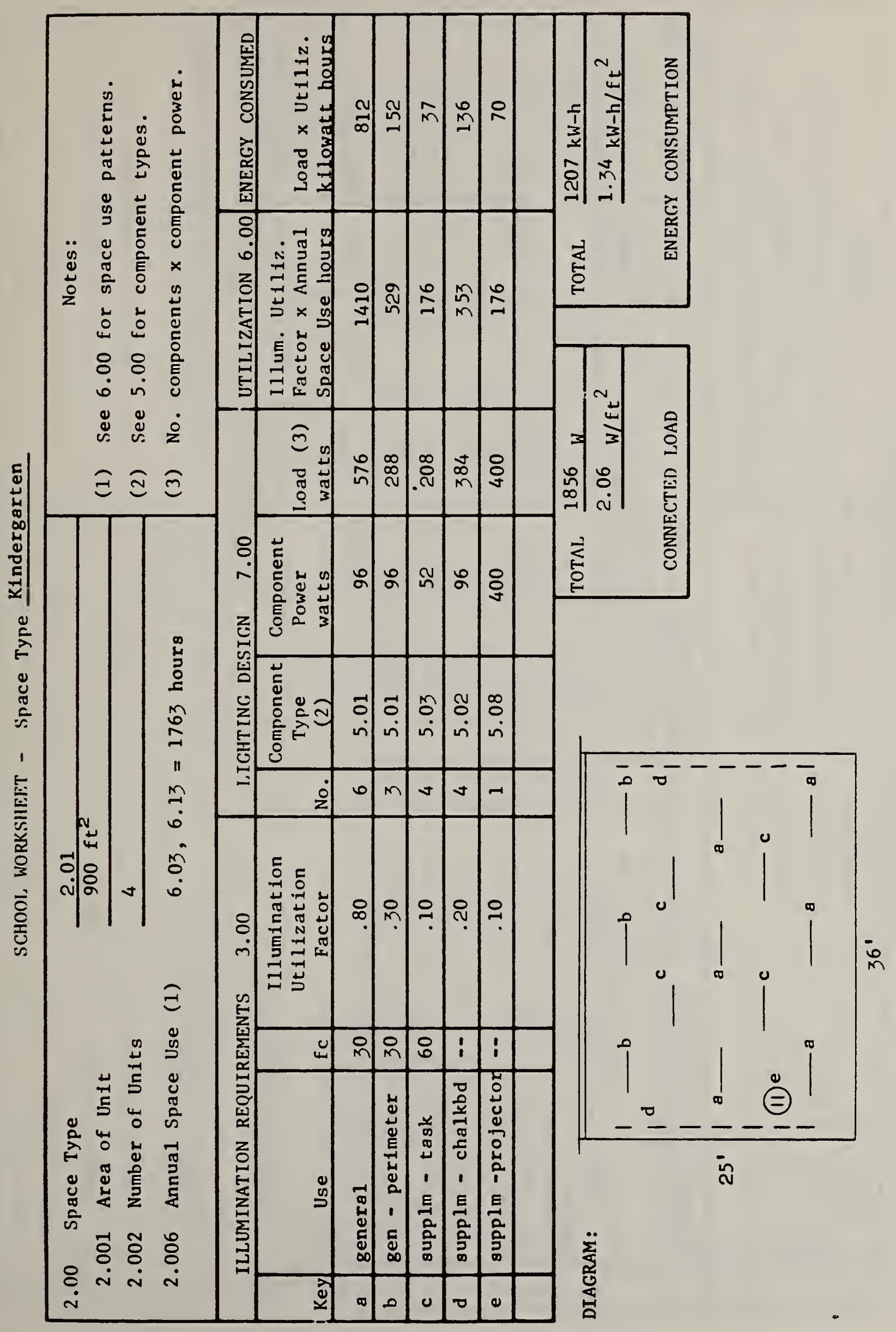




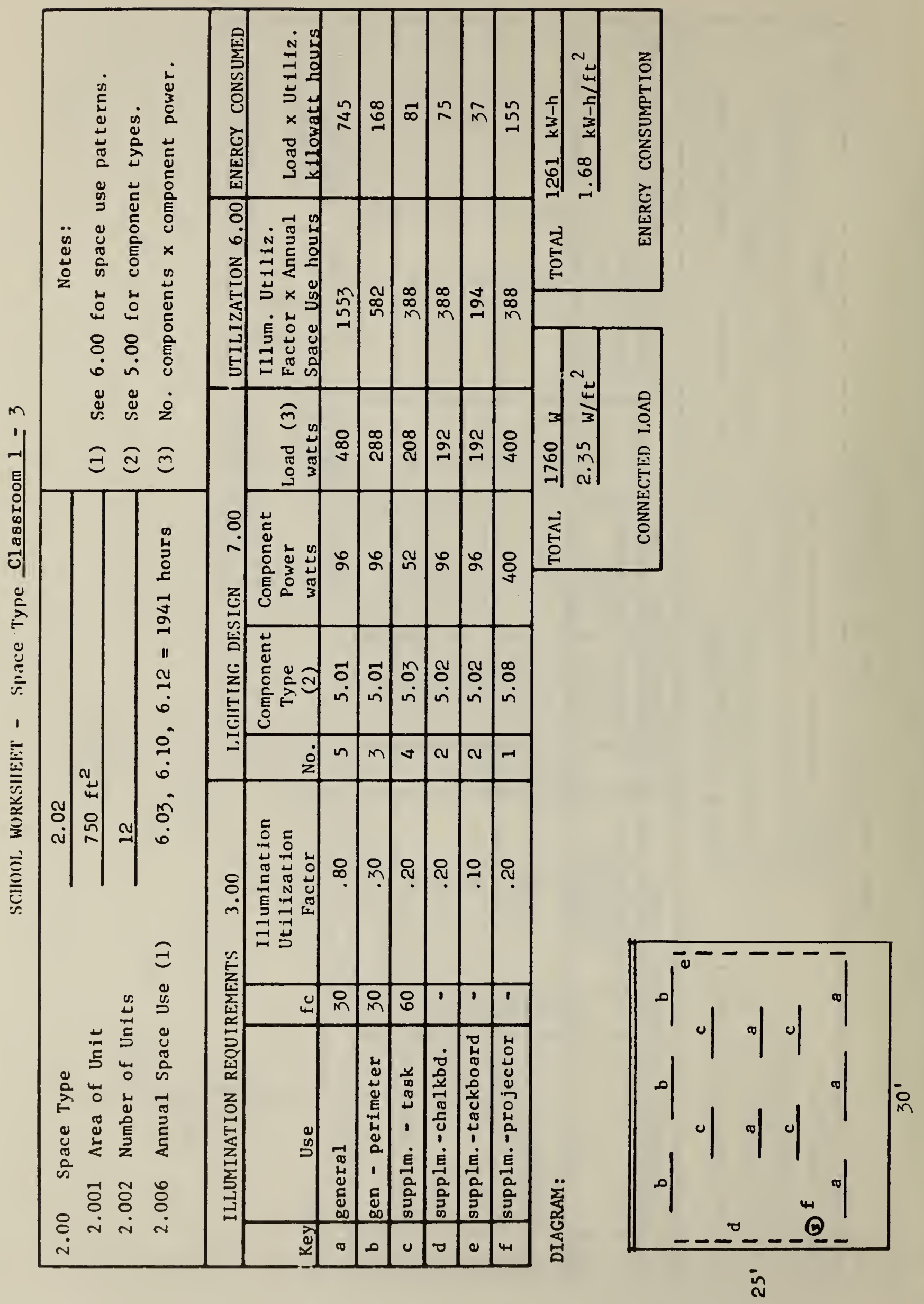




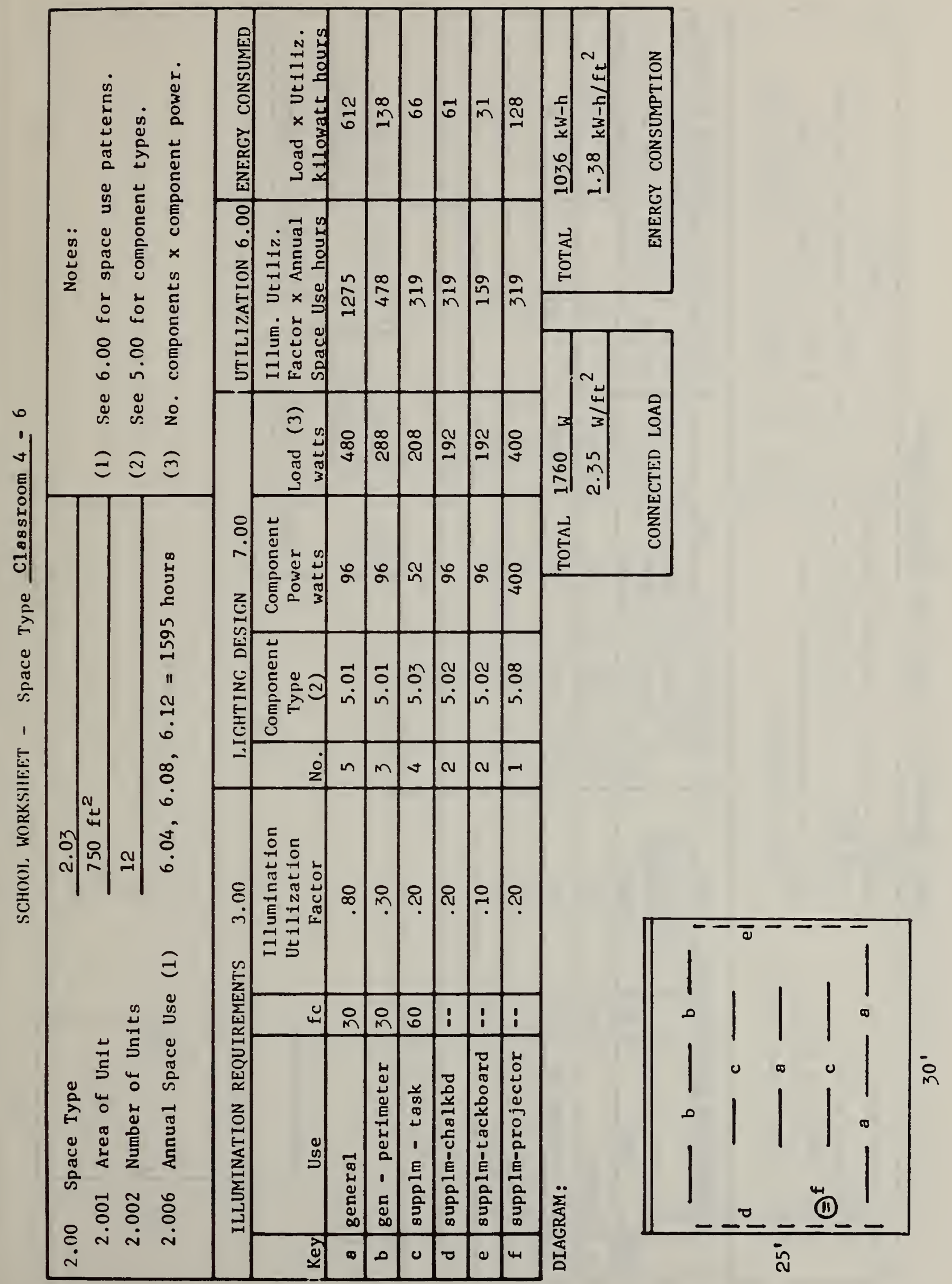




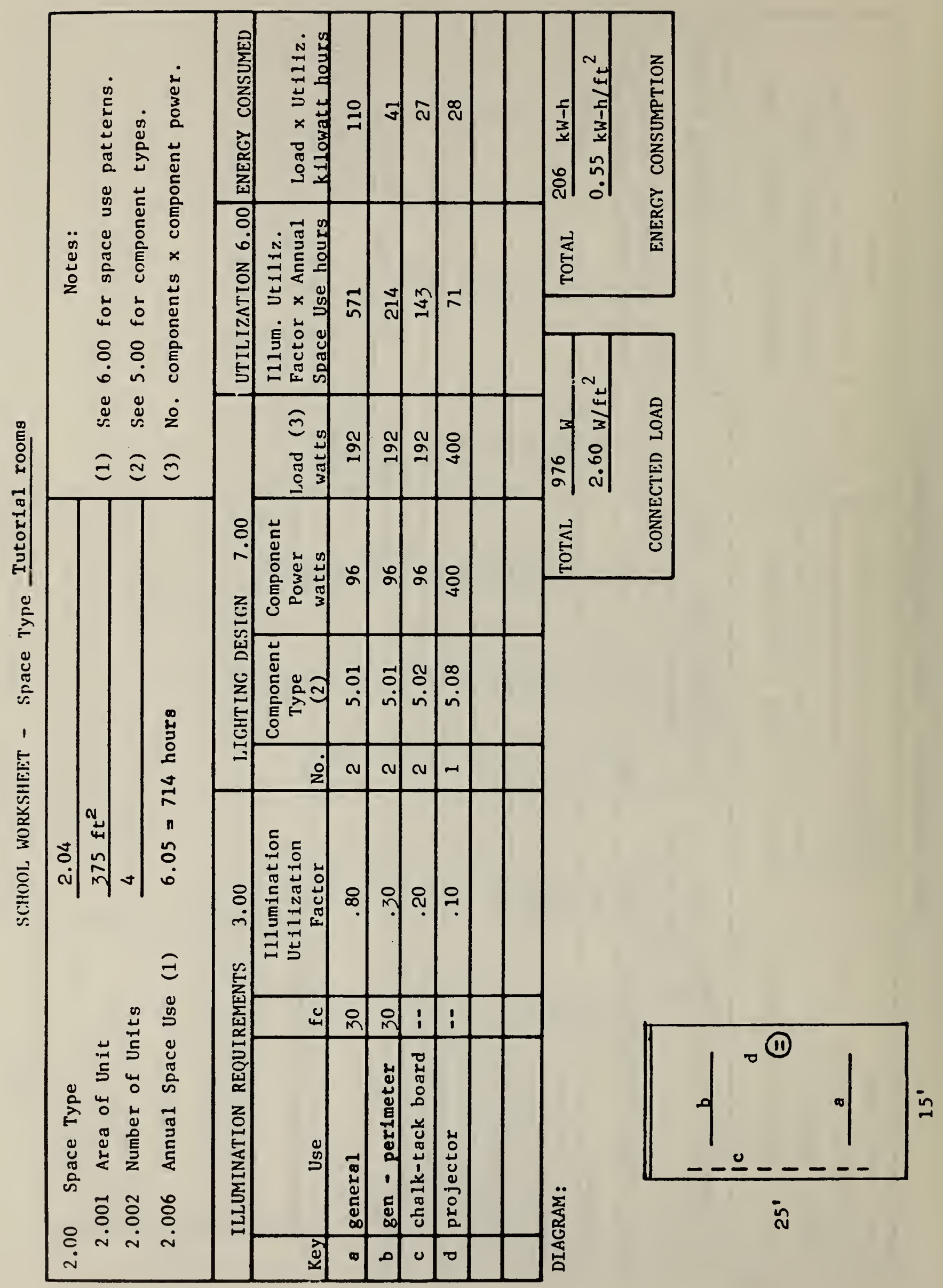




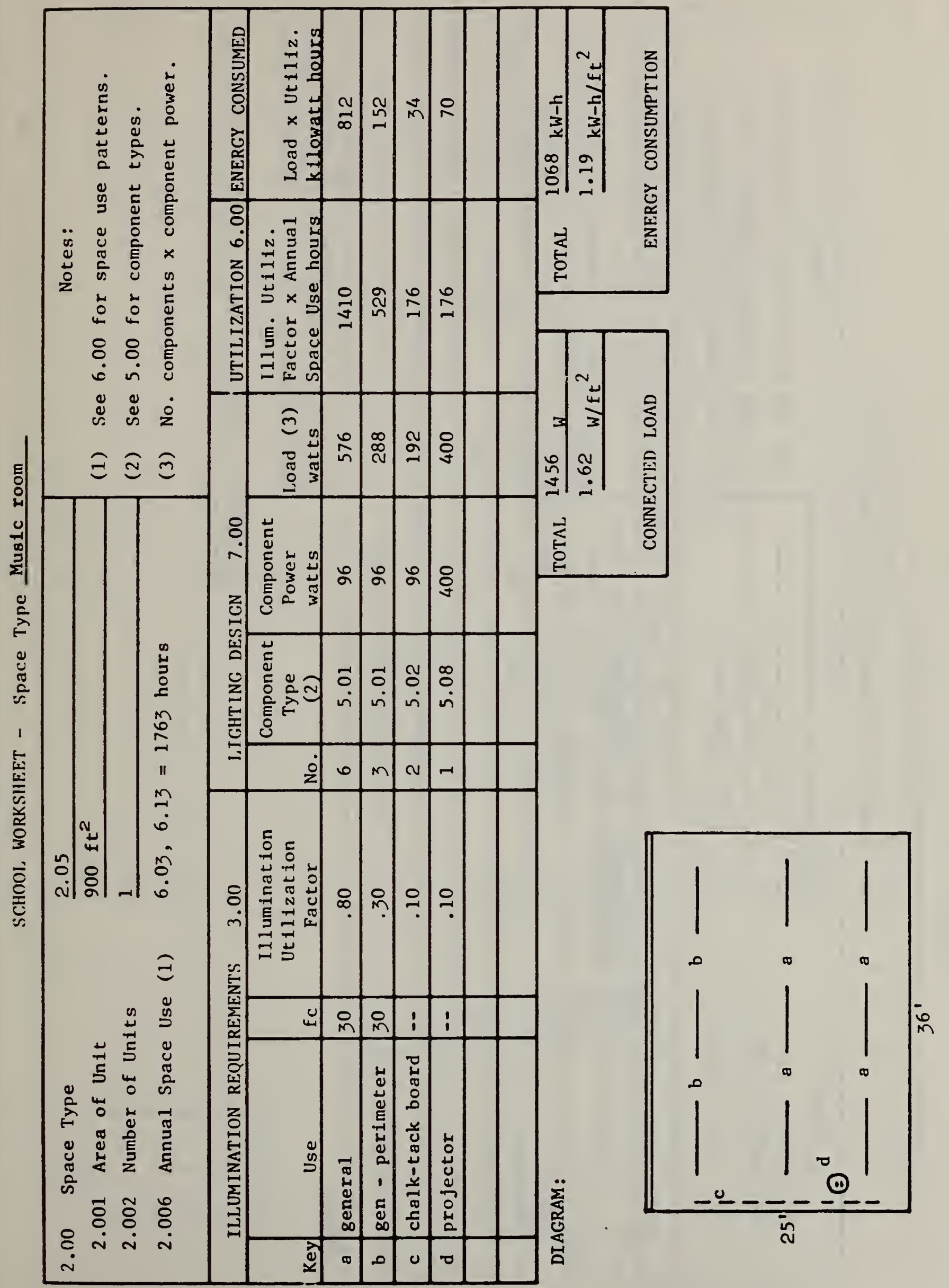




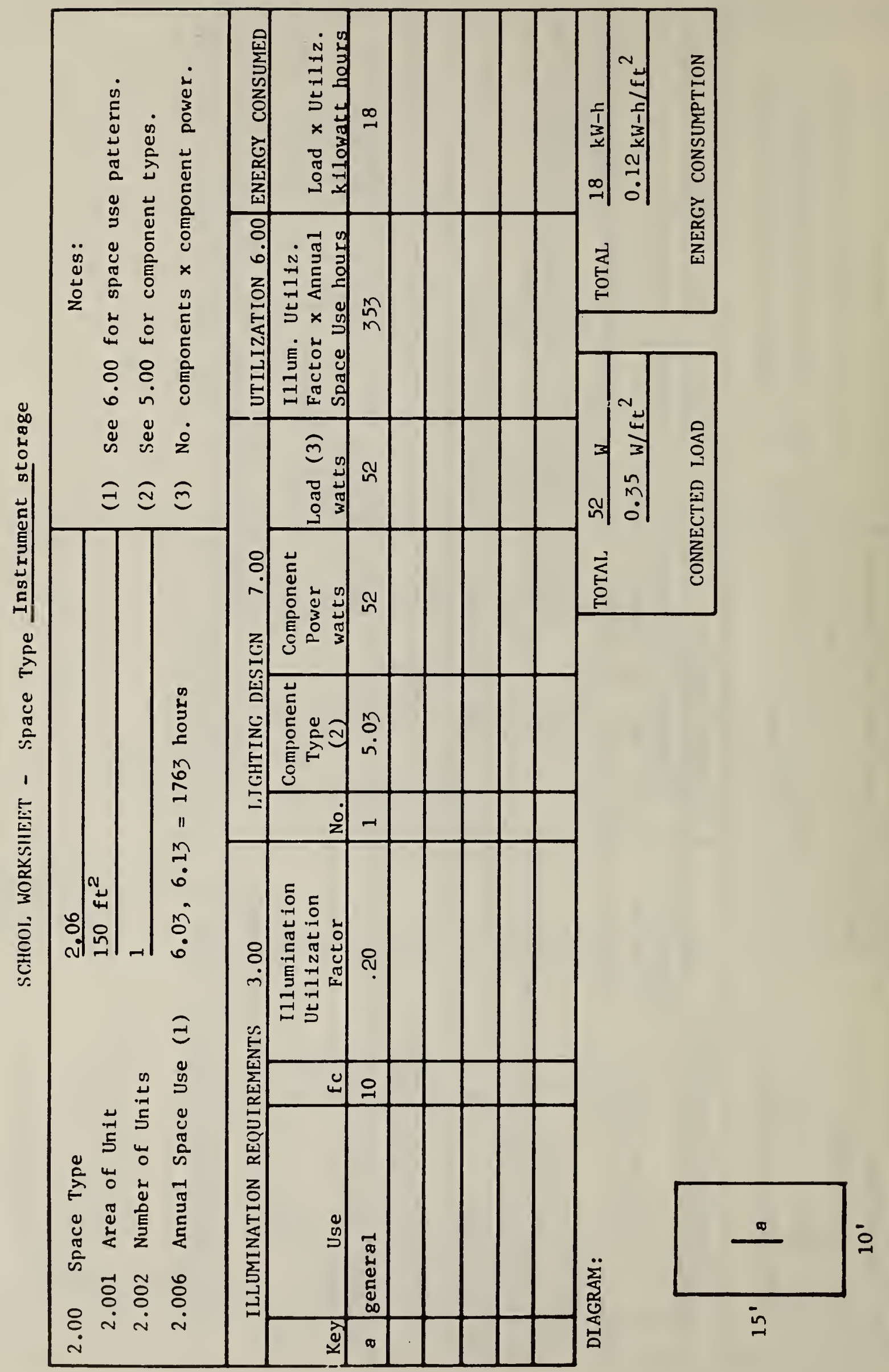




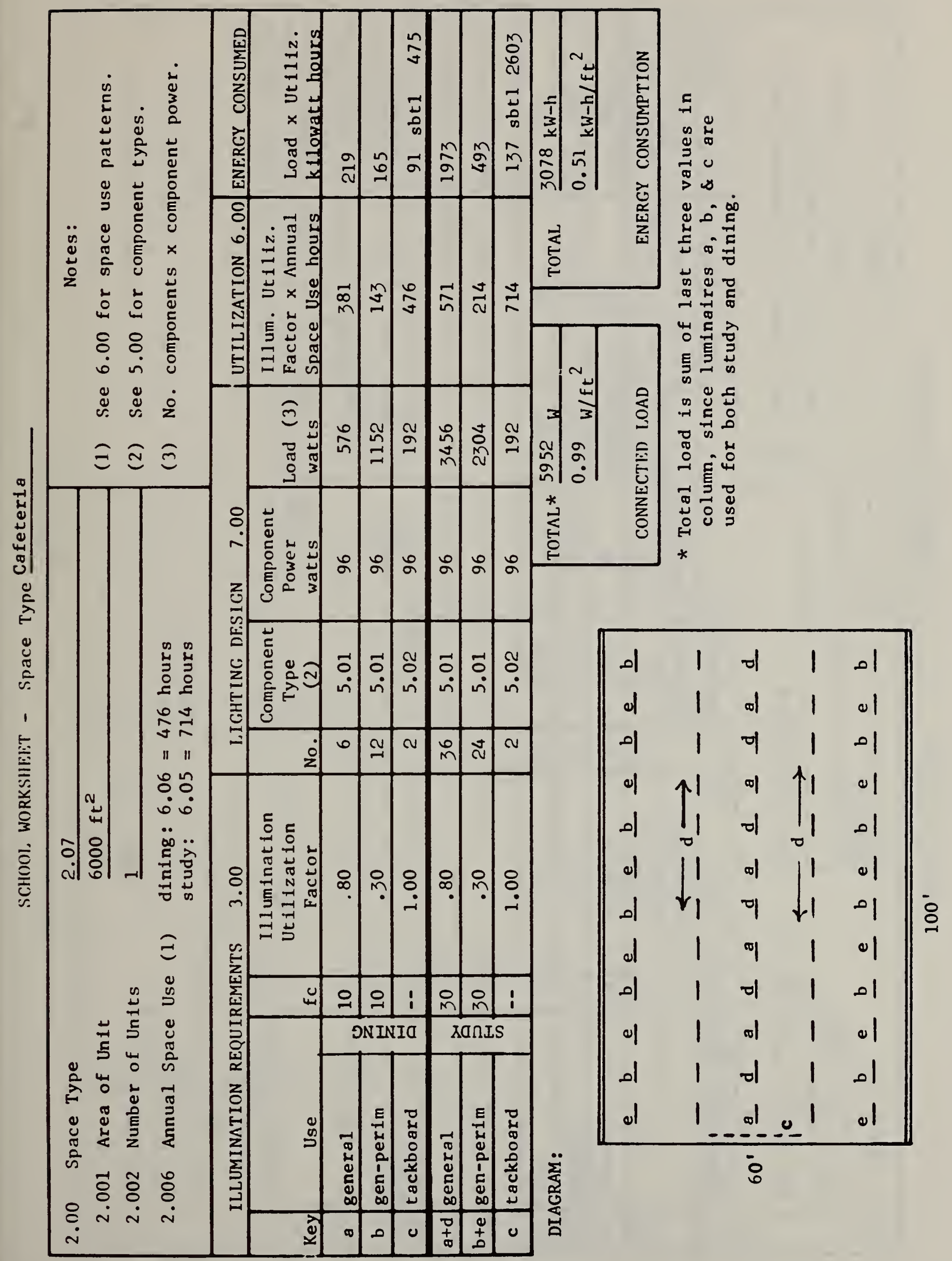




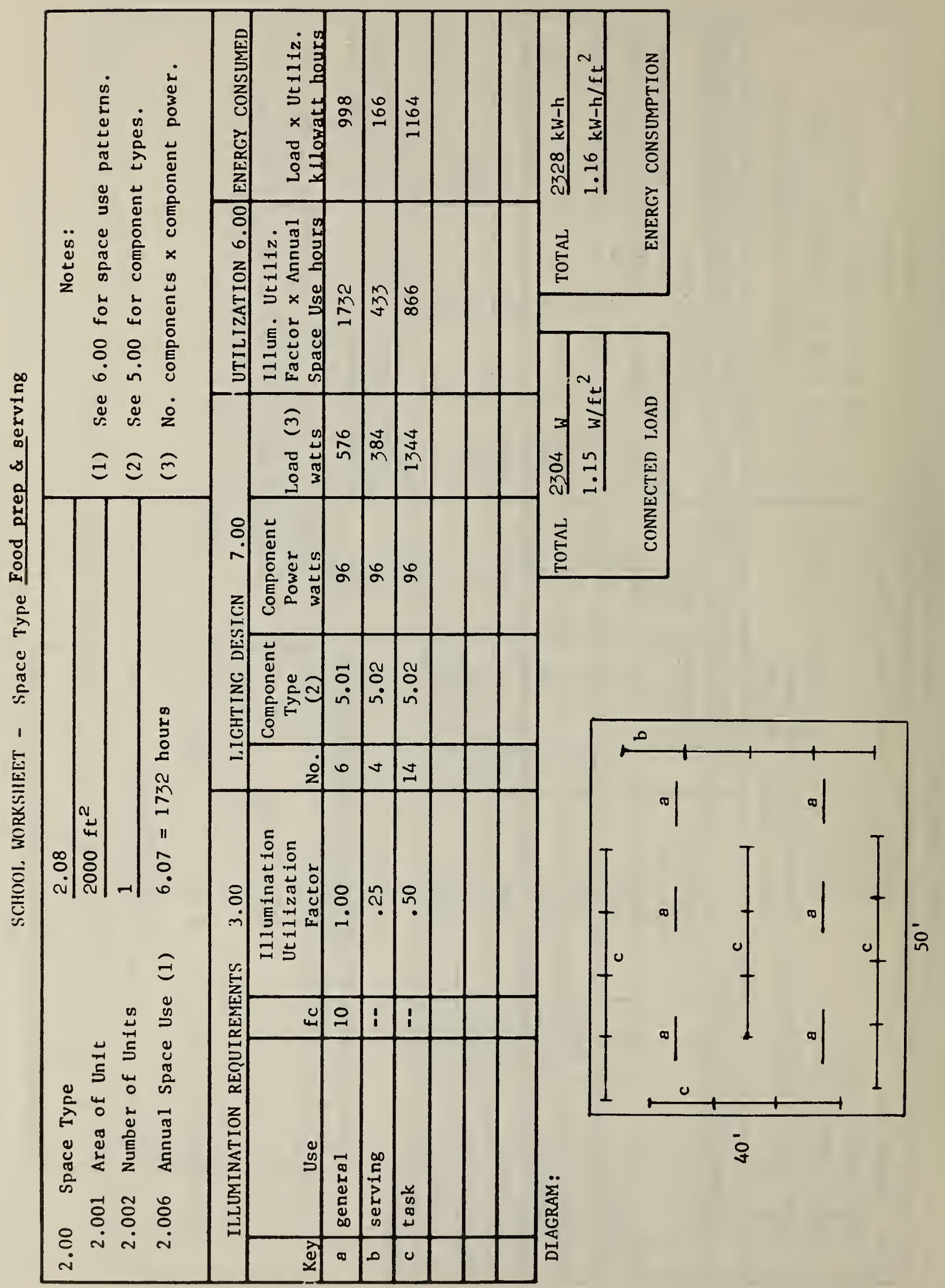




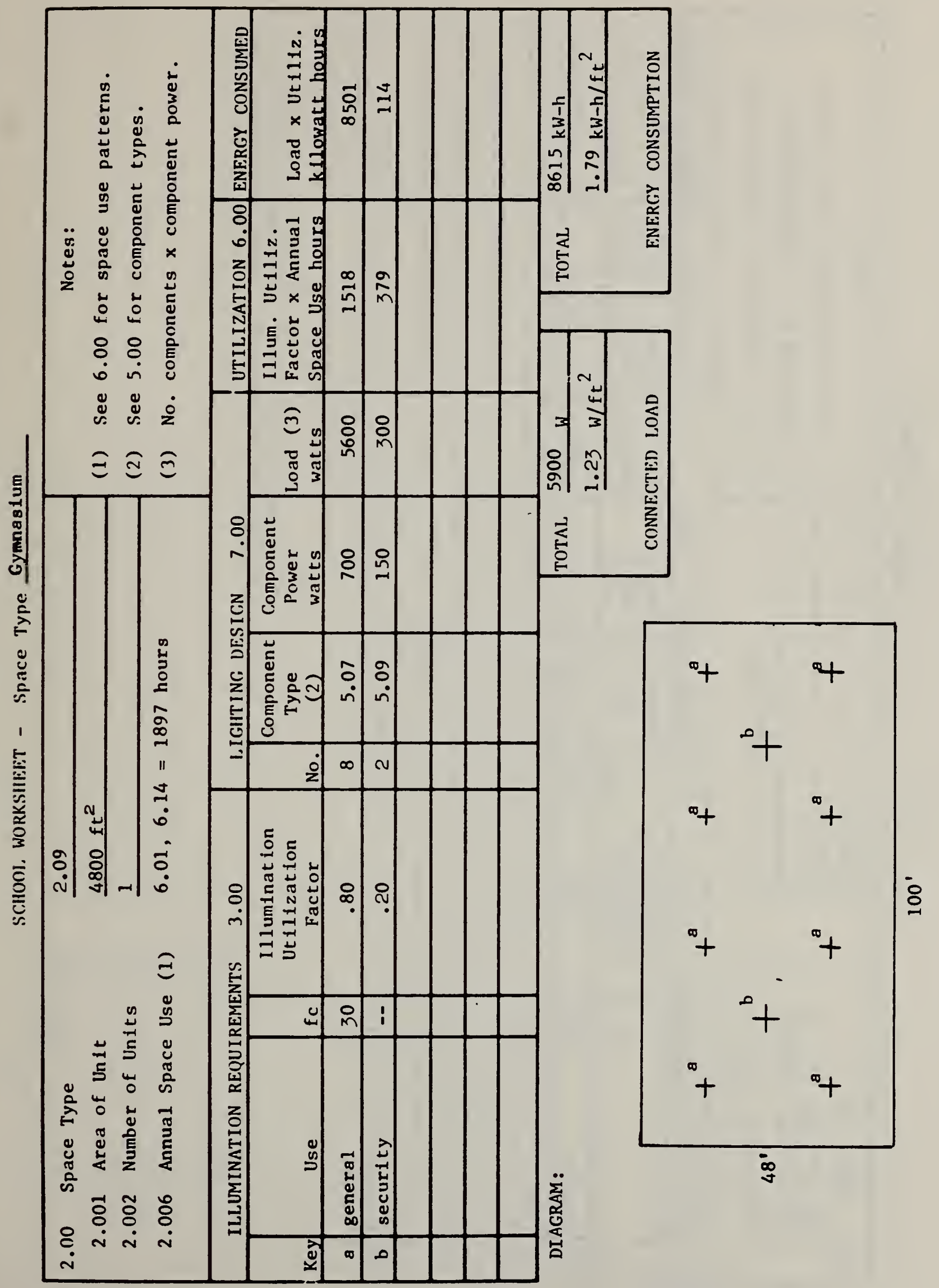




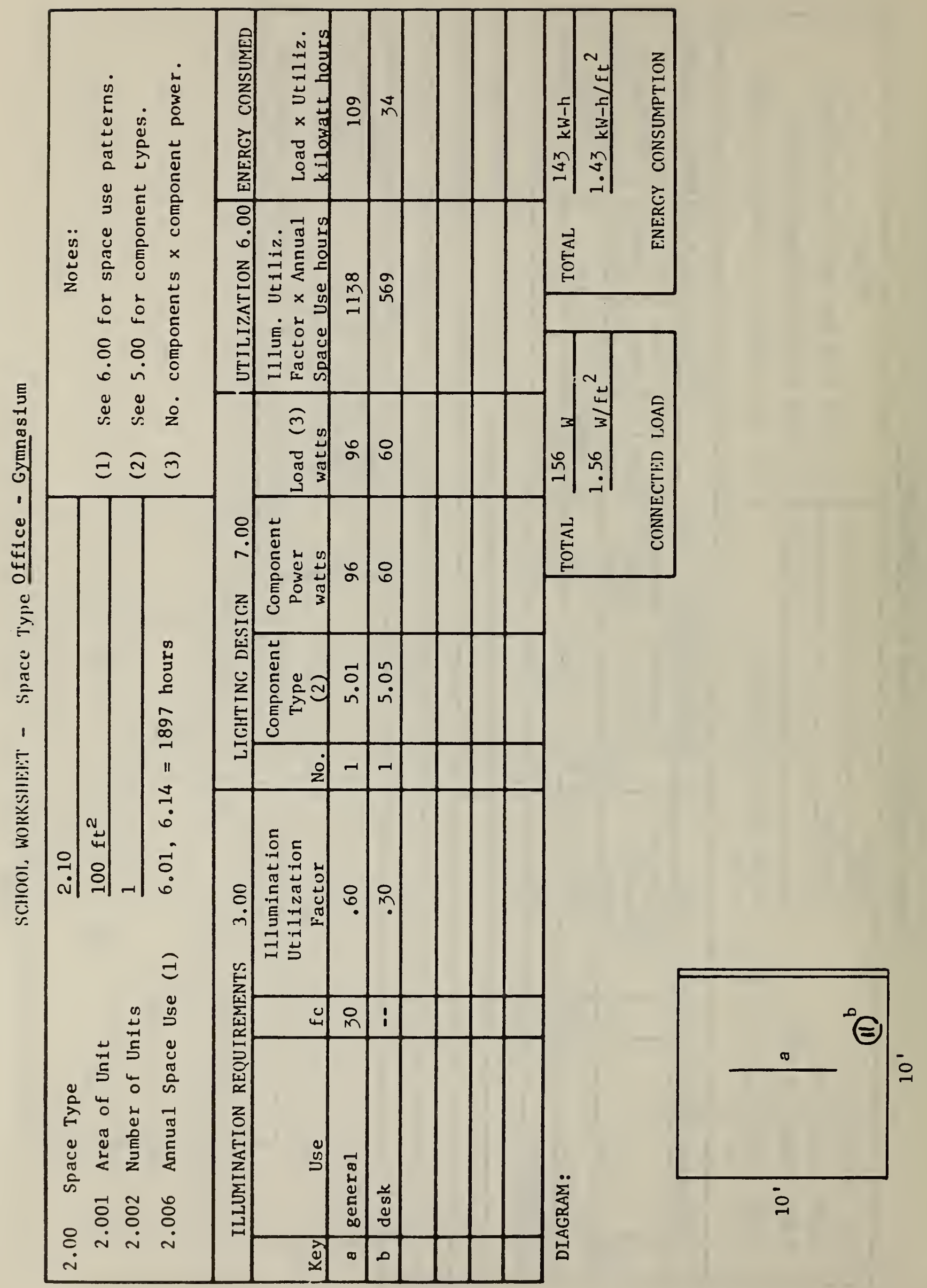



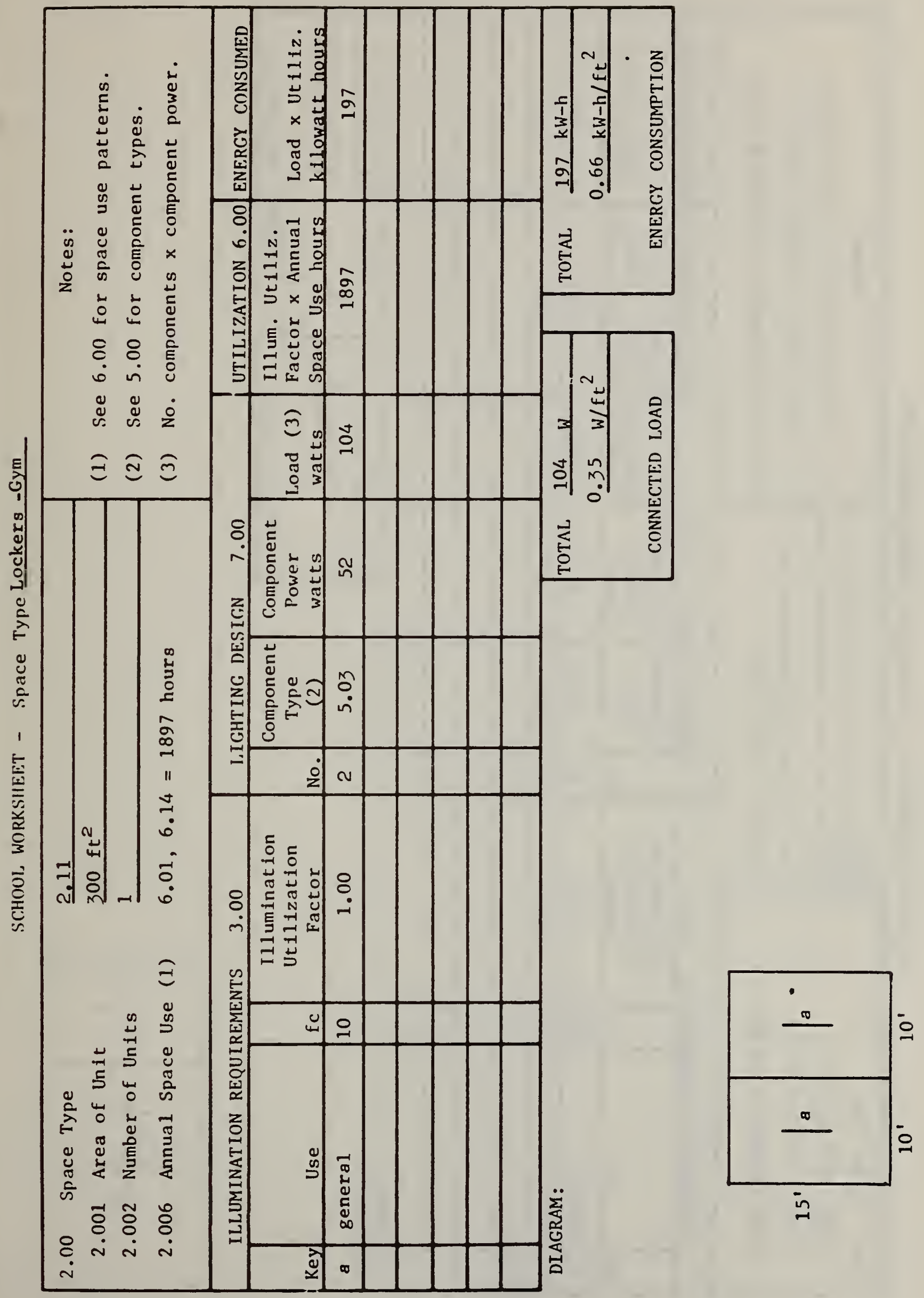

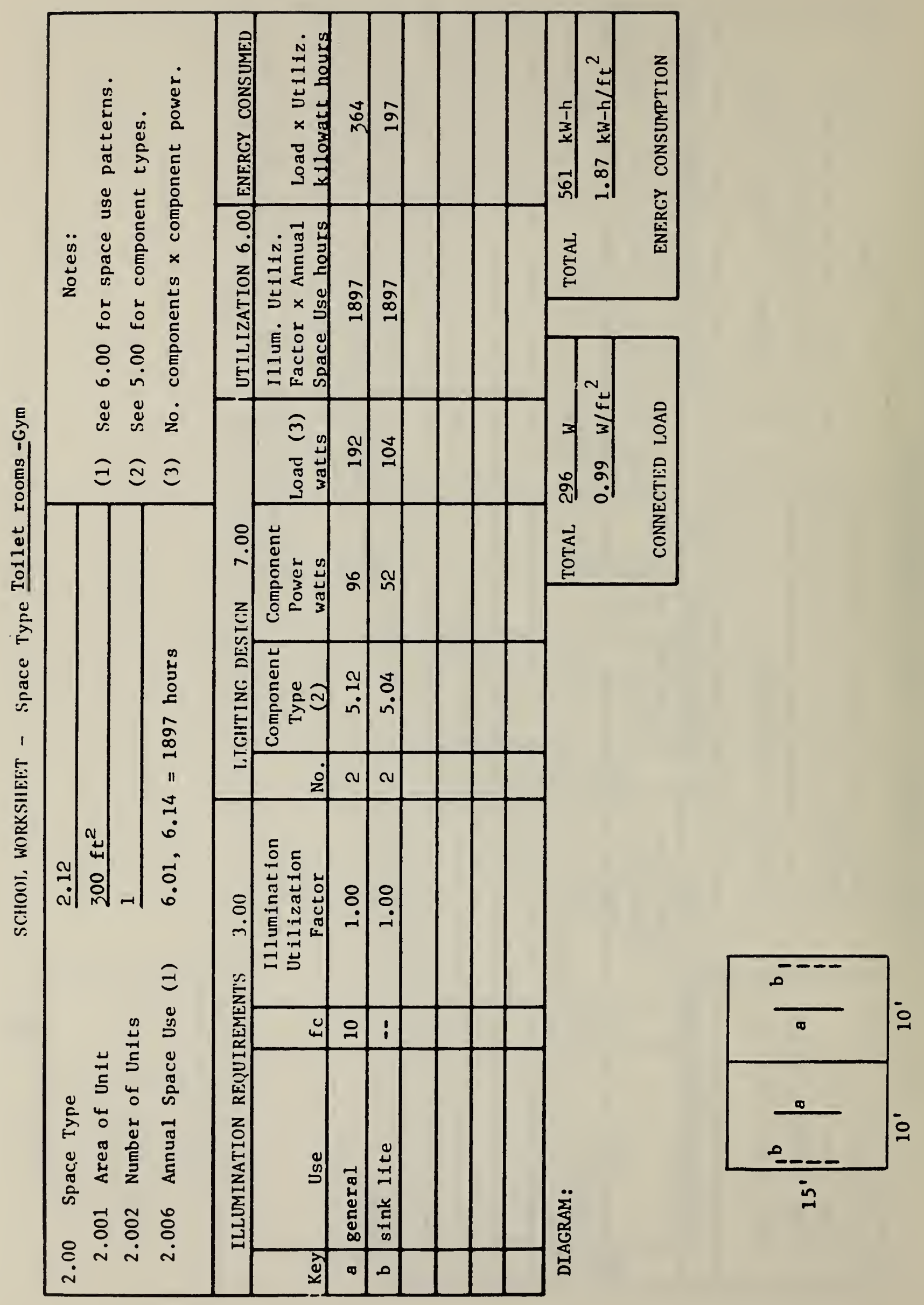

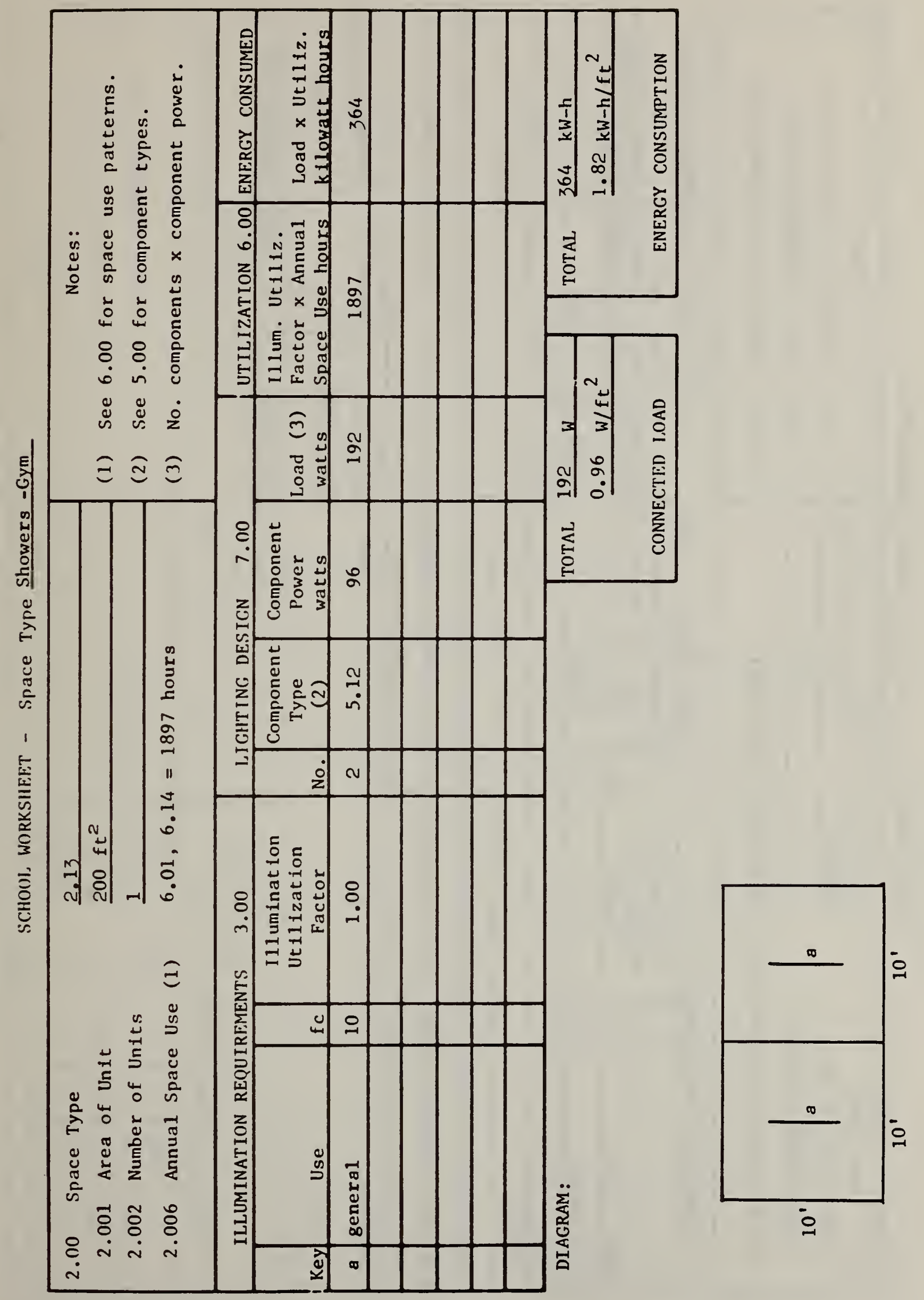


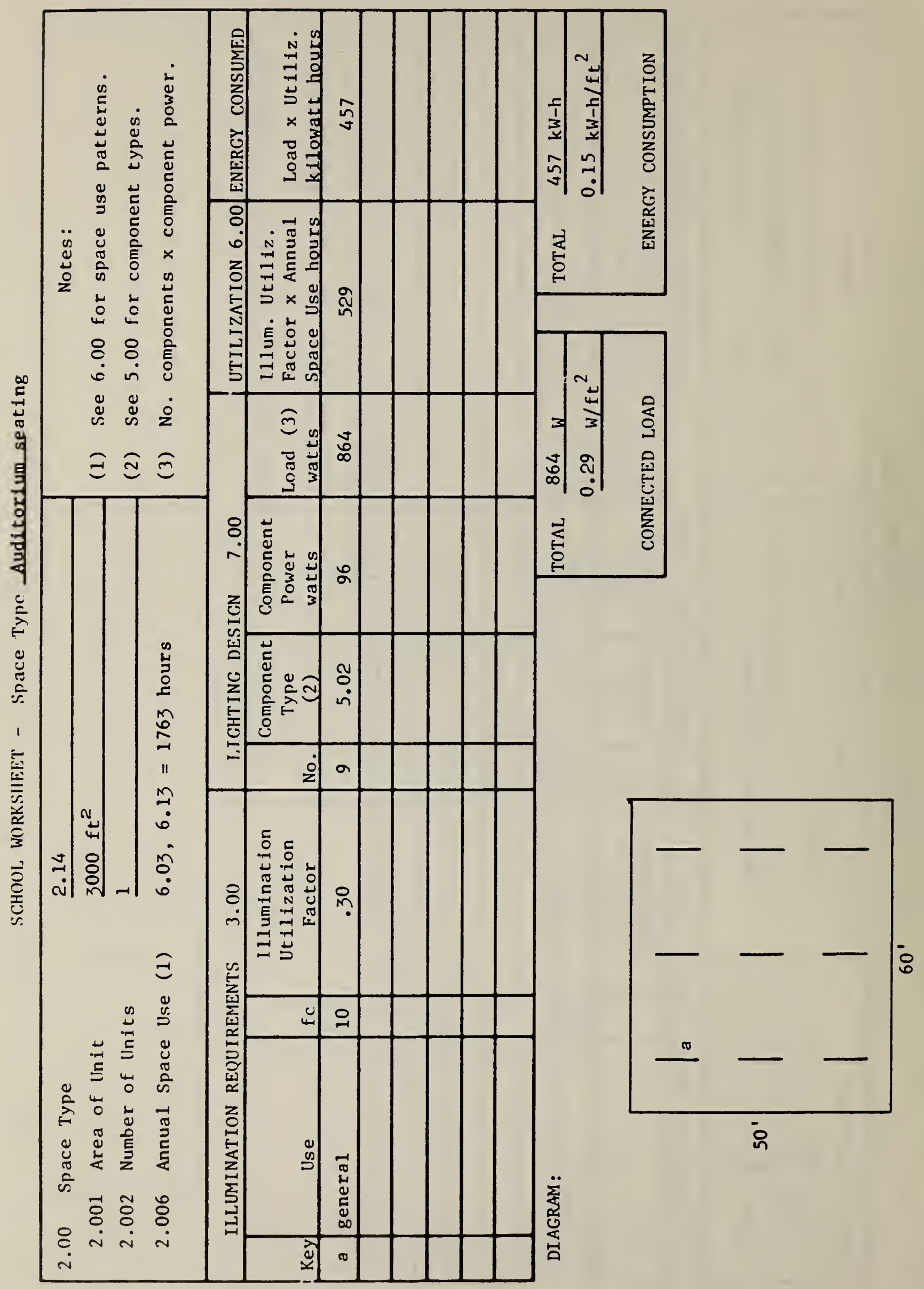




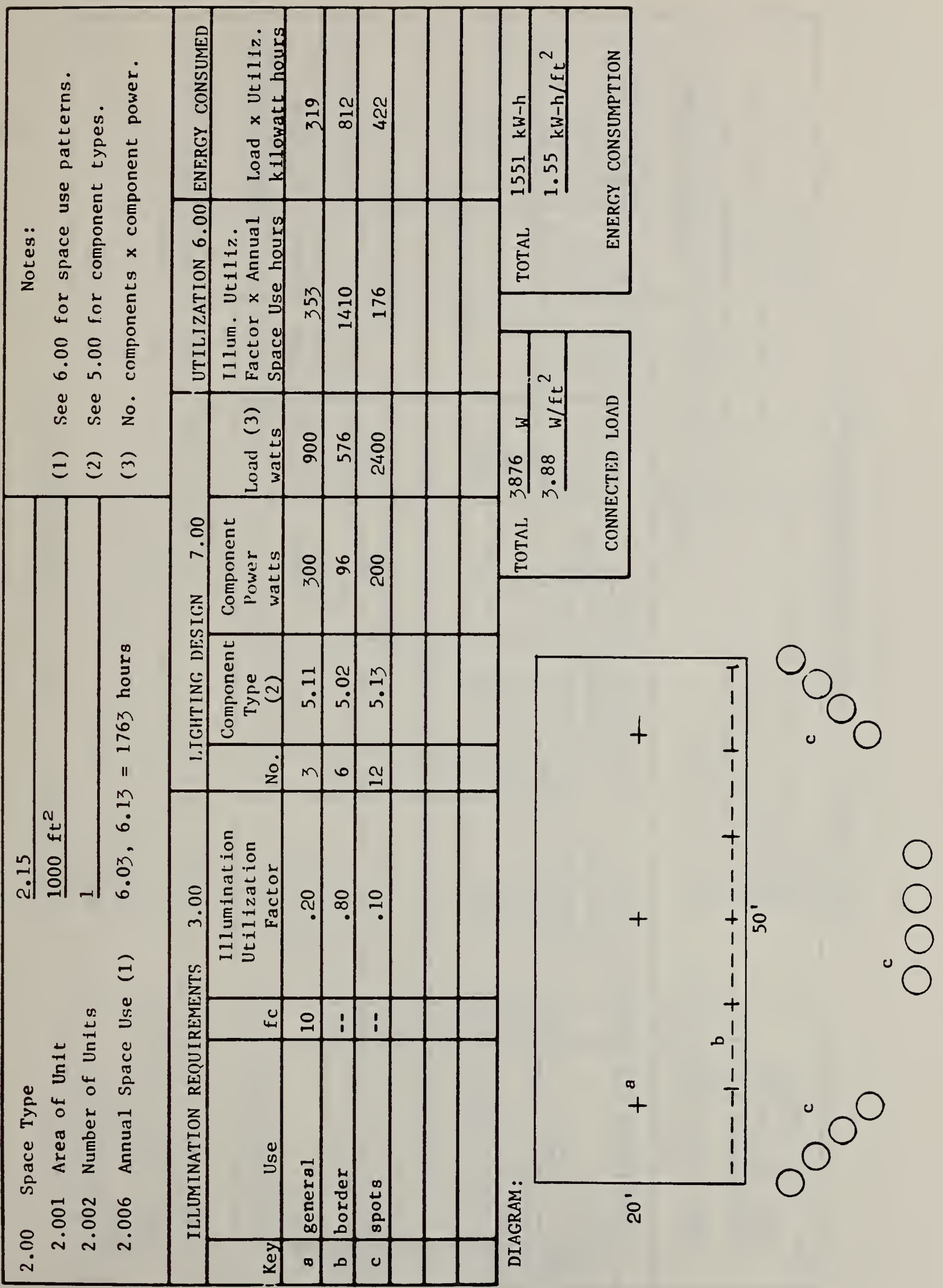



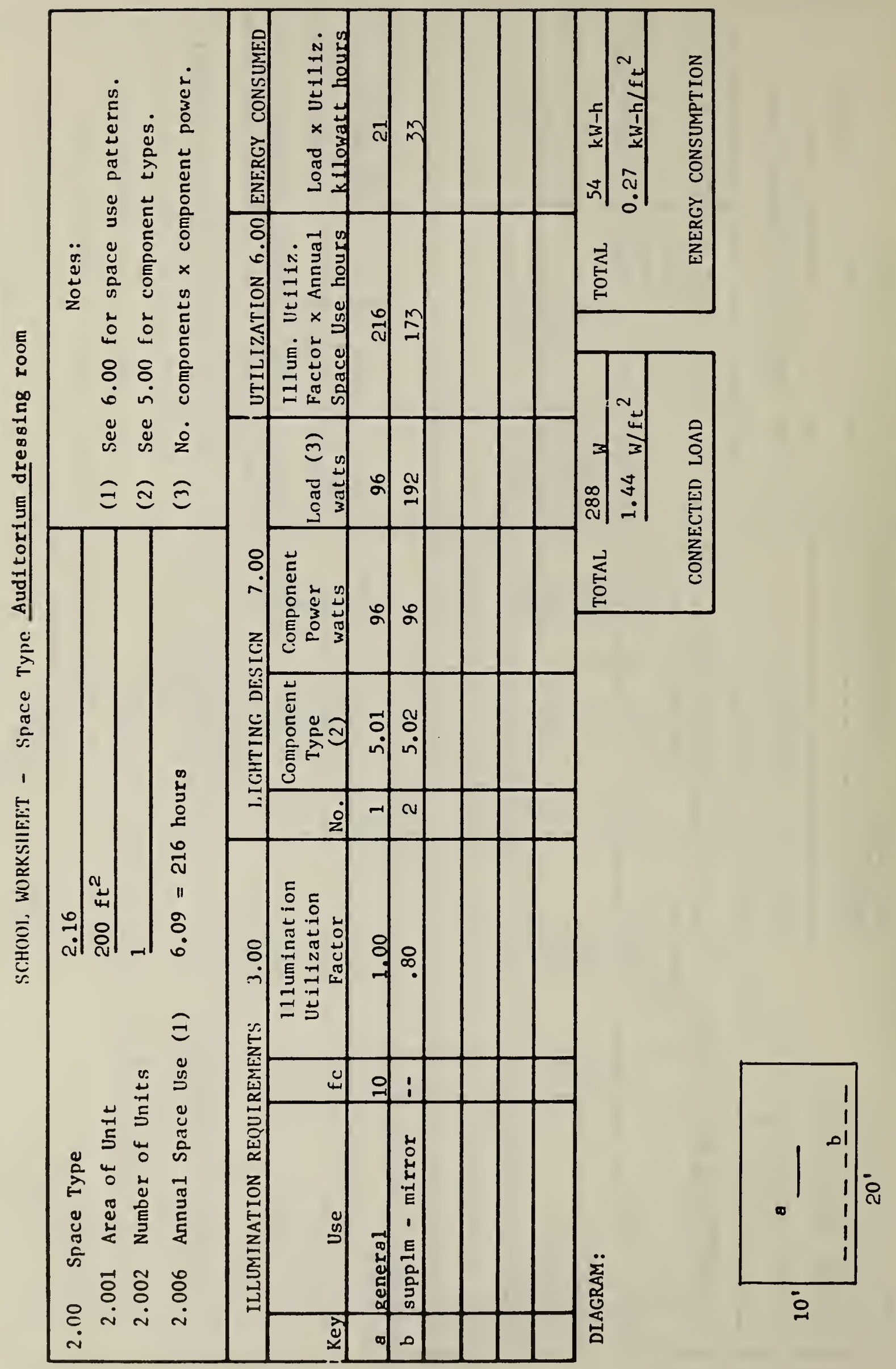


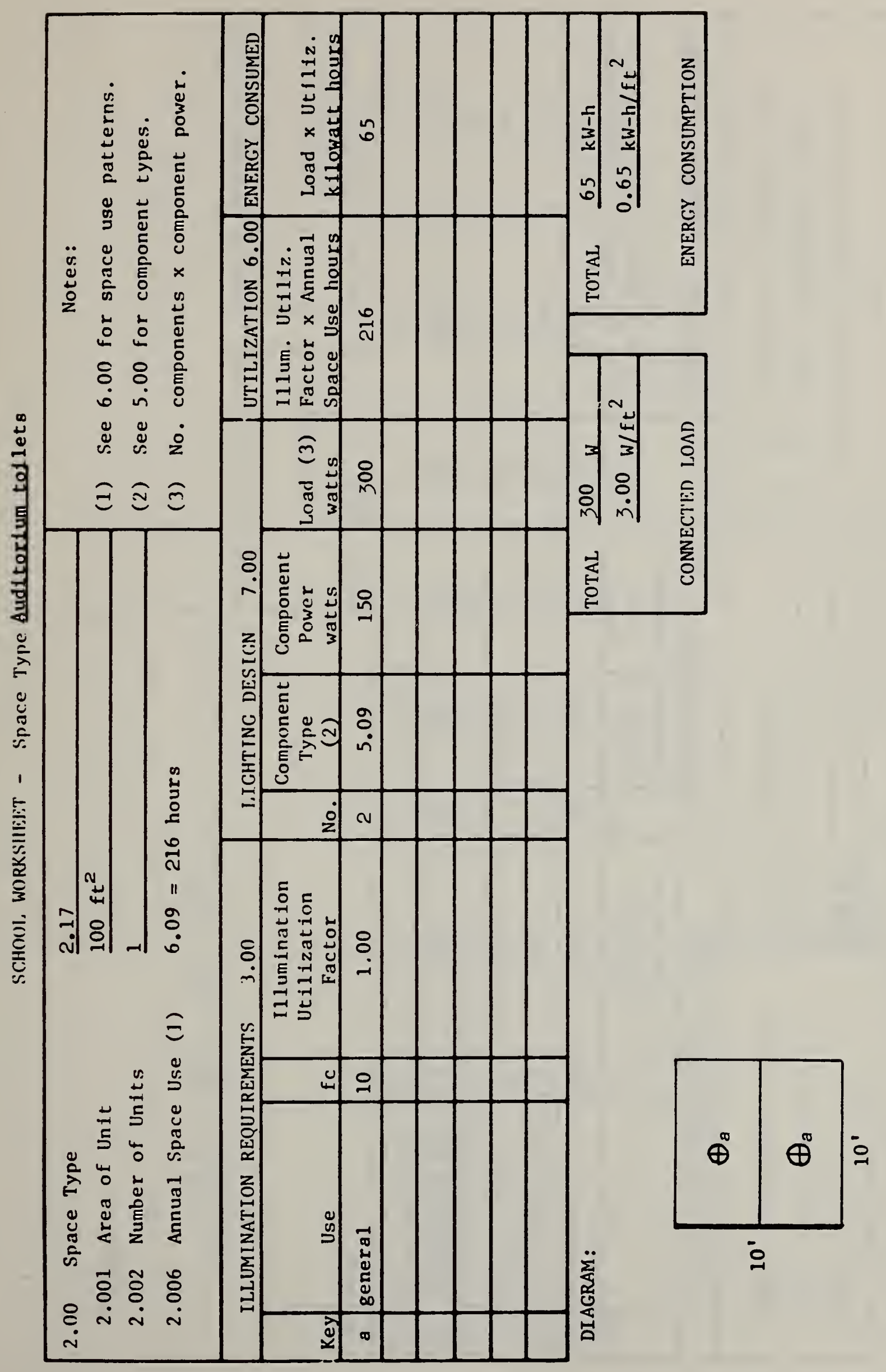



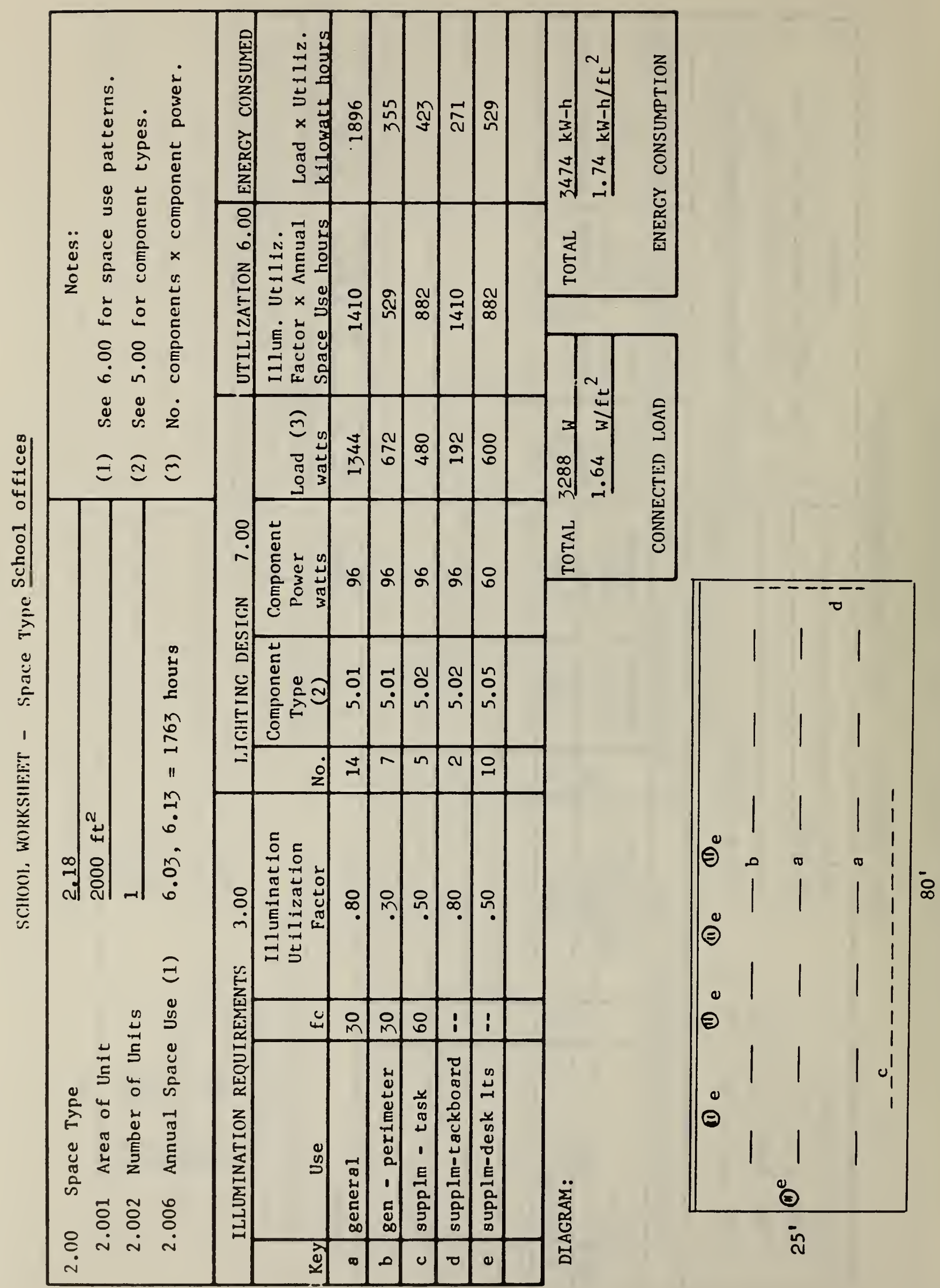


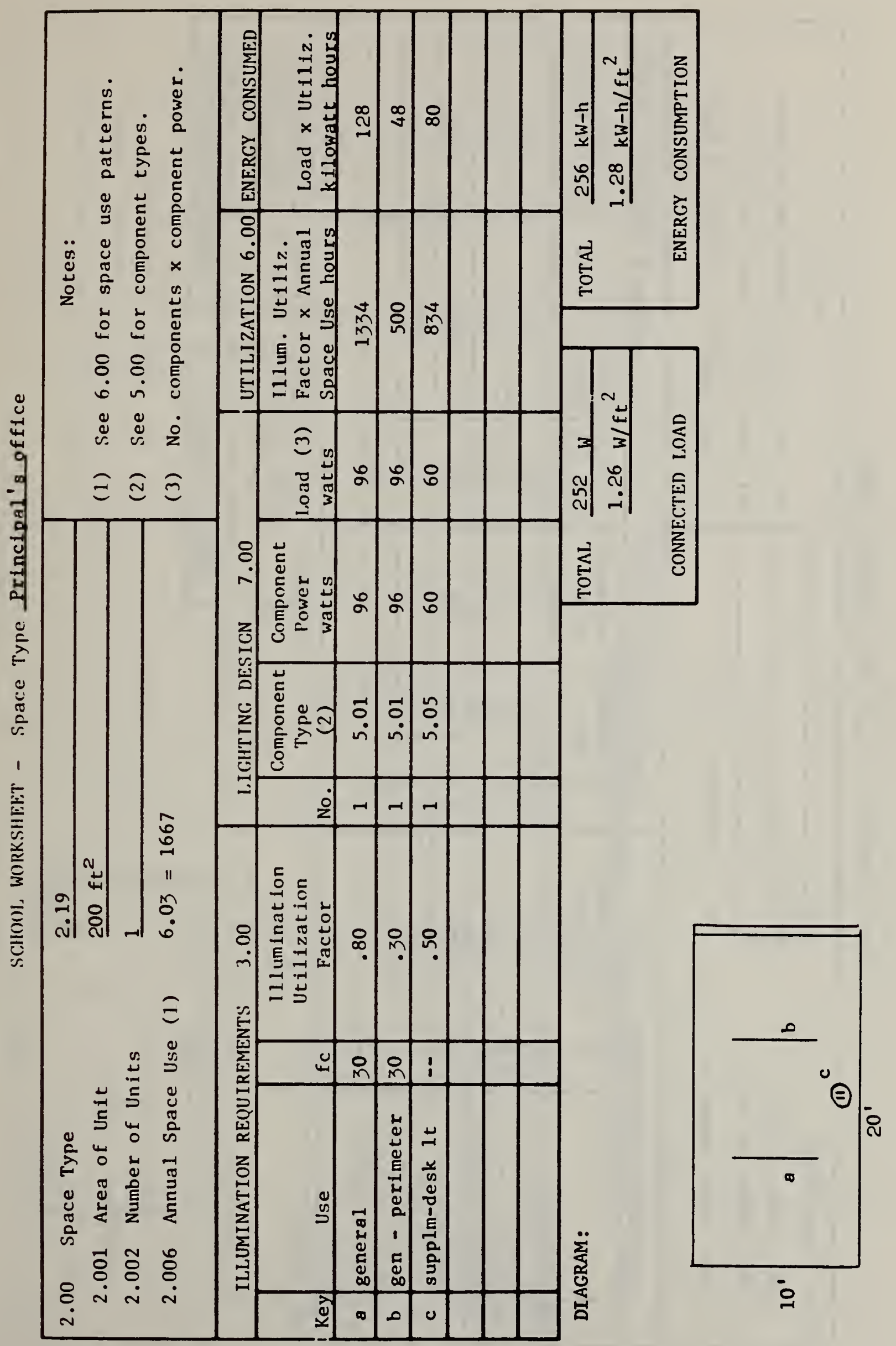




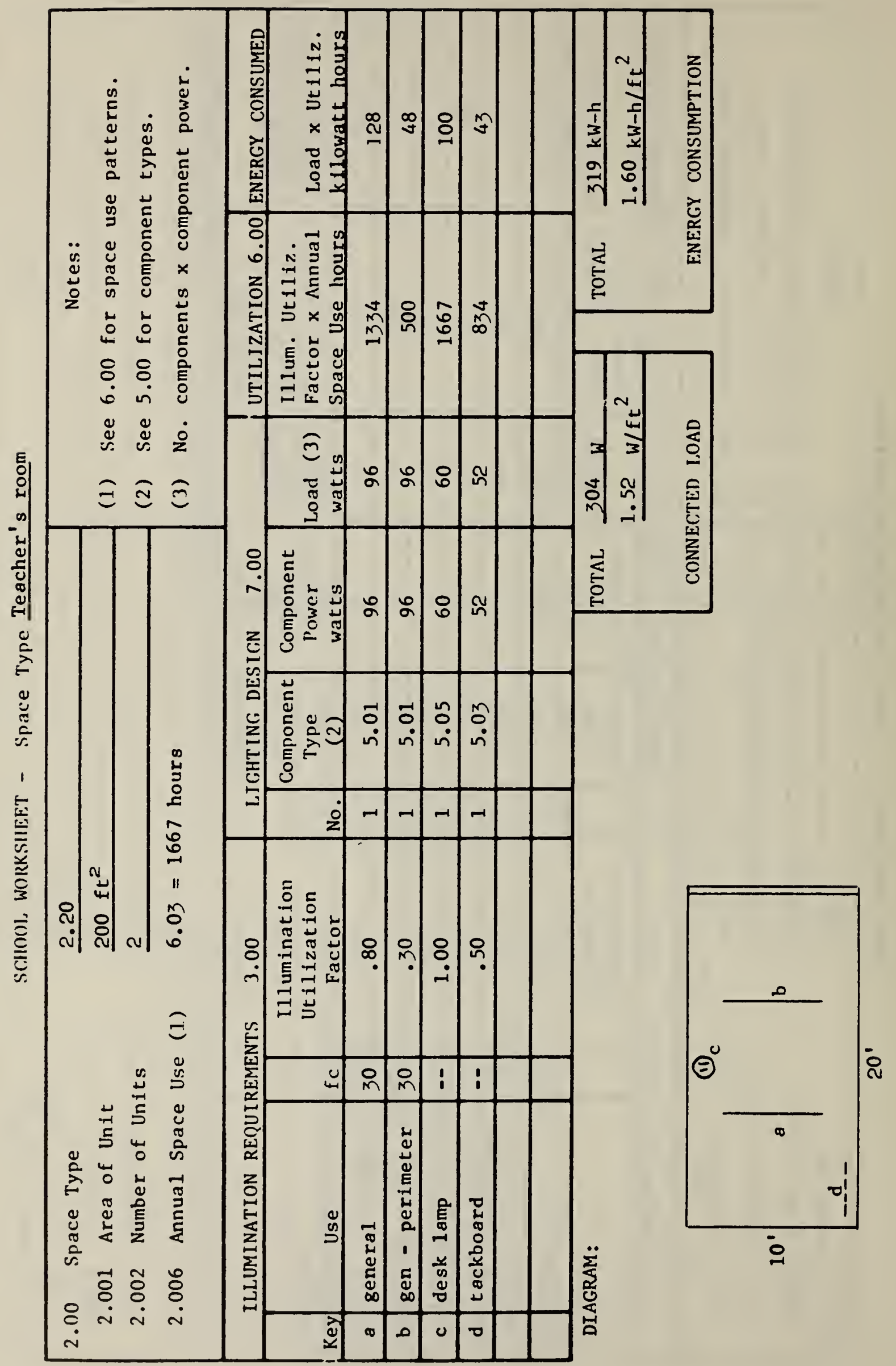




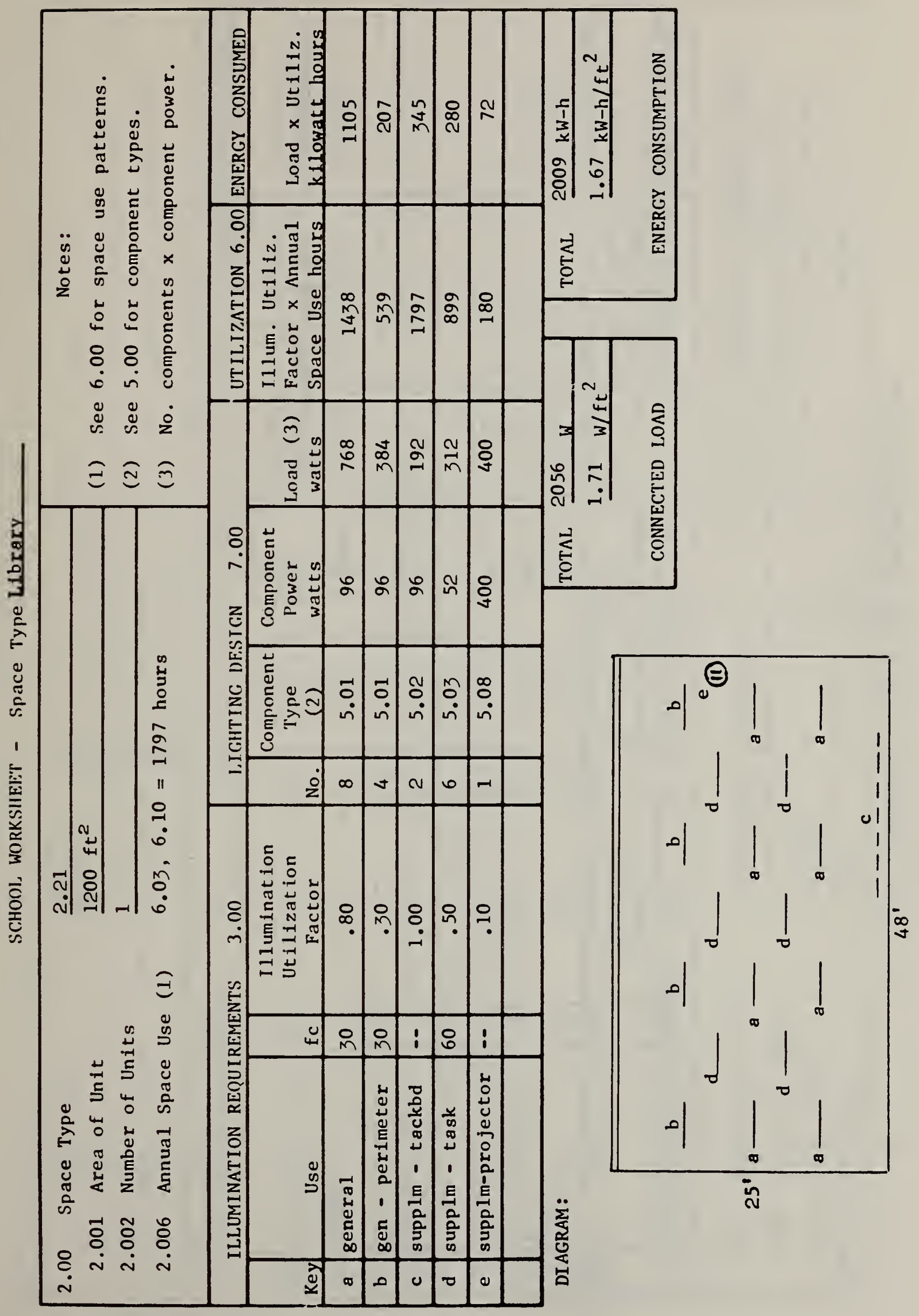




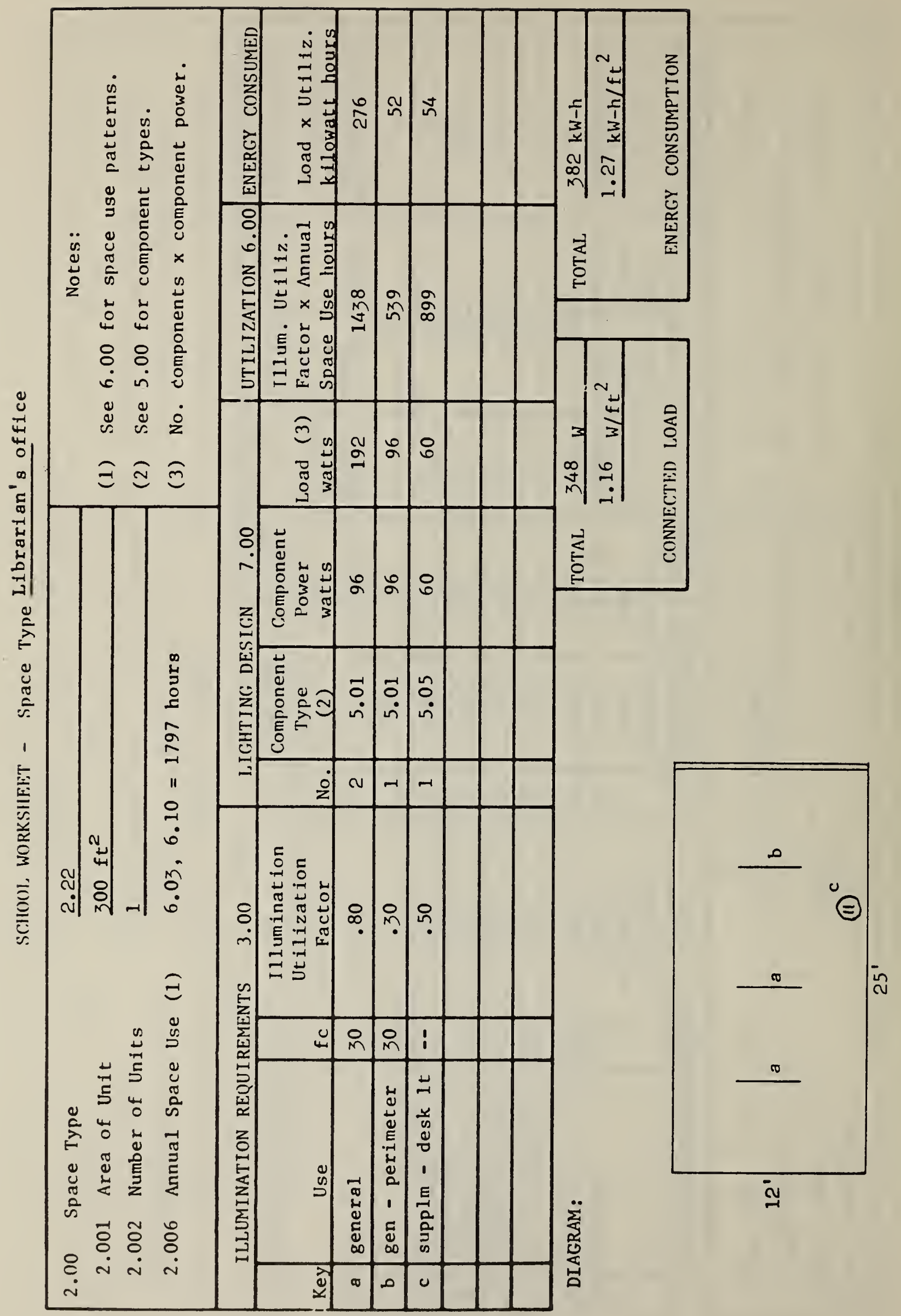




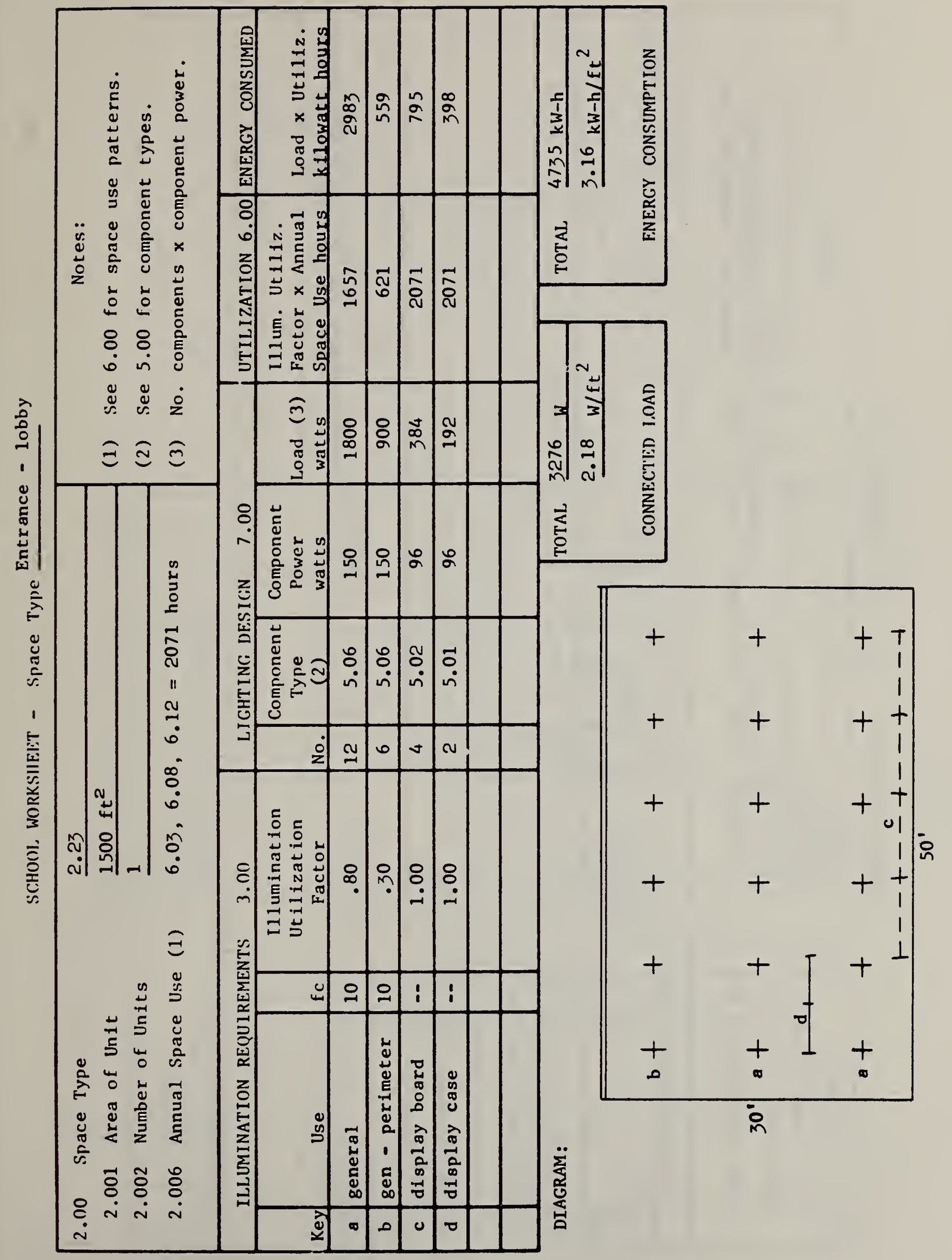




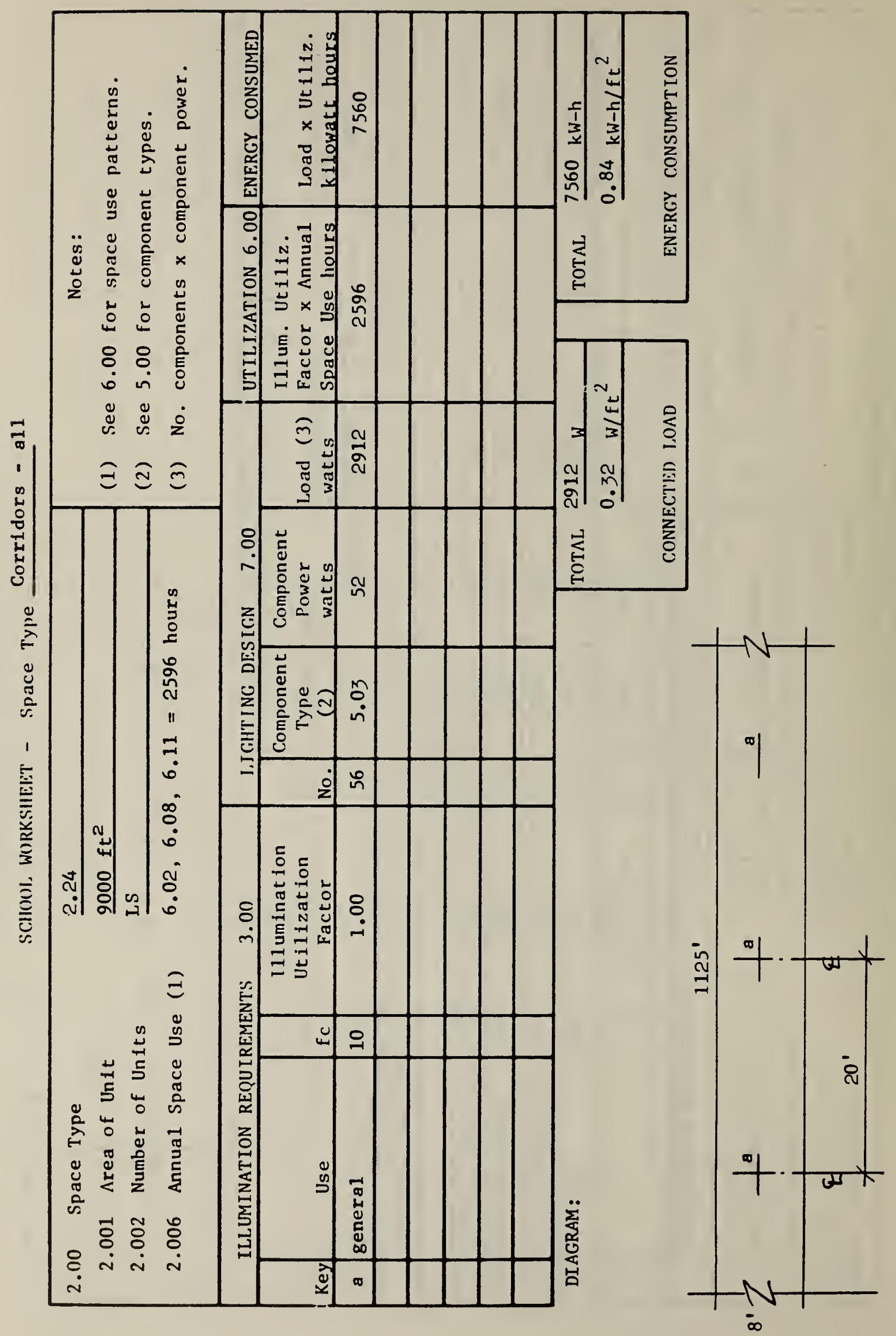




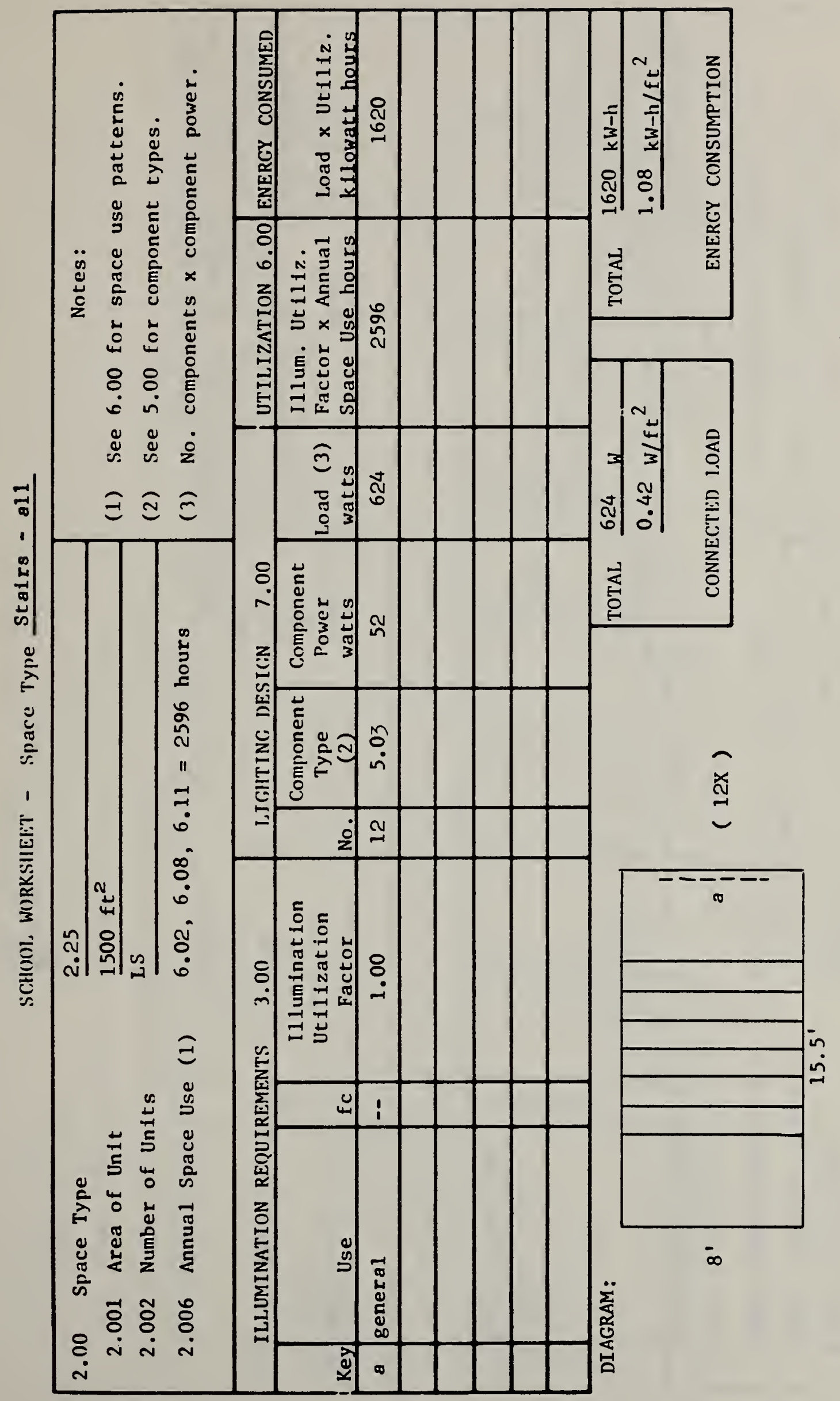




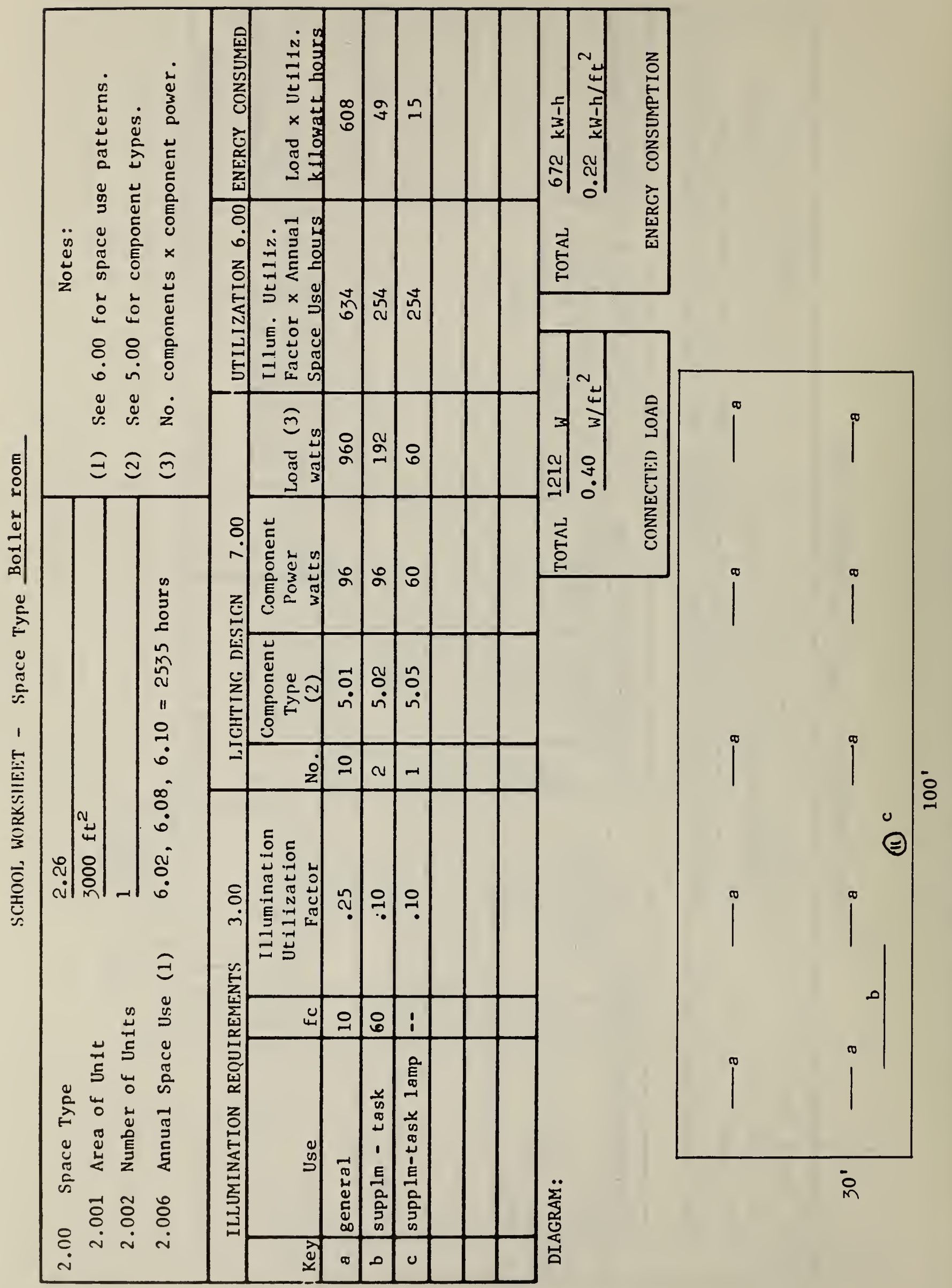




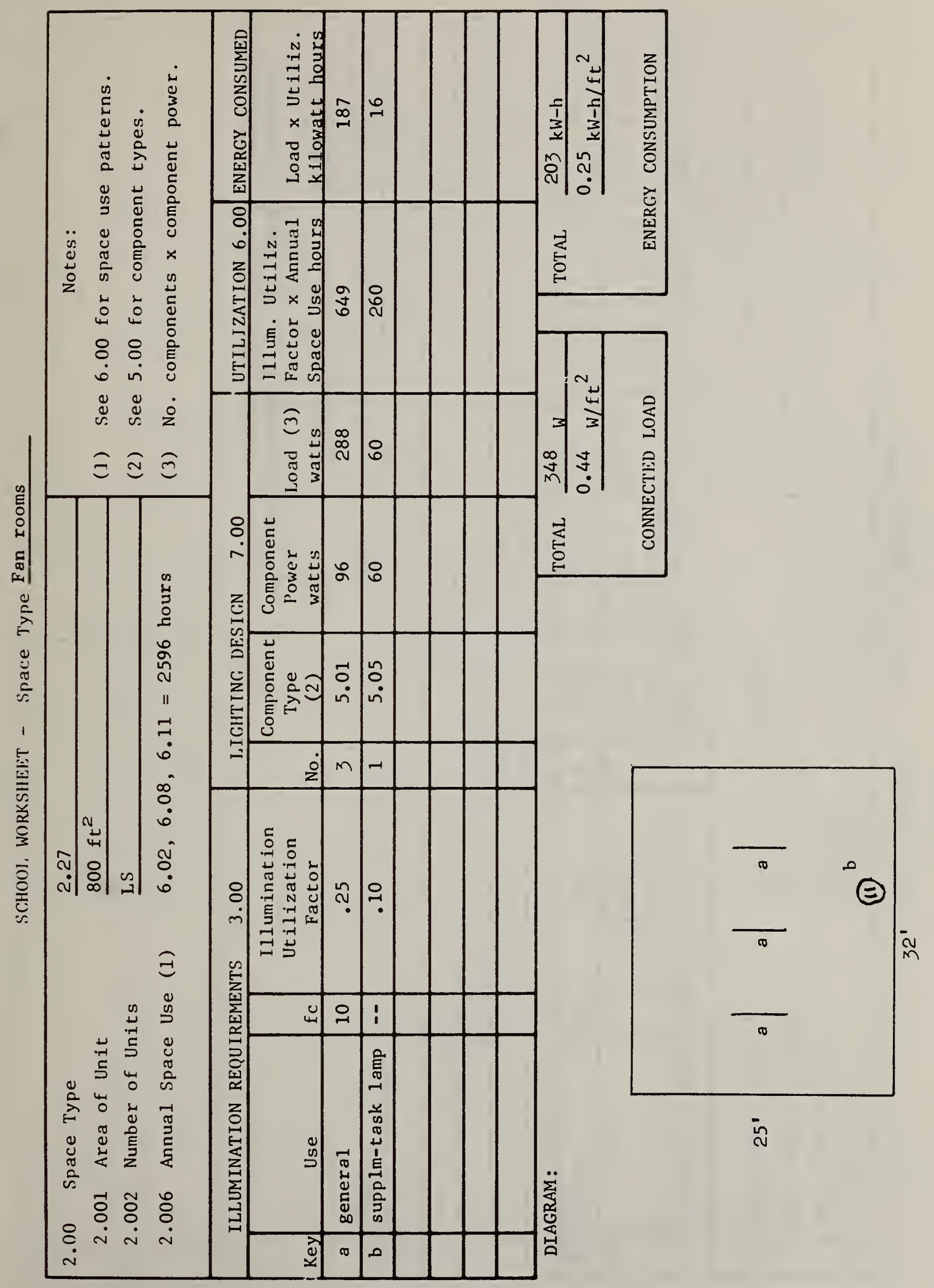




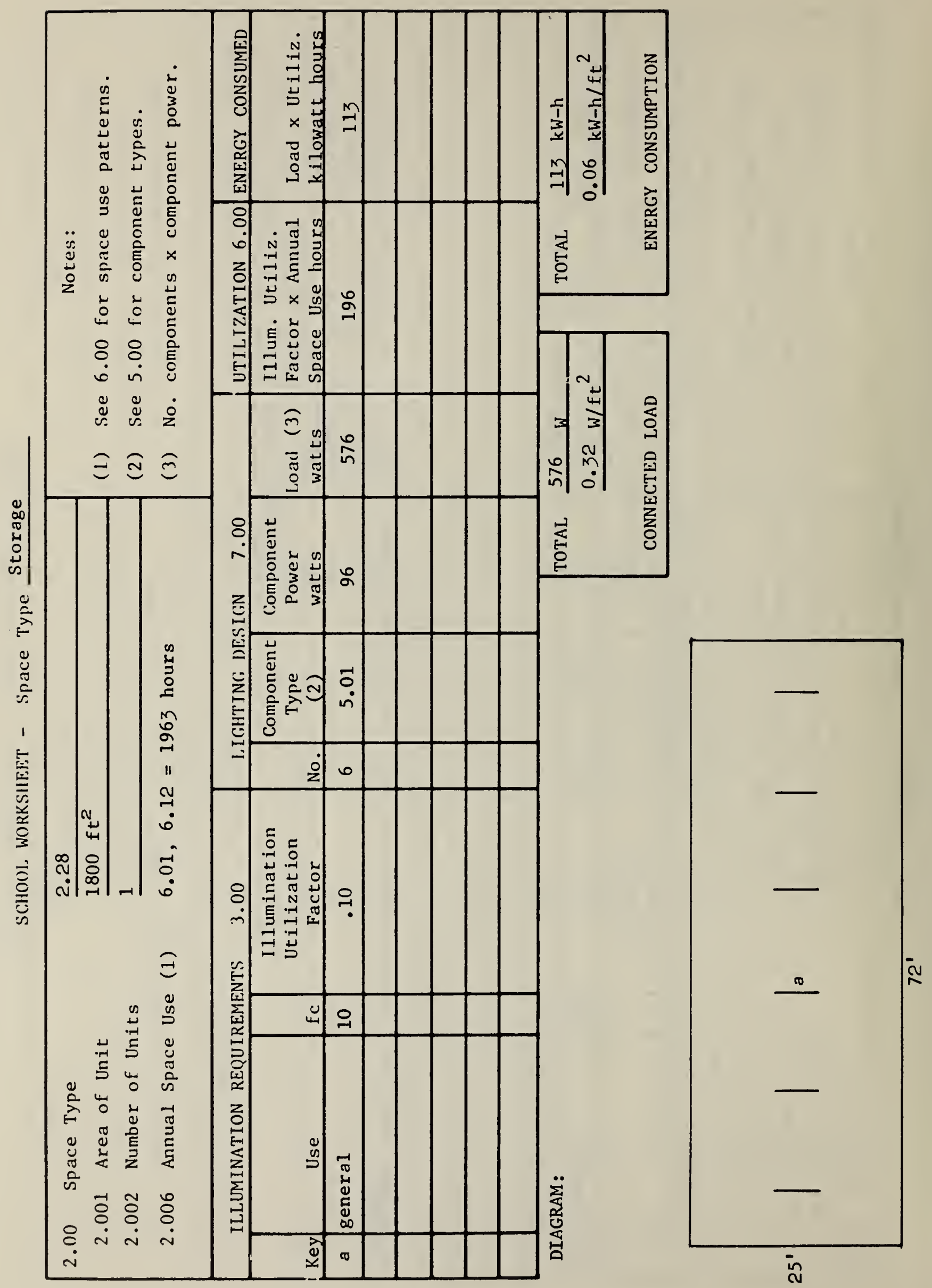



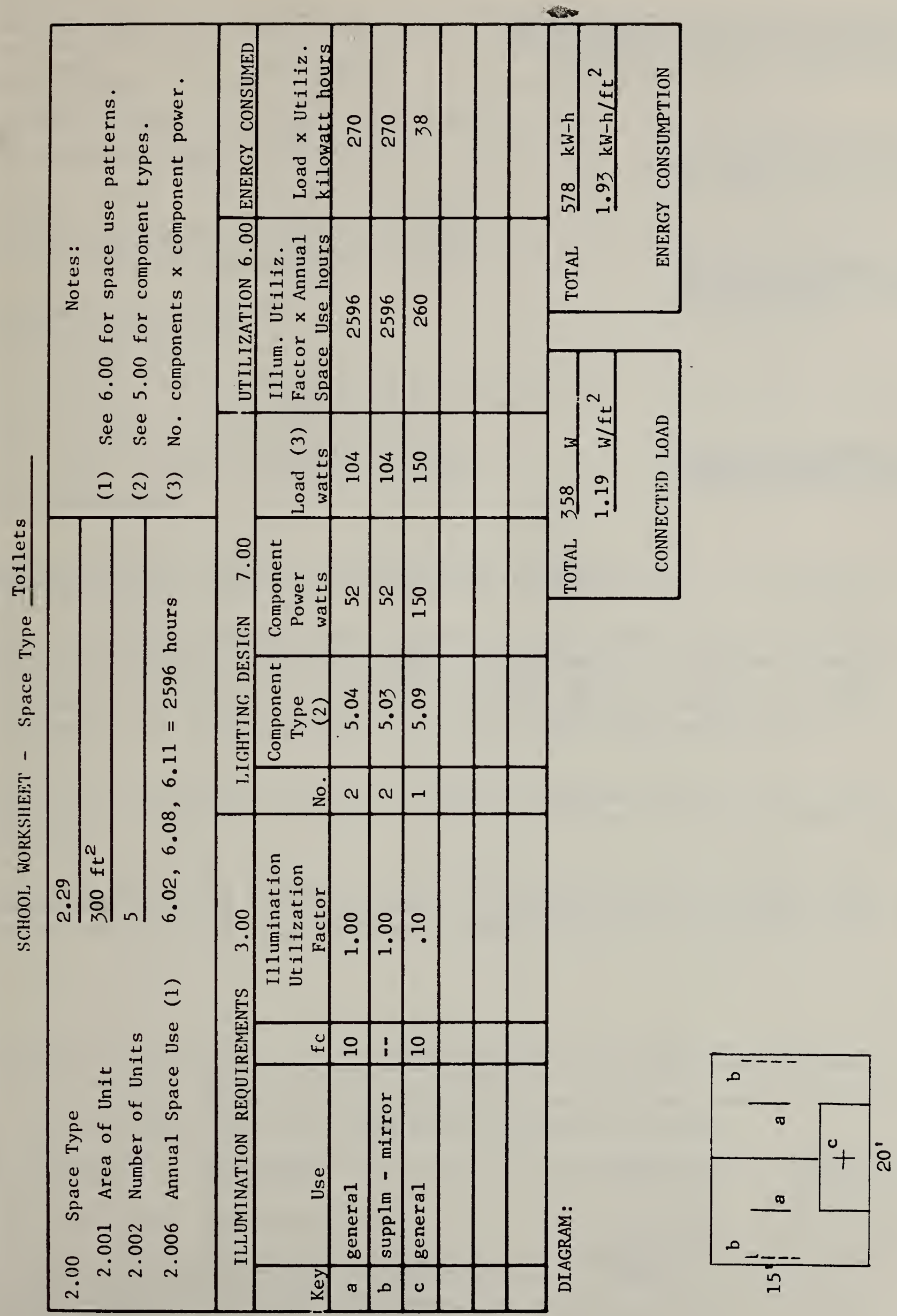

NBS-114A (REV. 9-78)

\begin{tabular}{|c|c|c|c|}
\hline $\begin{array}{l}\text { U.S. DEPT. OF COMM. } \\
\text { BIBLIOGRAPHIC DATA } \\
\text { SHEET }\end{array}$ & $\begin{array}{l}\text { 1. PUBLICATION OR REPORT NO. } \\
\text { NBSIR } 80-2052\end{array}$ & 2.Gov't Accession No. & 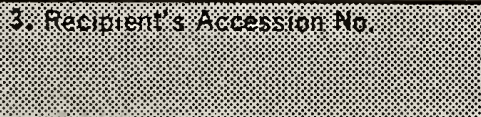 \\
\hline \multicolumn{3}{|l|}{ 4. TITLE AND SUBTITLE } & 5. Publication Date \\
\hline \multicolumn{3}{|c|}{ PERFORMANCE CRITERIA FOR ENERGY CONSERVING BUILDING } & May 1980 \\
\hline \multicolumn{3}{|c|}{ ILLUMINATION SYSTEMS } & $\begin{array}{l}\text { 6. Performing Organization Code } \\
742.05\end{array}$ \\
\hline \multicolumn{3}{|c|}{$\begin{array}{l}\text { 7. AUTHOR(S) } \\
\text { Albert T. Hattonburg and Jim L。 Heldenbrand }\end{array}$} & 8. Performing Organ. Report No. \\
\hline \multirow{2}{*}{\multicolumn{3}{|c|}{ 9. PERFORMING ORGANIZATION NAME AND ADDRESS }} & $\begin{array}{l}\text { 10. Project/Task/Nork Unit No: } \\
7426507\end{array}$ \\
\hline & & & 11. Contract/Grant No. \\
\hline \multirow{2}{*}{\multicolumn{3}{|c|}{$\begin{array}{l}\text { 12. SPONSORING ORGANIZATION NAME AND COMPLETE ADDRESS (Street, City, State, ZIP) } \\
\text { Technology and Consumer Products Branch } \\
\text { Office of Buildings and Community Systems } \\
\text { U. S. Dept. of Energy Washington, DC } 20545\end{array}$}} & 13. Type of Report \& Period Covered \\
\hline & & & 14. Sponsoring Agency Code \\
\hline
\end{tabular}

15. SUPPLEMENTARY NOTES

Document describes a computer program; SF-185, FIPS Software Summary, is attached.

16. ABSTRACT (A 200-word or less factual summary of most significant information. If document includes a significant bibliography or literature survey, mention it here.)

This report covers subsystem energy budget development procedures and performance criteria for building illumination which were developed by a consultant team of practitioners experienced in building illumination systems. A general procedure is described wherein the energy required for efficient illumination of a building is examined and corresponding power and annual energy budget guidelines are developed.

This methodology is applied to three classes of building-øoffices, schools, and residences--to illustrate the method. Representative power and energy budgets are developed.

The model performance criteria and illumination energy budget methodology are recommended as the basis for devclopment of national consensus standards, covering the principal classes of new buildings designed primarily for human occupancy.

17. KEY WORDS (six to twelve entries; alphabetical order; capitalize only the first letter of the first key word unless a proper name; separated by semicolons)

Building illumination systems; energy budget; energy conservation; energy performance criteria; illumination; lighting; power budget.

\begin{tabular}{|l|c|}
\hline $\begin{array}{l}\text { 19. SECURITY CLASS } \\
\text { (THIS REPORT) }\end{array}$ & $\begin{array}{c}\text { 21. NO. OF } \\
\text { PRINTED PAGES } \\
\text { UNCLASSIFIED }\end{array}$ \\
\hline $\begin{array}{l}\text { 20. SECURITY CLASS } \\
\text { (THIS PAGE) }\end{array}$ & 120 \\
UNCLASSIFIED & $\$ 9.00$ \\
\hline
\end{tabular}

For Official Distribution. Do lNot Release to NTIS

Order From Sup. of Doc., U.S. Government Printing Office, Wasinington, DC 20402, SD Stock No. SNO03-003-

X Order From National Technical Information Service (NTIS), Springfield, VA. 22161 




